Florida International University

FIU Digital Commons

FIU Electronic Theses and Dissertations

University Graduate School

3-26-2019

\title{
An Analysis of Performance-Based Funding Measures in Florida
}

Madelyn Cintron

Florida International University, cintronm@fiu.edu

Follow this and additional works at: https://digitalcommons.fiu.edu/etd

Part of the Higher Education Commons

\section{Recommended Citation}

Cintron, Madelyn, "An Analysis of Performance-Based Funding Measures in Florida" (2019). FIU Electronic Theses and Dissertations. 4041.

https://digitalcommons.fiu.edu/etd/4041

This work is brought to you for free and open access by the University Graduate School at FIU Digital Commons. It has been accepted for inclusion in FIU Electronic Theses and Dissertations by an authorized administrator of FIU Digital Commons. For more information, please contact dcc@fiu.edu. 


\section{FLORIDA INTERNATIONAL UNIVERSITY \\ Miami, Florida}

AN ANALYSIS OF PERFORMANCE-BASED FUNDING MEASURES IN FLORIDA

A dissertation submitted in partial fulfillment of

the requirements for the degree of

DOCTOR OF PHILOSOPHY

in

HIGHER EDUCATION

by

Madelyn E. Cintron

2019 
To: Dean Michael R. Heithaus

College of Arts, Science and Education

This dissertation, written by Madelyn E. Cintron, and entitled An Analysis of PerformanceBased Funding Measures in Florida, having been approved in respect to style and intellectual content, is referred to you for judgment.

We have read this dissertation and recommend that it be approved.

Eric Dwyer

Norma Goonen

Daniel Saunders

Benjamin Baez, Major Professor

Date of Defense: March 26, 2019

The dissertation of Madelyn E. Cintron is approved.

Dean Michael R. Heithaus College of Arts, Science and Education

Andrés G. Gil

Vice President for Research and Economic Development and Dean of the University Graduate School

Florida International University, 2019 
C Copyright 2019 by Madelyn E. Cintron

All rights reserved. 


\section{DEDICATION}

I dedicate this dissertation to my husband, son, and daughter. Without their

patience, understanding, support, and most of all love, the completion of this work would not have been possible. 


\section{ACKNOWLEDGMENTS}

I wish to thank the members of my committee for their support, and patience. I appreciate their direction, insight, and encouragement. Dr. Daniel Saunders was particularly helpful in guiding me through the methodology. Dr. Norma Goonen and Dr. Eric Dwyer expertise in higher education administration and policy were vital for my proposal. Finally, I would like to thank my major professor, Dr. Benjamin Baez. From the beginning, he had confidence in my abilities to complete a degree. His passion and dedication to educate and engage graduate students in well-thought arguments is inspirational.

I was fortunate to work with brilliant professors through the program that motivated me to work better and harder. The coursework throughout the Higher Education Program was stimulating and thoughtful. It provided me with the tools with which to explore both past and present ideas and issues. 


\title{
ABSTRACT OF THE DISSERTATION
}

\section{AN ANALYSIS OF PERFORMANCE-BASED FUNDING MEASURES IN FLORIDA}

by

\author{
Madelyn E. Cintron \\ Florida International University, 2019 \\ Miami, Florida \\ Professor Benjamin Baez, Major Professor
}

Florida adopted Performance-Based funding $(\mathrm{PBF})$ as the tool to fund the State University System (SUS), and the Florida College System (FCS). SUS and FCS are the two public higher education systems in Florida. Under PBF, the state governing boards evaluate institutions based on performance outcomes such as graduation rates, retention rates, and job placement, amongst others. Researchers have investigated whether the implementation of PBF would positively affect graduation and retention rates. Shin (2010) found no conclusive evidence that PBF has positively affected them. Others, such as Dougherty and Reddy (2013), Dougherty and Hong (2006), Phillips (2002), and Bell (2005) reported some positive changes in graduation rates, but also cautioned against claiming that the increases in degrees or graduation rates are due to PBF. Empirical research on PBF, therefore, has been inconclusive. There is no research on how PBF affects changes to both public higher education systems in Florida.

The purpose of the study was to explore the role of PBF in the two public highereducation systems in Florida. In order to understand this role, this study analyzes student success outcome variables over time. Specifically, this study attends to changes in graduation and retention rates, student employment data, student to faculty ratios, and 
institutional expenditures, variables considered to be determinants of degree productivity for both the FCS and SUS. The data in this study supports what the literature about PBF has found. Changes in the graduation rates are slow and small, and retention rates seem to be unaffected by the implementation of PBF. The employment metric shows a constant increase for the SUS while for the FCS it decreases for the 2015 cohort. Student to faculty ratio decrease patterns seem to be unaffected by the adoption of PBF while expenses seem to shift to instruction (for the FCS) and institutional support (for the SUS).

Future research should investigate the reasons for the shifts in expenditures. If PBF leads institutions to invest more funds in instruction and institutional support, one should understand what the direct result of such a shift is, and whether such shift contributes to degree productivity. 


\section{TABLE OF CONTENTS}

CHAPTER

PAGE

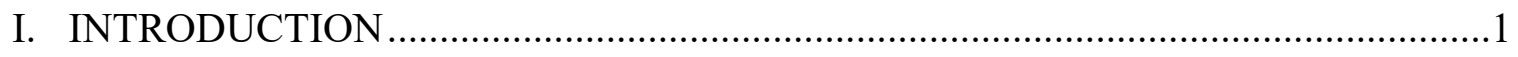

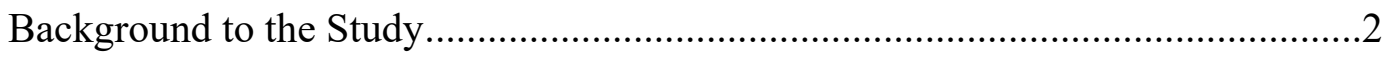

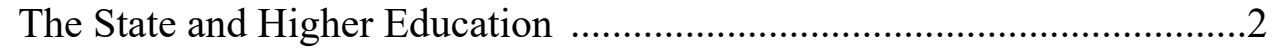

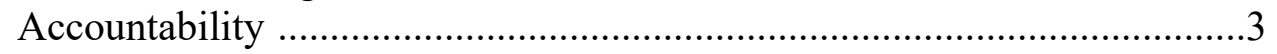

Performance-Based Funding ............................................................... 5

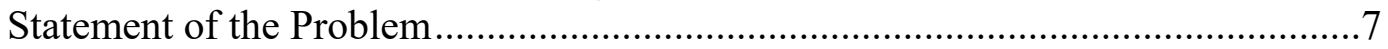

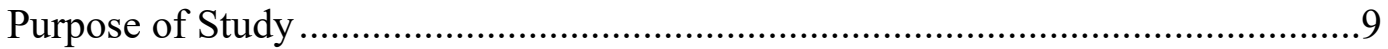

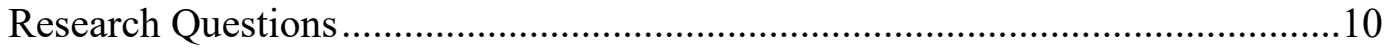

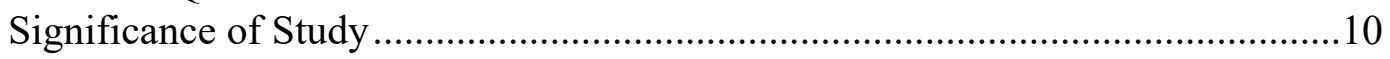

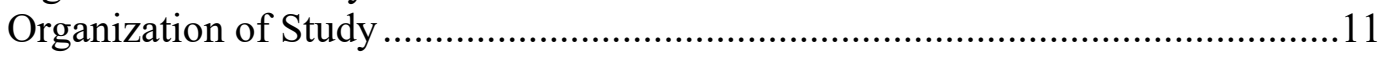

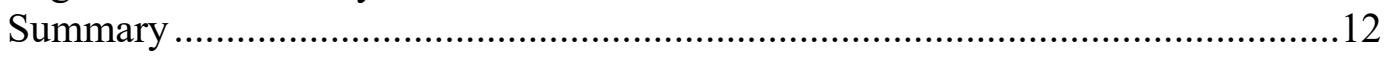

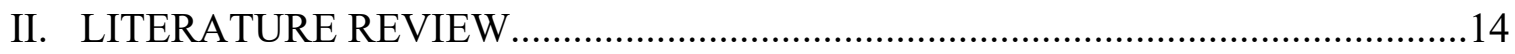

Performance-Based Funding, Issues and Concerns ....................................... 14

Performance-Based Funding Outcomes ..........................................................21

Performance Funding and Type of Institution .............................................25

Performance Funding and Student Success ................................................28

Performance Funding, Institutional Expenditures, and Student to Faculty Ratio .33

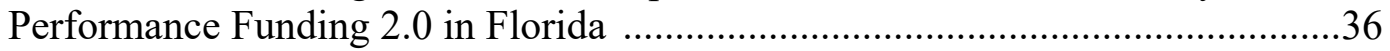

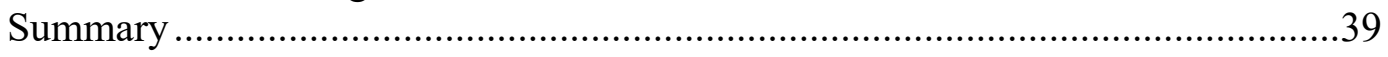

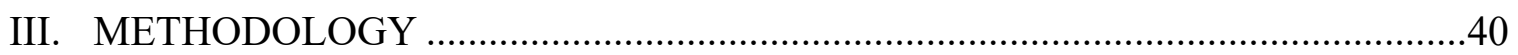

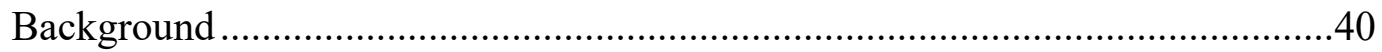

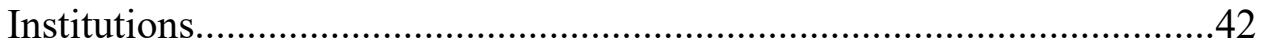

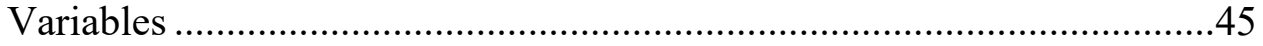

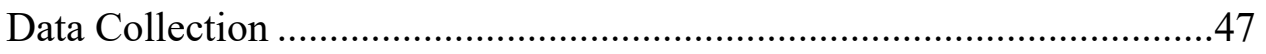

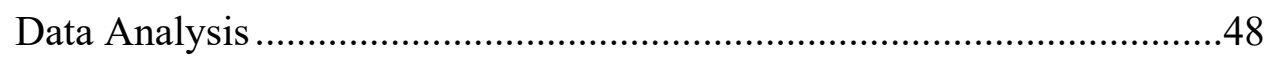

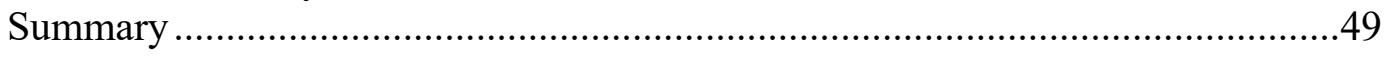

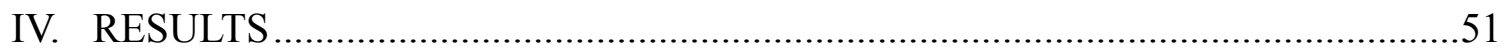

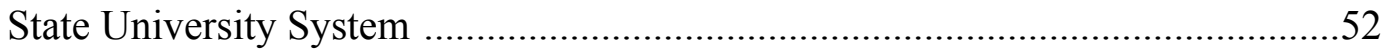

Student Success Outcomes: Graduation ...............................................52

Student Success Outcomes: Job Placement ...........................................58

Student Success Outcomes: Retention...................................................62

Administrative Outcomes: Student to Faculty Ratio ..............................65

Administrative Outcomes: Institutional Expenditures............................68

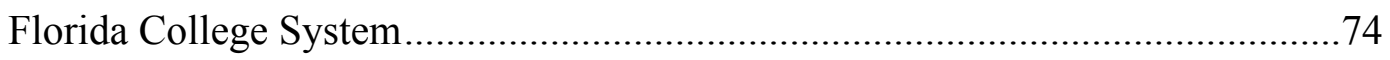

Student Success Outcomes: Graduation ..................................................74

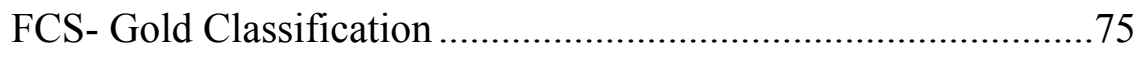

FCS- Silver Classification..................................................76

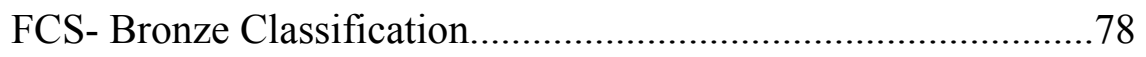


FCS- Rate of Change

Student Success Outcomes: Job Placement ..........................................83

Student Success Outcomes: Retention ....................................................8

Administrative Outcomes: Student to Faculty Ratio ...............................93

Administrative Outcomes: Institutional Expenditures.............................98

SUS and FCS: A Comparison .........................................................105

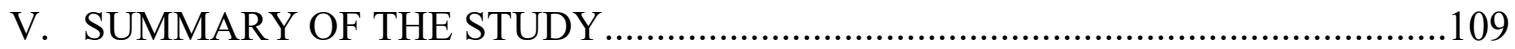

Research Question 1: Role of Performance-Based Funding (PBF) in Student

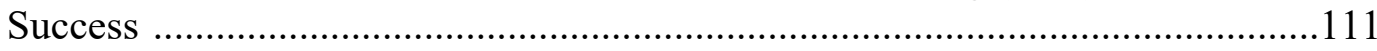

Research Question 2: Role of Performance-Based Funding (PBF) in

Administrative Outcomes ........................................................................... 113

Implications and Recommendations for Practice, Policy, and Research............116

Limitations and Areas for Future Research ......................................................119

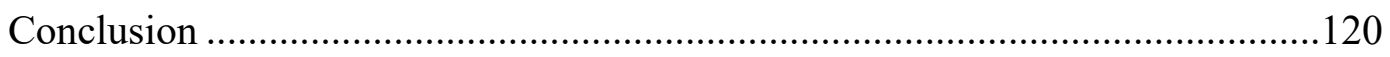

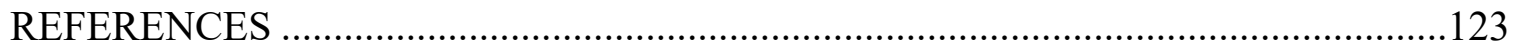

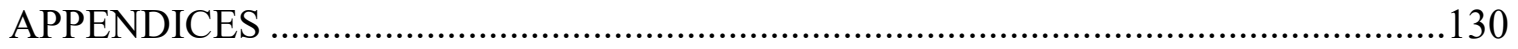

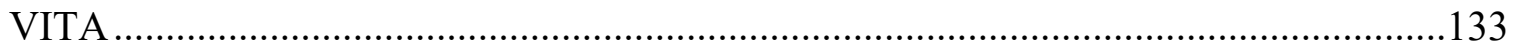




\section{LIST OF TABLES}

TABLE

PAGE

1. Florida Public Higher Education Institutions ......................................................45

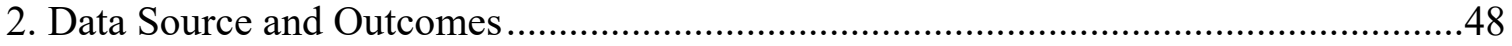

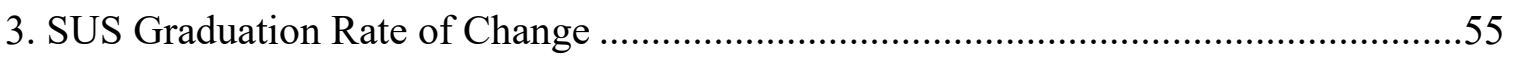

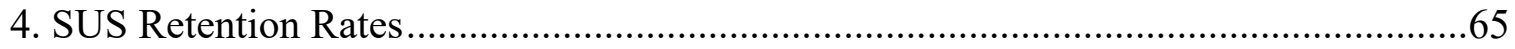

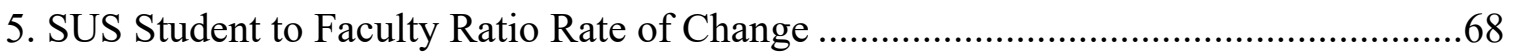

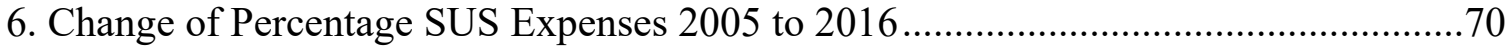

7. Rate of Change for the Florida College System from 2005 to 2016 ...........................81

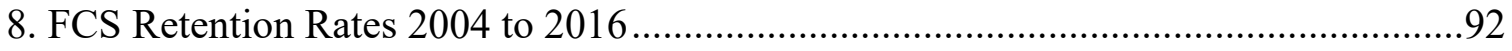

9. Change of Percentage FCS Expenses 2005 to 2016 .................................................99 


\section{LIST OF FIGURES}

FIGURE

PAGE

1: Performance-Based Funding and the Public Higher Education System..................... 42

2: Descriptive Statistics for the SUS Graduation Rate from 2004 to 2016 .....................52

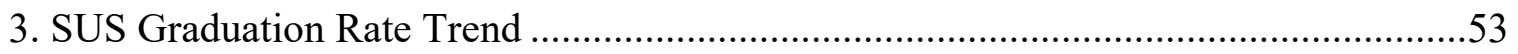

4. Graduation Rate Trends for the State University System ..........................................54

5. SUS Graduation Rate of Change Stack Graphic...................................................56

6. SUS Institutions Graduation Rate of Change Stack Graphic....................................56

7: SUS Calculated PBF Score for the Six-Year Graduation Based on IPEDS 2005-2016

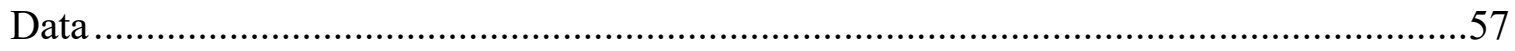

8. SUS Total Employment or Continuing Education Rates..........................................60

9. SUS Employment or Continuing Education Rates ............................................61

10. Rate of Change Employment or Continuing Education SUS .................................62

11: Descriptive Statistic for the SUS Retention Rates from2004 to 2016 ...................... 63

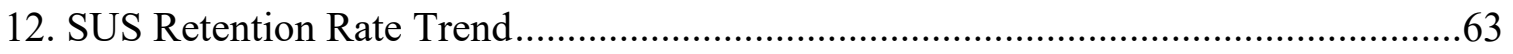

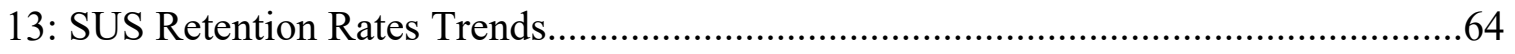

14: Descriptive Statistics for the SUS Student to Faculty Ratio from 2008 to 2016 ........66

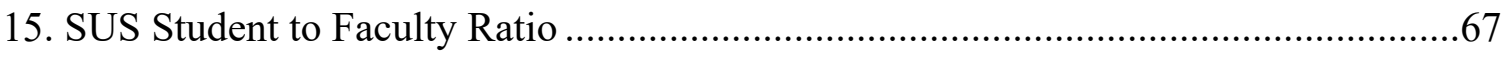

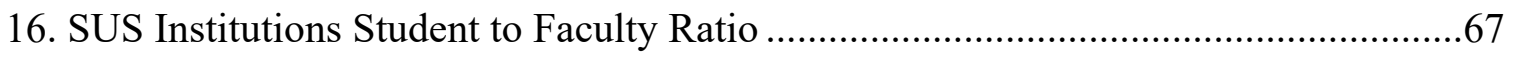

17: SUS Average Expenses per FTE 2004-2016 …................................................ 70

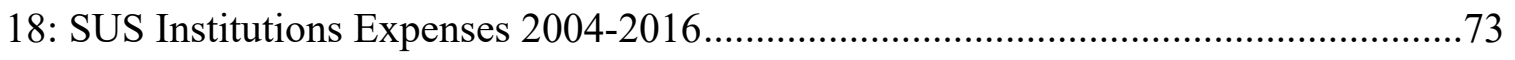

19: Descriptive Statistics for the FCS Graduation Rate from2004 to $2016 \ldots \ldots \ldots \ldots \ldots \ldots \ldots . . . . .74$

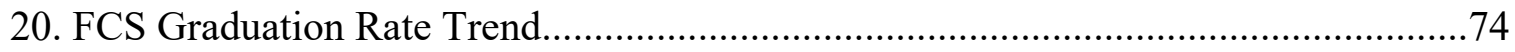


21. FCS Graduation Rate Trend for Each Classification in the PBF Program

22: Graduation Rate Trends for the FCS Gold Classification .76

23: Graduation Rate for the FCS Silver Classification Upper 8 Institutions. .77

24: Graduation Rate for the FCS Silver Classification Lower 8 Institutions .78

25: Graduation Rate for the FCS Bronze Classification

26: Stack Line Chart for the FCS PBF Calculated Scores-Six-Year Graduation Rates from 2005 to 2016 .83

27. FCS Total Job Placement or Continuing Education Rates .85

28. FCS Job Placement or Continuing Education Rates. .86

29. Rate of Change FCS Job Placement /Continuing Education .87

30: Descriptive Statistics for the FCS Retention Rate from 2004 to 2016 .88

31. Retention Rate FCS. .89

32. Retention Rates for Institutions within the FCS .90

33: FCS Retention Rate of Change One Year after the Implementation of PBF .90

34: Descriptive Statistics for the FCS Student to Faculty Ratio From2008 to 2016 93

35. FCS Total Student to Faculty Ratio .94

36: FCS Student to Faculty Ratio Rate of Change .95

37. FCS Student to Faculty Ratio .97

38: FCS Average Expenses Per FTE 2004-2016 .98

39: FCS Institutions Expenses 2004 - 2016 .104 


\section{CHAPTER I}

\section{INTRODUCTION}

Florida has two large public higher-education systems, the Florida College System (FCS) and State University System (SUS). As of 2018, both systems have in place a Performance-Based Funding (PBF) program. SUS established its PBF in 2013, while FCS established its PBF in 2015. PBF in the state has come with much controversy because it uses a ranking system in which institutions compete for the same pot of money, with many questioning whether PBF contributes to improving the graduation rates of students (Zarkesh \& Beas, 2004; McKeown-Moak, 2013; Dougherty \& Reddy, 2011). In order to evaluate how effective PBF programs are in Florida, it is necessary to understand how and to what extent these programs perform in the state.

The purpose of this study is to explore the role of PBF in the two public highereducation systems in Florida. In order to understand this role better, this study will be analyzing student success outcome variables over time. Specifically, this study attends to changes in graduation and retention rates, student employment data, student to faculty ratios, and institutional expenditures, variables considered to be determinants of degree productivity for both the SUS and FCS. Exploring changes in these outcomes would offer an understanding of the role of PBF in the quality of public higher education in Florida. This work seeks to contribute to initial understanding of how PBF works in Florida. In order to understand PBF and its role in the state' higher education system, it is essential to first review some of the historical events that contributed to what higher education is today. 


\section{Background to the Study}

\section{The State and Higher Education}

One critical historical event that explains how higher education became accountable to the state is the Morrill Land Grant Act of 1862 (Akey, 2012; Zumeta, 2011). The Morrill Land Grant Act of 1862 was as a partnership between the federal government and the state. After the Civil War (1861-65), higher education institutions went through a transformation. Students, as well as faculty, went to war. The structure of some of the colleges' campuses was affected because of the war. The war's disruptions created destabilization of the economic conditions of the country and provided the political opportunity for Congress to approve the Morrill Land Grant Act. "The purpose of the grant was to find a way to use some of the western lands" (Thelin 2005, p.75). Thelin (2004) describes The Morrill Land Grant Act as an "influential piece of legislation" (p.75), but this was not the first time national or state government used a land grant to stimulate the building of colleges. There was also the Northwest Ordinance (1781) that provided some land for college-building (Thelin, 2004). Then, what makes the Morrill Land Grant Act special?

As Thelin explains it, this was not just a gift of land for the construction of colleges; it was a partnership between the federal government and the institution. In this complex partnership, the land given to state colleges was determined using a formula that considered the number of their congressional representatives as part of the calculation (Thelin, 2004). The institution would sell the land and use the money collected from the sale to fund the establishment of specific programs. These specific programs were then known as "useful arts," such as agriculture and mechanics, expanding the curriculum and 
making it more practical. Although the reporting between institution and state was minimal, it did start a relationship between government and higher education.

This relationship has evolved through time, framed within the political and economic reality of the country in different periods. One of the historical events that influenced higher education was World War II and subsequently the GI Bill. After World War II and the GI Bill, the number of people enrolling in higher education increased dramatically (Zumeta, 2011; Zarkesh \& Beas, 2004, Akey, 2012; Bowles \& Gintis, 1976). There was a demand for higher education, and some authors have argued that this demand provoked the proliferation of institutions and the creation of governing boards to oversee state funding (Zumeta, 2011). Thus, the relationship between government and higher education became stronger and made higher education accountable to the state. Since then, this emphasis on accountability has increased even more. Zumeta (2011) argues there are three reasons for this emphasis on accountability. The first reason is the recession of 1980; the second is the implementation of a business model; and the third is the concern with workers' skills. Zumeta (2011) confirmed what others have said: that the recession of 1980 made people question the state's investment in higher education; this questioning generated a desire for efficiency and prompted the implementation of a business model for higher education. Fryar (2011) argued that "the public and elected officials have lost their faith in public universities and are no longer willing to allow institutions to enjoy the autonomy they once had" (p. 7).

\section{Accountability}

Two well-known reports in the narrative of accountability in the United States are Measuring Up (2008) and A Test of Leadership (2006). These documents were used 
to further strengthen the emphasis on making higher education accountable. In "Measuring up," the author assigned a grade to different higher education institutions based on specific performance measures (i.e., completion, graduation). In "A Test of Leadership," the authors question the skills of those who have a post-secondary degree (Bogue \& Johnson, 2010). In it, former Secretary of Education, Margaret Spellings, affirmed that literacy among college graduates was lower than ever, and that the number of college graduates who do not have the necessary skills to perform in the workforce was increasing.

In her report, Spellings explained that for many years the U.S. was in a privileged position ahead of other competitors in the global market. According to the report, the U.S. was offering the best higher education possible. The report argued that the U.S. got complacent with this position, stopped striving for higher standards, and placed the quality of higher education at risk; consequently, its position in the global market began to wane. The report pointed out that the U.S. was not only falling behind academically but also in transparency and accountability (USOE, 2006). The report concluded that colleges and universities were not clear about student progress, and this was "preventing higher education from demonstrating its contributions to the public good" (USOE, 2006, p. 4). In the report, she then recommended that the entire system of higher education needed to be improved. Both reports were unpopular with some audiences. However, they both emphasized accountability.

Researchers in the field of higher education policy also use the arguments in these two reports to explain the existence of PBF. Hillman, Tandberg, and Fryar (2015), for example, explained "that the United States [was] falling behind other countries in terms 
of degree completion and that colleges [were] not producing enough graduates to keep pace with changes in the labor market, state policymakers view performance funding as a way to align colleges with broader state policy goals" (p. 1).

\section{Performance-Based Funding}

Performance-Based Funding (PBF) gained popularity in the 2000s (Hillman, Tandberg \& Fryar, 2015). PBF allows state funding to be attached to the production of specific outcomes. So far, there have been two iterations of PBF: PBF 1.0 and PBF 2.0:

Performance funding 1.0 takes the form of a bonus, over and above regular state funding for higher education. The funding is allocated on the basis of certain typical indicators: ultimate outcome indicators such as numbers (or percentages) graduating or being placed in jobs; intermediate achievement indicators such as retention, developmental education completion, and transfer student; and more occasionally, input indicators such as enrollments of students of certain backgrounds and indicators of program quality such as percentage of licensure exam takers who pass (Dougherty \& Reddy, 2011, p. 6).

PBF 2.0, however, is not a bonus above regular state funding; instead, it embeds performance funds into the base state funding formula.

These two models, PBF 1.0 and PBF 2.0, have been the most prominent forms of PBF in the last three decades, but they are not the only ones. Dougherty (2013) explains that performance accountability comes in three forms: performance funding, which connect funding directly to a formula; performance budgeting, for which there is no explicit formula tying funding to performance; and performance reporting, which involves little or no connection between performance and the funding. 
Examples of PBF 1.0 are the programs in Tennessee in 1979, Florida in 1994, Ohio in 1995, and Washington in 1997. Tennessee's program included both two-year and four-year institutions, and the money allocation was a bonus of two percent above their state appropriation for the year. This two percent was given based on how well the institutions performed in five indicators (program accreditation, student major field performance, student general education performance, evaluation of the instructional program, and evaluation of academic programs). In Florida, two programs were running simultaneously: one was the performance budgeting that lasted from 1994 to 2008, and the second program, the Workforce Development Education Fund, was active from 1997 to 2002. Both programs affected two-year institutions, and funding was between two percent and six percent of state funding. Performance indicators changed over time in Florida, but the focus was on graduation or degree completion. In Ohio, the program focused on colleges and indicators such as the percentage of transferred students. Funding began at two million when it started in 1995 and increased to 54 million when it finished in 2009. The first program in Washington lasted from 1997 to 1999 and included both two-year and four-year institutions, and the second program started in 2007. Both funded institutions by allocating extra money or new money in exchange for performing well on specific indicators (Dougherty \& Reddy, 2013).

Performance-Based funding 2.0 emphasizes outcomes such as course completion, as well as graduation rates, completion of developmental education courses or programs, and passage of key gateway courses (Daugherty \& Reddy, 2011). PBF 2.0 programs embed funds in the regular base state funding formula. Rutherford and Rabovsky (2014) summarized the difference between both programs, whereas PBF 1.0 is a bonus 
incentive, PBF 2.0 is a portion of base funding. As states across the U.S. implemented various PBF policies, institutions started to prioritize performance outcomes.

The literature on PBF is varied and sometimes contradictory. Some researchers suggest PBF can motivate higher education institutions to improve graduation rates (Tandberg \& Hillman, 2014; Jenkins, Wachen, Moore, \& Shulock, 2012), while others believe that PBF is nothing more than a political strategy to manipulate higher education institutions (Zarkesh \& Beas, 2004; McKeown-Moak, 2013). Still, others question the validity of the measures, particularly their ability to evaluate quality in higher education (Zarkesh \& Beas 2004; Frolich, 2011; Jongbloed \& Vossensteyn, 2001).

\section{Statement of the Problem}

Zarkesh and Beas (2004) suggest that "some lawmakers firmly believe that the use of PBF has encouraged colleges to pay closer attention to the specific needs of their students" (p. 65). State legislators also find PBF useful, since it provides the information about higher education institutions that they can give to taxpayers. Others question the usefulness of this data (Zarkesh \& Beas, 2004, p. 65). For example, administrators in Zarkesh and Beas (2004) study questioned the importance of collecting graduation data if this information does not lead to reform (p. 65). There is also some concern on the part of faculty concerning the specific standards considered in the performance formulas. Faculty worry that if successful completion of a course is all that matters, it will lead to grade inflation and pressure to graduate unqualified students (McKeown-Moak, 2013, p. 5). PBF thus has been the object of much controversy.

The arguments for implementing PBF was that the U.S. was falling behind in comparison with other countries regarding degree completion. Changing the funding 
formula for higher education could have implications. As of today, both public higher education systems in the state have a PBF program in place. It is essential to understand if and how they affect the Florida higher education systems.

While many studies have looked at the effectiveness of PBF in multiple states, these results are inconclusive (Shin, 2010; Dougherty \& Reddy, 2013; Dougherty and Hong, 2006; Phillips 2002; Bell, 2005). For example, Shin (2010) studied whether PBF affects institutional performance and found no conclusive evidence that PBF has positively affected it. Others, such as Dougherty and Reddy (2013), Dougherty and Hong (2006), Phillips (2002), and Bell (2005) studied the effects of PBF on number of degrees and graduation rates and, while reporting some positive changes in graduation rates, cautioned against claiming that the increases in degrees or graduation rates are due to PBF. Sanford and Hunter (2011), however, found that PBF had no impact on retention or graduation rates. Empirical research on PBF, therefore, has been inconclusive. As of today, no single study looks at both Florida's public higher education systems and the role of PBF. This dissertation seeks to fill this gap by looking at the role of PBF on both systems regarding student success outcome measures and administrative outcomes such as student to faculty ratio and institutional expenditures. This study intends to offer the initial groundwork in a series of studies in Florida.

It is crucial that higher education institutions understand how this PBF affects students. Researchers in the field of PBF explain that the formulas used in PBF programs may incur a disadvantage for some institutions and student populations, especially if the institutions that lose the funding are those who need the funding the most (Hillman \& 
Corral, 2018). It is then our responsibility as higher education professionals to be aware of how PBF is contributing to the educational system.

\section{Purpose of Study}

As of 2015, the National Conference of State Legislatures counted 24 states that have PBF (2.0) in place at four-year institutions. In Florida, it has been in place since 2013 in the SUS and 2015 in the FCS. The purpose of this study is to explore the role of PBF in the two public higher-education systems in Florida. In order to understand the role of PBF, this study analyzes student success outcome variables over time. Specifically, this study attends to changes in graduation and retention rates, student employment data, student to faculty ratios, and institutional expenditures. These variables are considered important in determining degree productivity in both the FCS and SUS.

Exploring changes in these outcomes offer an understanding of the role of PBF on the quality of public higher education in Florida. Evidence of PBF suggests that it has had "little to no effect on degree completion, but it is possible that it has positively affected intermediate outcomes such as student retention rates" (Hillman, Tandberg \& Fryar, 2015, p. 5). It would be worth exploring whether PBF has led to changes in graduation rates, retention rates, and any other student success outcome variables used by PBF programs in Florida. Using data from the Integrated Postsecondary Education Data System (IPEDS) and the governing boards for the FCS and the SUS, this study explores changes in student and institutional outcomes before and after the implementation of PBF.

There is very little research on many of the student outcomes used in PBF in Florida. Hillman, Tandberg, and Fryar (2015) explained, "We have a substantial gap in 
our knowledge of the effectiveness of these new strategies" (p.6). This dissertation seeks to help in filling out this gap by studying how PBF led to changes over time in both public higher education systems in Florida on key student success outcome measures (i.e., graduation, retention, and employment rates) and on two administrative outcomes (i.e., student to faculty ratios and institutional expenditures) that are identified in the literature as possibly being affected by PBF programs.

\section{Research Questions}

The following research questions guided this study:

1. What is the role of Performance-Based Funding (PBF) in student success, specifically, as it attends to changes over time on graduation rates, retention rates, and student employment data before and after the implementation of the policy in Florida's public higher education systems?

2. What is the role of Performance-Based Funding (PBF) as it attends to changes over time on student to faculty ratio and institutional expenditures in Florida's public higher education systems?

\section{Significance of Study}

This study is the first to focus on how PBF might influence system-wide changes by looking at changes in trends. This research will expand the limited body of research about PBF. This dissertation does not discuss the political implications of the policy, rather it provides the base for future studies that could explore further PBF in Florida. Researchers cannot find evidence that PBF indeed increases degree production (Dougherty et al. 2016; Hillman, Tandberg \& Fryar, 2015). We should be asking questions, such as, are there institutions that always score in the bottom? Which 
institutions are always scoring in the top? Studying changes in trends and positioning of the institutions, and conducting a comprehensive descriptive study not only will be the initial step in a series of studies we should be conducting about PBF in Florida, but it will also help us understand if and how PBF affects the system and each institution within the system.

The body of research about PBF in Florida was expanded by exploring the role of PBF in the SUS and the FCS. Specifically, this dissertation provides new information on changes over time in graduation and retention rates, student employment data, student to faculty ratios, and institutional expenditures, variables considered to be determinants of degree productivity for both the FCS and SUS.

\section{Organization of Study}

Chapter 1 includes the background, the statement of the problem, the purpose of this study, the guiding research questions, and the significance of this study. Chapter 2 will present an overview of the relevant literature on PBF, and the research on the outcomes used in this dissertation as they relate to PBF. Chapter 3 will describe the methodology of this study, which is a comprehensive descriptive analysis. This analysis explores institutional-level changes by variable, relative institutional positions (within a system) by variable, overall system changes by variable, and overall institutional position within the performance funding system for graduation rates. Chapter 4 will present the data analysis for graduation rates, retention rate, employment, student to faculty ratio and institutional expenditures in both the SUS and FCS. Specifically, the focus in this chapter is on reporting the extent of changes in these variables $\mathrm{X}$ years before and after the 
implementation of PBF. Finally, Chapter 5 offers answers to the research questions and discusses the implications for future research and for practice.

\section{Summary}

Empirical research on PBF has been inconclusive (Bell 2005; Dougherty \& Hong, 2006; Dougherty \& Reddy, 2013; Phillips, 2002). Researchers have not provided conclusive evidence that PBF models do positively affect student success performance indicators (Shin, 2010; Dougherty \& Reddy, 2013). Investigating whether PBF led to changes in Florida's higher education systems is vital to understanding student success in the state. This dissertation explored the role of PBF in the SUS and FCS. In order to understand this role, this study used a comprehensive descriptive analysis to examined student success outcome variables over time. Specifically, this dissertation evaluated changes in graduation and retention rates, student employment data, student to faculty ratios, and institutional expenditures, variables considered to be determinants of degree productivity, for both the FCS and SUS.

The data in this study support what the literature about PBF has found. Changes in graduation rates are slow and small, while retention rates seem to be unaffected by the implementation of PBF. The employment metrics show a constant increase for the SUS, while for the FCS it decreases for the 2015 cohort. Student to faculty ratio decrease patterns seem to be unaffected by the adoption of PBF while expenses seem to shift to instruction (FCS) and institutional support (SUS).

Both student outcome variables (e.g., Graduation rates, retention rates, and employment data), and administrative outcomes (e.g., institutional expenditures and student to faculty ratio) are critical areas to understand the role of PBF in Florida. Future 
research should investigate the reasons for the shifts in both aspects and whether they change even further. 


\section{CHAPTER II}

\section{LITERATURE REVIEW}

Reports such as Measuring up (2008) and A test of leadership (2006) express a desire to increase accountability for higher education institutions. PBF is the response to such desire. Nonetheless, it has not been received without apprehensions. Although it is a politically attractive mechanism to pursue better outcomes (Dougherty, Jones, Lahr, Natow, Pheatt, \& Reddy (2014), it has also been a point of concern for faculty, administrators and other groups in the higher education field (Dougherty, Natow, Bork, Jones, and Vega, 2013; Jongbloed \& Vossensteyn, 2001).

This chapter contains a review of research on the origin of PBF as well as the concerns about PBF. Much of this chapter will examine the literature on the effect of PBF on graduation rates, retention rates, employment data, two-year institutions, and -fouryear institutions. Because the purpose of this dissertation is to explore the role of PBF on Florida's public higher education systems, this chapter also contains a review of the available research on other aspects such as the student to faculty ratio and institutional expenditures and their possible relation to PBF student outcomes. The purpose of this chapter is to describe previous research in order to clarify the background and importance of the research topic and to expand our understanding of PBF, student success outcomes, student to faculty ratio, and institutional expenditures in Florida.

\section{Performance-Based Funding, Issues, and Concerns}

In the last few years, PBF has been one of the top ten policy issues in the U.S. (AASCU, 2012). Increased state and federal budget constraints made politicians eager to prove to citizens the effective use of taxes. To provide such information, politicians emphasized 
accountability as a tool to measure effectiveness (Alexander, 2000). The increased emphasis on the creation of policies that can effectively encourage quality in higher education, assuming limited resources, has caused the use of PBF 2.0 (Zarkesh \& Beas, 2004).

PBF emerges to serve an ideology of competition. A Test for leadership (2006), explicitly argues for this ideology of competition. This ideology may not be the only one in place, but it seems to be one used in the U.S. to explain the resurgence of PBF as policy for higher education (Dougherty \& Reddy, 2011; Ellis, 2015). In this framework of competition, the way to influence higher education to move toward the production of more graduates is to provide incentives in that direction through embeding performance funds into the base state funding formulas.

Dougherty and Reddy (2011) explained that the leading legislative advocate of PBF in Florida believes that "you could get performance altered by money" (p. 2). The use of funding in these formulas is a way to alter performance in the institutions and make them more responsive to the economic needs of society by eliminating the unpopular programs on the "grounds of efficiency" (Dougherty, \& Reddy, 2011, p. 21), or encouraging production (like enrollment and graduation).

Power (2000) points out:

The design of accounting reports and other measures by which organizations can be judged is greatly influenced by the imperative of making them auditable, and this has much to do with agendas for controls of these organizations. It follows that many audit processes are not neutral acts of verification but actively shape the design and interpretation of auditable performance (p.114). 
PBF is moving institutions toward this "auditable performance" in order for them to gain the funding they need. Frolich (2011) argued that the implementation of PBF is a matter of increased state control at the cost of professional autonomy.

Frolich (2011) briefly listed arguments against performance measurement systems, stating that performance is an incomplete indicator that obscures more than it reveals and that performance systems are excessively complex, rendering them unusable and too expensive. As Baile and $\mathrm{Xu}$ (2012) point out "using graduation rates, for example, policymakers can determine which institutions are graduating more of their students; however, what they will not know is whether this outcome is due to better prepared students and available resources, or due to college practices that influence students' outcomes" (p. 8).

In his research, Frolich (2011) investigated the perception of different stakeholders, including the Rectors' Conference, Research Association, Quality Assurance Agency, Ministry of Education and Research, Ministry of France and rectors and directors of the Norwegian Higher Education Institution in winter 2006, about PBF and whether PBF increased accountability and transparency or not. Frolich (2011) analyzed documents from the Ministry of Education and Research and Higher Education Institutions (complete list is available in the appendix in the Frolich article).

Frolich (2011) also conducted surveys on rectors, directors, researchers, and interviews with faculty in the United Kingdom. In his analysis of the documentation, he found that higher education institutions (which includes the Ministry of Education and researchers) supported PBF, but they had some reservations. They were concerned about the survival of smaller programs, the programs that did not produce enough graduates. 
When analyzing the stakeholders' surveys, he found the same concerns. Stakeholders wanted to know how PBF was going to affect the "unpopular" programs. They were concerned about how the new policies could affect faculty-student evaluations, including the criteria for assigned grades, because of the funding implications. Faculty believed that with the emphasis on the number of graduates there could be little attention to the quality of the students graduating.

Frolich's (2011) findings are not far from McKeown-Moak’s (2013) conclusions in the United States. McKeown-Moak (2013) argued that, in the United States, there is also some concern from faculty regarding the specific standards considered in the performance formulas. The faculty is concerned that if successful completion of a course is all that matters, it will lead to grade inflation and pressure to graduate unqualified students (McKeown-Moak, 2013).

McKeown-Moak (2013) argued that with PBF there is a change in the focus "from meeting the needs of higher education to meeting the needs of students, the state, and its economy" (p. 4). One of the issues that could arise in this setting is the conflict of interest between a higher education institution and the entity providing the resources. For example, when the state assigns funds based on a formula, that formula may be pushing an agenda that is different from the institution's mission. Given the diversity of institutions in a state, if the same formula applies to all, there is bound to be some tension. The conflict of interest between higher education institutions and the entity providing the resources is not an easy problem to work around; moreover, it could create funding inequities (McKeown-Moak, 2013). 
Although both studies, Frolich's (2011) and McKeown-Moak's, (2013), agreed that there is concern from the faculty about the effect of the policy on faculty behavior, it is necessary to consider that these studies represent a point of view from a particular population at a specific moment. Therefore, even though we recognize that there are some concerns amongst faculty members regarding the effect of PBF, there is not enough evidence to conclude that all faculty would share the same concerns or be concerned at all.

Burke and Modarresi (2001) argued that the issue with PBF is that the design of the program has to deal with conceptual and practical difficulties: from choosing the performance indicators, assessing higher education results, protecting campus diversity, and autonomy to supporting state priorities. These are not simple tasks, as there is a multiplicity of goals in higher education that makes the choosing and limiting of indicators a complex assignment. Burke and Modarresi (2001) investigated the stability of PBF programs in five states (Florida, Ohio, South Carolina, Missouri, and Tennessee). The researchers sent surveys to state and campus policymakers, government officials, education aids, education and fiscal committees, budget officers, and legislative chairs. They received 565 responses from five states, Missouri and Tennessee 177 responses, Florida 115 responses, Ohio 160 responses, and South Carolina 113 responses, for a response rate of $49 \%, 52 \%, 48 \%, 50 \%$, and $59 \%$, respectively. In their analysis, they designated Missouri and Tennessee as the "stable" states because their programs had been functioning for a long time continuously. The program in these two states also had "continuing support from the state and campus policymakers" (Burke \& Modarresi, 2001, 
p.53). Then they compared the other three states, the "unstable" states, to Missouri and Tennessee.

They found significant differences between both groups. States designated as "unstable" had outsiders (not leaders from the institutions) directing the programs. These outsiders believed that the goal of PBF was not achievable. On the other hand, the "stable states" believed they had achieved the goal, and their programs reflected quality. Other difference between both groups was that each state included a different number of indicators. Some states included too many indicators and others too few. At the end of their research, Burke and Modarresi concluded that Missouri and Tennessee saw the program as long-term, and the other states were not sure whether the program was going to be long-term or not. In this study, the unstable states showed anxiety about changing state priorities and budget instability.

Another aspect of Burke and Modarresi (2001) research to be noted is that they did not consider "type of institution" as a variable. As the authors discuss their findings, they do not specify if the stakeholders surveyed were stakeholders of two-year institutions, four-year institution, or both. Therefore, comparing findings should be done with caution, knowing that we may not be comparing the same type of institutions. Burke and Modarresi (2001) did a great job exploring stakeholders' considerations about the policy, but they do not establish if PBF works as intended, based on outcome data. Dougherty et al. (2013) investigated how PBF originated in six states, including Florida, Illinois, Missouri, South Carolina, Tennessee, and Washington. Then they looked at two states that had not implemented PBF. They intended to explain why PBF was developed in some states and not in others. To gather the information, the authors interviewed 
legislators, governors, higher education officials, higher education institution officials, higher education institution staff, advisers, business leaders, consultants, and researchers in each of the states. They also collected and analyzed newspapers articles, academic research literature in those states, and reports from public agencies.

The authors found that those states that implemented PBF did so because of the higher education board and the higher education institutions wanted to secure new funds. These states' higher education institutions and businesses believed the policy was a new means to secure more funding and a means to make higher education more efficient. The states that did not implement PBF did not have elected officials, the business community, or higher education officials, support. The common belief by these states was that PBF was an "excuse to keep down regular state funding and that it undercuts the autonomy of higher education institutions" (Dougherty et al., p. 23, 2013). Support from the state board officials was most critical for the implementation of PBF. Those states in which higher education officials were opposed to PBF (Washington and South Carolina), the state ended up dropping the program after some time, which indicates that support from higher education officials for the survival of PBF programs is crucial. Dougherty et al. (2013) concluded, echoing Burke and Modarresi (2001), that the states in which the program was functioning for a short time did not have full support from the people directing the programs, and these people directing the programs thought PBF goals were not achievable.

In their research, Dougherty et al. (2013) did not expound on the influence of the policy on students' outcomes such as graduation rate. They mentioned there were some concerns from administrative officials and stakeholders about equality and access for 
under served populations, low-income students, students of color, and older students. It is important to clarify that research performed by Dougherty et al. (2013) was based on PBF 1.0 and not on PBF 2.0. As explained before, the difference between both programs is that PBF 1.0 is a bonus incentive and PBF 2.0 is a portion of base funding for the institution (Rabovsky, 2014). Later, Dougherty et al. (2014) expanded the research and investigated how PBF 2.0 originated in comparison to PBF 1.0. They concluded that PBF 1.0 started the emphasis on accountability. PBF 2.0 brought the economy influence into the PBF models.

So far, the research presented discussed the issues about implementing PBF and the concerns about the policy in different states. We have seen that PBF causes anxiety for all stakeholders. The research in this section establishes that there are concerns about grade inflation, inequality, elimination of unpopular programs, the effect on institutional autonomy, budget instability, and others. Understanding how controversial this policy seems to be for higher education and the concern from different interest groups in higher education is important to understand while researching the effects of this policy on different states, and types of institution. Especially in a state like Florida where both public higher education systems have adopted the policy, it is of great importance to start looking at how the policy may affect both systems. It is time to look at some of the research on the outcomes used in different PBF programs and the effect of the policy on them.

\section{Performance-Based Funding Outcomes}

Dougherty and Reddy (2013) explain that "some of the student outcomes that states are attempting to affect trough PBF include improved numbers and rates of 
retention, successful remediation, credit accrual, transfer, graduation, and job placement" (p. 53). Nevertheless, there is not much research on whether these outcomes increase under PBF. The work of Zarkesh and Beas (2004) appears to be the initial step in understanding if PBF is indeed affecting these outcome indicators in any way. The authors affirmed that different performance based initiatives use different variables to measure performance; they suggest that how institutions are affected by PBF may vary depending on the indicators used in the institution.

Zarkesh and Beas (2004) reviewed the performance indicators in community colleges and assessed their effect on the institutions. They collected data from 47 states using a semi-structured interview and found that community colleges were being evaluated using some of the performance outcomes generally used to assess four-year institutions. Zarkesh and Beas (2004) claimed that those performance outcomes did not reflect the value of community colleges whose missions are different from four-year institutions. In their research, Zarkesh and Beas (2004) explained that some of the most commonly used indicators under PBF are graduation rates, employment rates, transfer rates, retention-persistence rates, and performance after transfer. They explain that one reason for this is that these indicators are easily quantified, reflect a nationwide trend towards accountability and responsibility for college outcomes and provide the ability to see patterns nationwide. Graduation rates are a popular indicator used to assess both community colleges and universities. The authors argued that even when "this indicator can be used correctly to measure the success of a university, it does not similarly reflect the value of a community college due to the many two-year college students who take classes for reasons other than simply to attain a degree” (p. 654). 
There are two critical points to consider based on Zarkesh and Beas's (2004) research. First, not all states in their study used the same variables to measure performance, but one variable common to all was the graduation rate. Thus, it might make sense for researchers to explore the influence of PBF on this variable. Second, the work of these authors indicates that the type of institution should be considered when studying PBF. Therefore, future research should consider both variables: type of institution and graduation rate.

The graduation rate is a controversial performance indicator. Some of the research about PBF indicates that the graduation rate does not present a complete scenario of higher education performance. Zarkesh and Beas (2004) discussed some of the PBF indicators and their implications. They wrote, "with so much attention given to indicators that can be easily measured, other information that can be difficult to measure (i.e., student learning) may be ignored" (Zarkesh \& Beas, 2004, p. 66). A problem that could arise out of states using graduation rates as a performance measure is that in an attempt to get more funding an institution may shift resources from one program to another, which produces more graduates and leaves some areas of the institution without the resources needed to perform efficiently. They asked, "if colleges are simply rewarded based on how many students they graduate, will their incentive to create programs that enhance teaching and student learning be reduced?" (Zarkesh \& Beas, 2004, p. 66). Even more, could this become an incentive to alter numbers regarding the graduation rates to secure more funding?

Another problem with graduation rates is that it has become a measure that favors one type of institution over another (Montgomery \& Montgomery, 2012; Dougherty \& 
Reddy, 2013). If an institution's mission is not aligned with the state's formula for measuring performance, then it will suffer the consequence of receiving less funding. This institution will inevitably be at a disadvantage; therefore, it could lead to an otherwise successful institution receiving fewer funds and thus experience a real decrease in performance (Dougherty \& Reddy, 2013).

Montgomery and Montgomery (2012) compared graduation rates from Historically Black Colleges and Universities (HBCUs) and Predominately White Institutions (PWIs). They used data obtained from the National Center for Educational Statistics (NCES) and the Integrated Postsecondary Educational Data System (IPEDS) to select a purposive sample of $10 \mathrm{HBCUs}$ and 10 PWIs for the study. The authors analyzed the use of graduation rate measures to assign funding to those institutions. The graduation rate for the PWIs sampled was 49 percent, while the graduation rate for the HBCUs tested was 35.9 percent, almost a 15 percent difference between both types of institutions when comparing both private and public institutions. Public institutions had a 28.7 percent graduation rate for HBCUs and a 42.7 percent graduation rate for PWIs. Private institutions performed better for both groups (HBCUs and PWIs). The results from Montgomery and Montgomery (2012) confirmed their initial hypothesis that graduation rates for HBCUs are lower than graduation rates for PWIs. Montgomery and Montgomery's (2012) results are an example of what McKeown-Moak (2013) concluded in his study: applying the same funding formula to all institutions without considering the diversity of each institution could create funding inequities.

Zarkesh and Beas (2004), Montgomery and Montgomery (2012), Dougherty and Reddy (2013), and McKeown-Moak's (2013) work bring two variables to consider when 
looking at the manifestations of PBF. One is the graduation rate, one of the most frequently used measures in PBF programs, and the other one is the type of institution. This section presents the research about the type of institution as it relates to PBF first, and then explores graduation rates, its uses and implications within PBF.

\section{Performance Funding and Type of Institution}

It is important to keep in mind that the type of institution is vital when exploring PBF on higher education institutions. Burke and Minassians (2004) expand on this by exploring differences between two-year and four-year institutions. Community colleges (two-year institutions) are very different from universities (four-year institutions). The application of the same performance indicators to both types of institutions, without considering the differences between them is dangerous. Burke and Minassians (2004) found that "performance indicators largely ignore the diverse clientele and the specific purpose of community colleges" (p. 53). Take for example the graduation rate; it is a measure used in both four-year institutions and two-year institutions. However, many of the students in two-year institutions are taking classes for reasons other than attaining a degree. In this case, the performance indicator does not reflect the value of a two-year institution (Zarkesh \& Beas, 2004). Christopher (2010) conducted a study that reflects how performance indicators work differently in four-year institutions and two-year institutions.

Christopher (2010) evaluated the relationship between retention rates and graduation rates as performance indicators of two institutions. One of the institutions he evaluated was a four-year institution and the other one a two-year institution. Christopher (2010) specified that when comparing a two-year institution to a four-year institution, 
graduation rates might not be an accurate measure of success because some students transfer out of the two-year institution to complete a degree somewhere else. He found a negative relationship between retention rates and graduation rates for the two-year institution.

Jongbloed and Vossensteyn (2001) conducted another investigation concerning the difference between two and four-year institutions. They evaluated government policies used to fund higher education in different countries. They explained that funding formulas use objective criteria, provide clear information into the distribution of funding, and therefore facilitate comparison between institutions. However, the same authors presented an argument against these funding formulas. The authors stated that the formulas "may lead to a common level of mediocrity because the institutions are funded on the same quantitative ground rather than [by] a qualitative assessment" (Jongbloed \& Vossensteyn, 2001, p. 130). These performance indicators do not measure quality, but rather production. The quality of the graduate produced should not be sacrificed to produce a higher quantity of graduates. Quality is at risk and mechanisms to ensure it need to be in place (Jongbloed \& Vossensteyn, 2001). It is convenient to measure performance using outputs such as the number of credits accumulated by students, the number of degrees awarded, the number of research publications, and the number of patents and licenses issued (Jongbloed \& Vossensteyn, 2001). Those things can be counted and easily inputted into a formula to determine who is going to get more funding. As stated before, none of these criteria reflect the quality of the instruction provided by the institution. 
Some institutions have tried to address this problem by using surveys and other instruments. However, the states are not considering these when evaluating the institutions' funding source. This type of statistical approach, though simple, begets many problems (Dougherty \& Reddy, 2013). Performance indicators are used to shape what issues to think about, by focusing the attention on specific aspects of institutional performance (Barnetson \& Cutright, 2000) and distracting from other aspects, which may be as important. In other words, it may narrow the view to only those issues represented in the instruments used to measure performance.

Funding formulas used in the PBF programs may also reduce the incentive to seek outside funding and may perpetuate funding inequities (Jongbloed \& Vossensteyn, 2001). The new formula in use (PBF 2.0) affects a more significant percentage of the funding since it is used for the regular state funding rather than a bonus above it, as was the case with PBF 1.0. Note, for example, that in Ohio 79 percent of state funds are distributed through PBF (Dougherty \& Reddy, 2013). If an institution feels that it, "dominates the formula" it may have less of an incentive to self-evaluate and improve the teaching and quality of the services it provides.

The first part of this section explored the concerns with the performance indicators used by PBF. Now, because it is so controversial, and yet, so widely used, the next part discusses the research about graduation and retention rates as two of the student success indicators used the most in PBF programs. Also, it includes the research surrounding employment rates as a performance indicator.

Additionally, some researchers found institutional expenditure and student to faculty ratio to be affected by institutional efforts to increase the graduation rate (Astin, 
1993; Gansmeyer-Topf and Schul, 2006; Goenner \& Snaith, 2003; Webber \& Ehrenberg, 2010). Because the purpose of this research is to understand the role of PBF in the SUS and FCS, this research also studies administrative outcomes related to graduation rates that could be affected by PBF. The next section explores both student outcomes and administrative outcomes.

\section{Performance Funding and Student Success}

Shin (2010) questioned if the new PBF indeed affects institutional performance. Shin is one of the few authors who evaluated graduation rates. In his research, he studied two variables-- graduation rates, and research funding. The author used data from 467 public institutions in his evaluation of graduation rates and 123 public institutions for his assessment of research funding. He used a Hierarchical Linear Model (HLM) to analyze the data. The resulting model initially included three levels. Level one included the growth rate of graduation rates; level 2 included institutional characteristics such as institutional mission, in-state tuition, incoming student academic achievement (measured through SAT and ACT scores), and dorm facility of the institution (available dorm beds for the students). The third level included state variables such as the state incoming student achievement (measured through SAT and ACT score), state appropriation per capita for higher education, state appropriation changes for ten years, and state unemployment rate.

Shin (2010) found that after adopting PBF, the research funding increased by a higher rate than the graduation rate. The new type of accountability (PBF) "did not contribute to the growth of graduation rates" (Shin, 2010, p. 59). Instead, the author suggested that a variety of factors influenced graduation rates (Shin, 2010). The author 
presented three models. In model one (program effects), he found that there was not a significant difference for which the implementation of the new accountability (PBF) did not contribute to the growth of graduation rates. In model two (effects by types), Shin found that states which have a PBF program have a higher increase in graduation rates than states without any performance-based accountability.

Shin conducted his study with data from 1997 to 2007, which means that the performance policy in place was PBF 1.0. Under PBF 1.0, the amount of state funding attached to the policy was minimal. He argued that if the financial incentive linked to PBF is attractive, then institutions might be more inclined to incorporate new measures of accountability in their internal system, therefore influencing institutional performance. Ultimately, his finding supported the idea that institutional characteristics can explain institutional performance. If the financial incentive tied to PBF 2.0 is higher than the one linked to PBF 1.0, it is possible that results under PBF 2.0 could be different.

One finding in Shin's research to consider when looking at the effect of PBF on graduation rates is the importance of institutional characteristics. PBF policies are in place now, and many of them rely on the graduation rate or a derivation of it (such as the graduation rate) in a specific area of study or for a particular type of population. It is essential to evaluate the nature of the new PBF effect on graduation rates. The result could be a direct one which should be visible after controlling for institutional characteristics, or it could be an indirect one. In that case, it is an institutional response to PBF by incorporation of the policy into their internal systems.

In his research, Dougherty and Reddy (2013) explained that Florida, Pennsylvania, South Carolina, Tennessee, Washington, Missouri and Ohio "reported data 
pertaining to changes in graduation numbers and rates that might be due to performance funding” (p. 53). They collected data from the Board of Regents documents and other authors' research, such as the work of Dougherty and Hong (2006), Phillips (2002), and Bell (2005). However, even when they all agree with the positive effect of PBF on graduation rates, all of them ask for caution when claiming the increase in degrees or graduation rates is due to the implementation of PBF. Echoing Shin (2010), they also argued there might be many other factors contributing to these increases in graduation rates; Dougherty and Reddy (2013) and Shin (2010) agree that graduation rate increases may depend on the type of institution (institutional characteristics). Looking at the SUS and FCS in Florida will allow us to see if the role of PBF is different for each system (SUS, FCS).

On the other hand, Sanford and Hunter (2011) found that PBF policies had no impact on retention or graduation rates in Tennessee. They argued that PBF might be insufficient to provoke change in institutional performance and outcomes. In their study, they used a linear mixed model (LMM) to analyze the data. They selected periods before and after the implementation of PBF. Using data from 2009, the authors only explored the impact of the increased financial incentive on the four-year graduation rate. They did not examine the impact on the six-year graduation rate. When comparing the six-year graduation rate change for Tennessee (graduation rates from 1999 vs. 2007), there was not a significant difference. When conducting the same process for Tennessee peer institutions, they found there was a significant change. The six-year graduation rate from 2007 was significantly higher than the six-year graduation rate for 1999. Sanford and Hunter (2011) did not find an effect over time, but they did see an intercept effect. The 
authors of this study also explored the impact on the retention rate but did not notice a significant difference in the change of retention rates over time in Tennessee. Sanford and Hunter's (2011) study had the same issue as the Shin (2010) study. Sanford and Hunter (2011) considered data mostly from Tennessee's time with PBF 1.0. They had recently switched to PBF 2.0 in 2010, and thus no conclusions could be drawn regarding the effect of the new PBF.

Dougherty, Jones, Lahr, Natow, Pheatt, and Reddy (2016) categorized the lack of research about PBF 2.0 as a problem. They argue that the impact of PBF 2.0 program will be more significant that of PBF 1.0 because it involves a more substantial proportion of state higher education funding. In their study, they evaluated the impact of PBF (2.0) in Indiana, Ohio, and Tennessee. They first looked at the descriptive statistics. They focused on graduation numbers, arguing, "They have been the principal concern of state performance funding programs" (Dougherty et al., 2016, p. 132). They found "graduation numbers increased by a larger amount than enrollment numbers" (Dougherty et al., 2016, p. 132). Using a combination of multivariate analyzing and controlling for student and institutional characteristics, the author examined the effect of PBF in these three states.

For the state of Indiana, they used a difference in difference analysis, running nine models. In all nine models, they found "that performance funding in Indiana did not lead to increases in the three-year average number of four-year graduates. The impact found although none was significant-were negative" (Dougherty et al., 2016, p. 133). The same was true for Tennessee and Ohio. The authors argued that the limited amount of time that the PBF 2.0 has been in place prevented them from concluding the impact of it on student outcomes in these three states. They did mention the effect of PBF might become 
pronounced with time. (Dougherty et al., 2016, p. 141). Hillman, Fryar, and CrespínTrujillo (2017) conducted a similar study using the state of Tennessee and Ohio. In their study, they looked at degree production, which included Certificates, Associates and Bachelors. Using a difference-in-difference design, they found that even when the bachelor production increased after the implementation of PBF in the state, such an increase was not significantly different from the trends in other states with no performance-based funding programs. Consequently, they concluded PBF had not induced four-year colleges and universities to produce more bachelor's degrees in Ohio and Tennessee (Hillman, Fryar \& Crespín-Trujillo, 2017).

Hillman and Corral (2018) are one of those authors who investigated the effect of PBF on Minority Serving Institutions (MSI). Inspired by the case of Tennessee where "the state's sole public Historically Black College and University has been at the losing end of the funding formula since 2011," they decided to investigate if MSIs had changes in state funding levels after the adoption of PBF (Hillman \& Corral, 2018, p. 1758). These authors concluded that the adoption of PBF resulted in a reduction of 750 dollars per FTE for MSI when compared to other states that did not have a PBF program in place. This reduction represents a significant loss of funding for those institutions.

The authors recommend looking at PBF critically especially for MSI institutions that could be at a disadvantage. Hillman and Corral (2017) explain,

with fewer resources from the state, MSIs might respond to these budgets cuts by decreasing their student to faculty ratio, curtailing student and academic support services, or by increasing tuition. Each of these responses would make it more difficult for MSIs to improve retention and degree completion, which in turn 
would result in additional funding cuts in future years. If left uncorrected, pay-forperformance regimes are likely to generate the unintended consequence of worsening-rather than reversing-educational inequality (p. 1759).

The literature about employment rates concerning PBF is minimal. Most of the studies researching the impact of PBF use unemployment rates as a control variable. This variable has shown to influence graduation rates. (Hillman et al., 2015; Hillman Tandberg \& Gross, 2014; Rutherford \& Rabovsky, 2014; Sanford \& hunter, 2011; Sin, 2010, Shin \& Milton 2004). Shin and Milton (2004) explained that unemployment rates have shown to have a negative association to graduation rate, which means that low graduation rates are related to high unemployment rates and vice versa. However, the employment rate is a common performance outcome in PBF programs (Dougherty \& Reddy, 2013). If we higher education professionals want to understand the role of PBF, it is important to look at as many variables related to PBF as possible. In the case of Florida, employment rate is part of the PBF program for both public higher education systems (SUS and FCS) and looking at the trends over time in this variable most certainly contribute to my understanding of PBF in Florida.

\section{Performance Funding, Institutional Expenditures, and Student to Faculty}

\section{Ratio}

The second aspect explored in this research is institutional expenditures and student to faculty ratio. The literature about institutional expenditures and PBF is minor. This section explores five PBF studies using institutional expenditures as a variable (Hillman, Tandberg, \& Gross, 2014; Rutherford \& Rabovsky, 2004; Sanford \& Hunter, 2011; Shin, 2010). Four studies explored expenditures on instruction; they used the 
variable as a control variable, meaning that instead of looking at how this variable may influence PBF they were controlling it to minimize its effect in the statistical model and explore the impact of PBF on graduation or retention rates. Rabovsky (2012) was the only author looking at PBF as a restructuring financial incentive tool and its influence on administrative behavior. Using IPEDS data, the author conducted a series of correlational analysis. Rabovsky (2012) found evidence that four year institutions in states with PBF dedicate a higher portion of their expenditure to instruction than those in states with no PBF.

The literature has not reached a consensus about how different types of institutional expenditures may influence graduation or retention rates. Astin (1993) argued that student service expenditures have a robust positive effect on student retention. Ryan (2004) found evidence that instruction and academic support expenditures positively affect graduation rates, which confirms Astin's findings. Gansmeyer-Topf and Schul (2006) found a direct relationship between institutional expenditures, retention, and graduation rates. The authors explained that "institutional expenditures dedicated to instruction significantly contributed to first-year retention and six-year graduation rates" (p.631). However, Belfield and Thomas (2000) found no relationship between the department unit's expenditure levels and student performance.

More recently, Webber and Ehrenberg (2010) explored the effect of noninstructional expenditure categories on graduation and first-year persistence rates of undergraduate students. They found student service expenditures to influence graduation and persistence rates positively. This effect seems to be greater in those institutions with lower entrance test scores and higher Pell Grant expenditures per student. The authors of 
this study explained that this effect is less visible in those institutions who achieve a balance of institutional expenditures between instructional and student services. As is evident in the literature, there is a relationship between institutional expenditure and degree attainment (Gansmeyer-Topf and Schul, 2006). Exploring the changes over time in institutional expenditures could help us understand the role of PBF in higher education institutions and student outcome variables.

As with the research about institutional expenditures, the study about student to faculty ratio seems to be inconclusive. In 2003, Goenner and Snaith explored the role of institutional factors in determining graduation rates at doctoral universities. One of the factors they looked at was the student to faculty ratio. The researchers found that a higher student to faculty ratio was positively related to graduation rates. Goenner and Snaith (2003) explained their result as:

The most plausible explanation in our view is that this variable is positively correlated with some other institutional variable that has not been accounted for in our models. For example, an institution with a high student to faculty ratio may be more likely to have in place other academic support systems such as advisement, tutoring, and honors programs that more than offsets any negative effects of a high student to faculty ratio. [ ] It may be the case that this variable is negatively related to the quality of the education received but not to the actual attainment of the degree (Goenner and Snaith, 2003, p 417).

Alternatively, Bound, Lovenheim, and Turner (2010) explored college completion declines in 2010. They investigated "what accounted for the limited expansion in the supply of college-educated workers to the labor force, despite the relatively high level of 
the college wage premium. (p. 1)" The researchers looked at changes in preparedness of entering students and changes in collegiate characteristics. They included the type of institution and resources per student. One of the resources they looked at in their research was the student to faculty ratio. The authors found a reduction in institutional resources in the sectors that experienced declining completion rates. They also found a shift in preparation of students entering college. Institution resources were measured by increases in college student to faculty ratios. The shift in preparation of students and the increases in college student to faculty ratios "accounted for about one-quarter of the observed completion rate decline" (Bound, Lovenheim \& Turner, 2010, p.2).

Although the research about student to faculty ratio and graduation rates seem inconclusive, student to faculty ratio has been used to rank higher education institutions by magazines, newspapers, websites, governments, or academics such as the U.S. World and News Report. IPEDS started to publish them in 2008. The Florida legislation expressed concern about a higher student to faculty ratio as an unintended consequence of PBF. As part of understanding PBF and its role in Florida's higher education systems, it is essential to look not only to student outcomes but to those aspects that may expand the knowledge of PBF in Florida such as institutional expenditures and student to faculty ratio.

\section{Performance Funding 2.0 in Florida}

Florida has two public higher education systems, the State University System (SUS) and the Florida College System (FSC). The Board of Governors (BOG) in Florida published a press release indicating the official adoption of PBF for the SUS in 2013 (http://www.flbog.edu/pressroom/news.php?id=509, Press Release, 10/09/2013). They 
authorized \$20 million tied to specific goals for Florida public universities (State University System, SUS). In 2013, they started the program with three metrics: average wages of employed baccalaureate graduates, the percentage of baccalaureate graduates employed or continuing their education further, and cost per undergraduate degree. The state assigned 50 million dollars for PBF's second year, along with ten metrics instead of the original three. In a January 2014 press release, the BOG announced the official implementation of the new PBF model for 2014-2015 with strong support from the Florida Senate as expressed by the Senate president, Don Gaetz:

Florida's policy must be to make sure a college degree actually leads to a real job in the real economy. [That is] why we strongly support the Board of Governors in tying funding of education to the measurable performance of our colleges and universities. (http://www.flbog.edu/pressroom/news.php?id=516, Parr. 6.) Under this new PBF program, they evaluate all universities in the State University System (SUS) in seven common metrics. These metrics included percentage of bachelor's degree graduates employed or continuing their education, average wages of employed baccalaureate graduates, cost per undergraduate degree, six-year graduation rate for full-time and part-time first-time-in-college students, academic progress rate (2nd-year retention with GPA above 2.0), bachelor's degrees awarded in areas of strategic emphasis (including STEM), and university access rate (percentage of undergraduates with a Pell grant). Metric number eight, graduate degrees awarded in areas of strategic emphasis, applies to 10 of the state's 11 universities. New College of Florida has an alternative metric (freshmen in top 10\% of graduating high school class). The Board of Trustees for each institution decided the last two metrics. The allocation of 
funding within this system depends on the total points (maximum of 100 points) obtained by each of the institutions, based on the ten metrics. Institutions in the bottom three or with less than 50 total points do not receive any state funding. In the approved changes for the 2019-2020 model, they eliminated the bottom three requirements. During 2014, 2015,2016 , and $2017,100,150,225$, and 245 million respectively were allocated for PBF in Florida.

The SUS in Florida has 12 institutions, but only 11 participate in the PBF program. The six-year graduation rate for first-time in college students is one of the first metrics to be included in the SUS PBF program. Starting fall 2018, the SUS PBF program will not consider the six-year graduation rate, one of the student outcomes in the program; instead, it will be evaluating the four-year graduation rate.

The Florida College System (FCS) is the other public higher education system in Florida. The FCS consists of 28 colleges. The commissioner of education asked the FCS to develop a PBF model in 2014. Similar to the SUS PBF model, the FCS PBF model consists of excellence and improvement points; they also compare colleges' performance within themselves. The program has three levels of compensation: gold, silver, and bronze. The gold level consists of the seven colleges with the highest point total. These colleges have their base funding restored, receive a proportional amount of performance dollars, and a proportional amount of performance dollars based on the size of their recurring base budget and the total points they earned. The silver colleges are one standard deviation below the mean. These colleges have their base funding restored and receive a proportional amount of performance dollars. The bronze colleges have total points of two or more standard deviations below the mean. Bronze colleges have part of 
their "base funding withheld with the opportunity to submit an improvement plan to the State Board of Education and, upon showing progress in its implementation, have that base funding restored," as explained in the Florida college system performance funding overview $(2015$, p. 3$)$. The system is evaluated in four metrics: completion rates, retention rates, job placement, and entry-level earnings. During 2014, the total proposed appropriation for the FCS PBF program was 40 million dollars; the first year of the FCS PBF program was 2015 (See the appendix for allocation tables 2015-2016).

\section{Summary}

As problematic as the research presented in this section may be, $\mathrm{PBF}$ is a current policy that will, most likely, be in place for a long time. Research on how PBF affects different type of institutions is the first step in a long process of exploration and analysis. PBF is Florida's public higher education system funding mechanism. Its implementation not only affects all universities and colleges in the state, but it also affects the students in the systems. Understanding the role of PBF on Florida's public higher education system should be a priority. This dissertation seeks to contribute to the body of research on PBF by being one of the first exploring the role of the policy on Florida's student outcomes and the administrative related aspects such as student to faculty ratio and institutional expenditures. There is very little research about the influence of PBF on many of the student outcomes used in this policy. As Hillman, Tandberg and Fryar (2015) explained, "we have a substantial gap in our knowledge of the effectiveness of these new strategies" (p.6). This lack of knowledge served as motivation for their study as well as for this one. 


\section{CHAPTER III \\ METHODOLOGY}

\section{Background}

The research about PBF is diverse and mixed. Some authors claim that PBF can help improve student success outcomes. Others claim there is not enough evidence indicating PBF does improve student success outcomes. Florida provides a unique opportunity to explore the role of PBF in two public higher education system. PBF is in place at the State University System (SUS) and at the Florida College System (FCS), which recently adopted it in 2015 . At this point, it is too early to explore the impact of PBF in Florida. Nevertheless, if in the future, we higher education professionals want to explore the effect of PBF on student outcomes in higher education, we must start by understanding the role of PBF in Florida's public higher education system. This study precisely seeks to explore such role by looking into changes in graduation and retention rates, student employment data, student to faculty ratios, and institutional expenditures, variables considered to be determinants of degree productivity for both the FCS and SUS since the implementation of PBF in Florida.

Student outcomes are not the only aspect PBF can affect. In their research, Hillman and Corral (2018) explained that some of the aspects that may be affected by decreased funding due to PBF might include the student to faculty ratio, student academic support services and tuition increases. They make clear, "With fewer resources from the state, Minority Serving Institutions might respond to these budget cuts by decreasing their student to faculty ratio, curtailing student and academic support services, or by increasing tuition" (Hillman \& Corral, p. 1759, 2018). Recently the Florida state Senate 
presented concerns about the effect of PBF on the student to faculty ratio. Although they did not include the student to faculty ratio in the final verbiage of the Florida Excellence in Higher Education Act of 2018, it was a topic of discussion. Senator Bill Galvano had two requests for the new Higher Education Act:

1. Require that the BOG legislative budget request include five-year trend information on the ratio of student enrollment to faculty.

2. The ratio of students to administrators may not grow at a higher rate than the ratio of students to faculty (FIU Government relation, personal communication, January 22, 2018).

Most of the discussions around PBF in Florida are related to the student success outcomes. However, to understand PBF, it is essential to also look at other administrative outcomes that may be affected by it such as the student to faculty ratio and institutional expenditures. The purpose of this work is to lay down the initial steps in a long list of consecutive studies needed in order to understand the full extent of PBF in the Florida. This research focuses on two areas, student success outcomes and administrative outcomes, as well as on two systems, the State University System (SUS), and Florida College System (FCS). Therefore, the questions guiding this study are:

1. What is the role of Performance-Based Funding (PBF) in student success, specifically, as it attends to changes over time on graduation rates, retention rates, and student employment data before and after the implementation of the policy in Florida's public higher education systems? 
2. What is the role of Performance-Based Funding (PBF) as it attends to changes over time on student to faculty ratio and institutional expenditures in Florida's public higher education systems?

These questions are designed to help us explore the role of PBF in the public higher education system in Florida as it pertains to student success outcomes, and administrative outcomes such as student to faculty ratio and institutional expenditures. Figure 1. Below shows the multidirectional cycle this researcher seeks to engage with during this investigation.

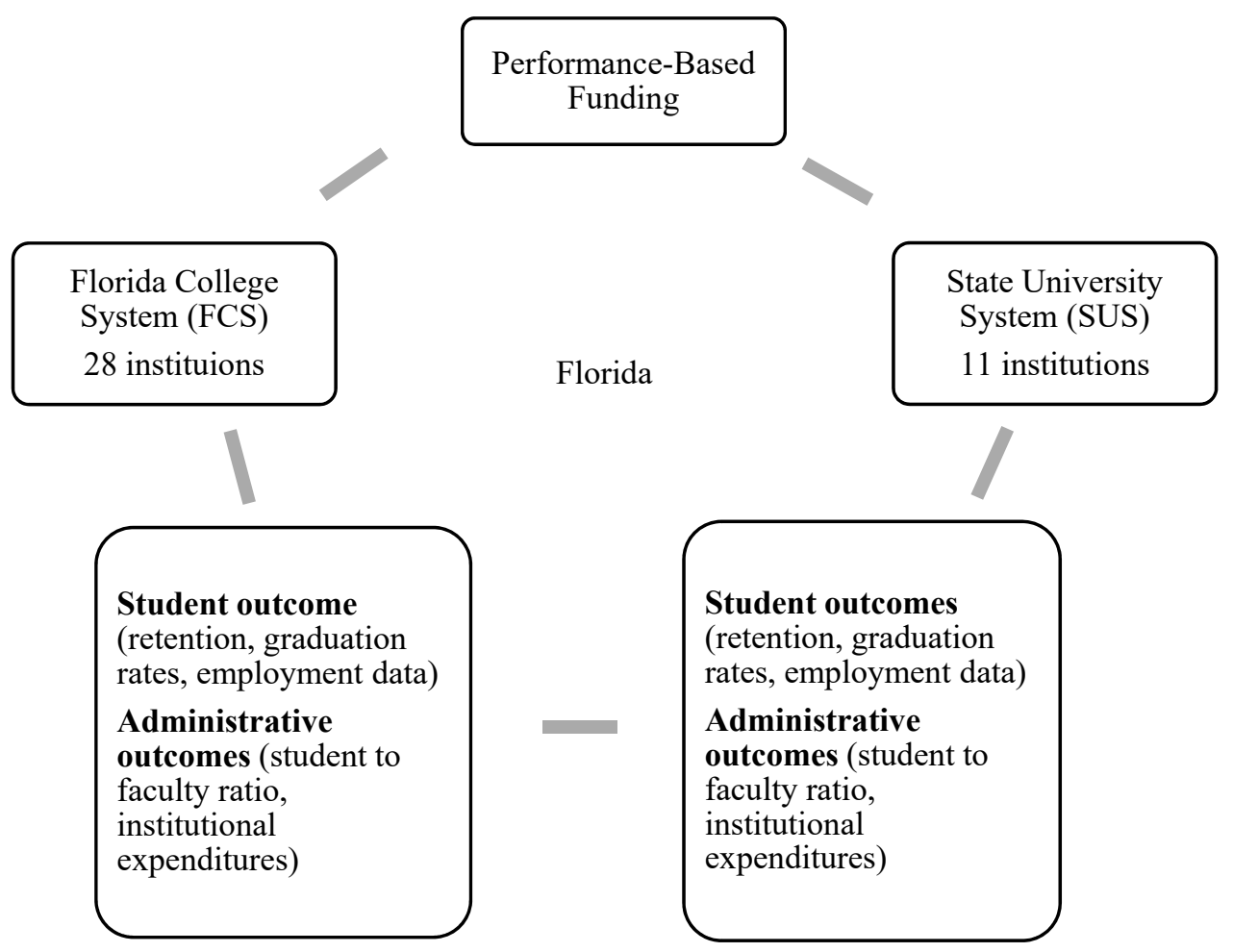

Figure 1: Performance-Based Funding and the Public Higher Education System.

\section{Institutions}

The two public higher education systems in Florida are the Florida College System (FCS) and the State University System (SUS). The FCS consists of 28 colleges. 
The commissioner of education asked the FCS to develop a performance-based funding model in 2014. Similar to the SUS PBF model, the FCS PBF model consists of excellence and improvement points. The program has three levels of compensation: gold, silver, and bronze. The gold level colleges are the top seven colleges; they have their base funding restored, receive a proportional amount of performance dollars, and a proportional amount of performance dollars based on the size of their recurring base budget and the total points they earned. The silver colleges are one standard deviation below the mean. They have their base funding restored and receive a proportional amount of performance dollars. The bronze colleges "have part of their base funding withheld with the opportunity to submit an improvement plan to the State Board of Education and, upon showing progress in its implementation, have that base funding restored," as explained in the Florida college system performance funding (2015, p. 3). Each college is evaluated using four metrics: completion rates, retention rates, job placement, and entrylevel earnings. During 2014 the total proposed appropriation for the FCS PBF program was 40 million dollars; the first year of the FCS PBF program was 2015 (See the appendix for allocation tables 2015-2016).

The Board of Governors (BOG) regulates the State University System in Florida. The BOG published a press release indicating the official adoption of PBF for the state in 2013 (http://www.flbog.edu/pressroom/news.php?id=509, Press Release, 10/09/2013). They authorized \$20 million tied to specific goals for Florida public universities. In 2013, they started the program with three metrics: average wages of employed baccalaureate graduates, the percentage of baccalaureate graduates employed or continuing their education further, and cost per undergraduate degree. For the second year, they assigned 
50 million dollars to PBF along with ten metrics instead of the original three. In a January 2014 press release, the BOG announced the official implementation of the new PBF model for 2014-2015. Seven metrics are common to all universities in the State University System (SUS) under PBF. These metrics are percentage of bachelor's degree graduates employed or continuing their education, average wages of employed baccalaureate graduates, cost per undergraduate degree, six-year graduation rate for fulltime and part-time first-time students, academic progress rate, bachelor's degrees awarded in areas of strategic emphasis, and university access rate (percentage of undergraduates with Pell grants). An eighth metric, graduate degrees awarded in areas of strategic emphasis, applies to 10 of the state's 11 universities. The New College of Florida has an alternative metric (freshman in Top 10\% of Graduating High School Class). Each institution's Board of Trustees decided metric number nine and number ten for their institution. Therefore, metrics nine and ten are different for each of them. The allocation of funding within this system depends on the total points (maximum of 100 points) obtained by each of the institutions, based on the ten metrics. Institutions in the bottom three or with less than 50 total points do not receive any state funding. In the approved changes for the 2019-2020 model, they eliminated the bottom three requirement. During 2014-2015, they allocated 100 million for PBF in Florida, 150 million in 2015-2016, 225 million in 2016-2017, and 245 million allocated for 20172018.

Both systems have a similar mechanism in their PBF programs. They both have student outcome indicators. They evaluate both systems for excellence and improvement 
points. They both use a scaling methodology. Table 1 shows the list of institutions for

both systems.

Table 1. Florida Public Higher Education Institutions

\begin{tabular}{ll}
\hline Florida College System & State University System \\
\hline Palm Beach State College & Florida A\&M University \\
St. Petersburg College & Florida Atlantic University \\
Chipola College & Florida Gulf Coast University \\
Pensacola State College & Florida International University \\
Gulf Coast State College & Florida Polytechnic University \\
College of Central Florida & Florida State University \\
Daytona State College & New College of Florida \\
State College of Florida, Manatee-Sarasota & University of Central Florida \\
North Florida Community College & University of Florida \\
St. Johns River State College & University of North Florida \\
Eastern Florida State College & University of South Florida \\
Broward College & University of West Florida \\
Indian River State College & \\
Miami Dade College & \\
Florida SouthWestern State College & \\
Florida Gateway College & \\
Lake-Sumter State College & \\
Northwest Florida State College & \\
Polk State College & \\
Florida Keys Community College & \\
Florida State College at Jacksonville & \\
Santa Fe College & \\
Seminole State College of Florida & \\
South Florida State College & \\
Tallahassee Community College & \\
Valencia College & \\
Hillsborough Community College \\
Pasco-Hernando State College & \\
\hline
\end{tabular}

\section{Variables}

As mentioned before, the metrics used in PBF programs are primarily quantitative measures. This research focuses on exploring patterns of change in those quantitative measures included in both PBF programs (SUS and FCS). This section presents two groups of variables, student success outcomes and administrative outcomes. Student 
success includes all the metrics capturing student data such as graduation rates, retention rates, and employment after graduation. The administrative outcomes include the quantitative variables that are not in direct relation to PBF. These variables are student to faculty ratio and the institutional expenditures.

Considering the literature, there is a common concern from faculty and other groups about the effect of PBF on other aspects not related to student success. A recent legislative update for the state discussed the inclusions of measures to evaluate student to faculty ratios in the State University System. This new measure refers not only to student to faculty ratio but also to student administration ratio. As discussed, authors like Shin (2010) looked not only at the student success related measures but also institutional expenditures to evaluate how institutions invested the new funding coming from PBF programs.

The goal of this study is to understand the role of PBF in Florida higher education systems by looking at student success measures and administrative outcomes. Doing so starts the groundwork for understanding how PBF works. Other researchers can use these findings to conduct further research about PBF. In order to answer the research questions in this study, this researcher explores patterns of change over time as well as differences within each system and differences between both systems. The variables in this study will be six-year graduation rate, retention rate, percent of bachelor's graduates employed or continuing their education further one year after graduation, job placement or continuing education, student to faculty to ratio, and institutional expenditures. 


\section{Data Collection}

Table 2 shows the outcomes explored in this study, the data sources for each outcome, and the span of years for which data was available. IPEDS is a source of annual panel data for institutions of higher education. It provides institutional level data for enrollment, ethnicity, admissions, graduation, and so forth. Data for each outcome generated from IPEDS responds to years of availability. Even though IPEDS offered public data sets in the 1980s, it was not until 2004 that the database included graduation rates. The data for the institutional expenditure outcome became available in 2005 and for the student to faculty ratio in 2008. The Florida Board of Governors (BOG) publishes individual outcomes data for each university in the SUS in a document called Final Metric Score Sheet. A final metric score sheet includes each institution's data for each of the metrics in the PBF program for the SUS. The State Board of Education (SBOE) publishes individual college outcomes data for each institution in the FCS in a document called FCS Measure Outcomes. An FCS Measure Outcomes includes each institution's data for each of the metrics considered in PBF for the FCS. Job Placement or continuing education is an outcome for both the SUS and FCS and is calculated by their respective governing boards. 
Table 2. Data Source and Outcomes.

\begin{tabular}{|c|c|c|c|}
\hline \multirow{5}{*}{$\begin{array}{c}\text { Student } \\
\text { Success } \\
\text { Variables }\end{array}$} & Variables & Source & Years of availability \\
\hline & Graduation Rate & IPEDS & $2004-2016$ \\
\hline & $\begin{array}{l}\text { Job Placement or continuing } \\
\text { education - SUS }\end{array}$ & $\begin{array}{l}\text { BOG-PBF } \\
\text { Metrics }\end{array}$ & 2014-2017 \\
\hline & $\begin{array}{l}\text { Job Placement or continuing } \\
\text { education - FCS }\end{array}$ & $\begin{array}{l}\text { FCS-PBF } \\
\text { Metrics }\end{array}$ & $2012-2016$ \\
\hline & Retention Rates & IPEDS & 2004-2016 \\
\hline $\begin{array}{l}\text { Other } \\
\text { Variables }\end{array}$ & $\begin{array}{l}\text { Institutional Expenditures: } \\
\text { Instructional } \\
\text { Research } \\
\text { Public Service } \\
\text { Academic Support } \\
\text { Student Services } \\
\text { Instructional Support } \\
\text { All other core expenses } \\
\text { Student to Faculty Ratio }\end{array}$ & IPEDS & $2005-2016$ \\
\hline
\end{tabular}

As this study explored changes in student and institutional outcomes before and after the implementation of PBF in Florida in 2013, it engages with a substantial amount of existing institutional and state-wide data. The unevenness of data collection on each variable precludes a single period from framing the study, and table 2 indicated the specific years that data were available and analyzed for each variable.

\section{Data Analysis}

A comprehensive descriptive analysis was conducted to explore trends in student and institutional outcomes surrounding the period before and after the implementation of PBF programs in Florida. Specifically, this study explored: 1) institutional-level changes by variable, 2) relative institutional positions (within a system) by variable, 3) overall system changes by variable, and 4) overall institutional position within the performance funding system for graduation rates. Given that there were no formal across-institutional 
rankings before the establishment of PBF, the researcher calculated a composite score based on the relative institutional positions for the graduation rate variable for each year before 2013 for the SUS and 2015 for the FCS used as a proxy of institutional position. Improvement and excellence points, which serve as the basis for current PBF rankings, were assigned following each PBF program guidelines to evaluate how each intuition within each system would have performed under PBF guideline prior its implementation based on graduation rates.

The data analyses for all four major parts of the study aim to show change; therefore, most results will be depicted visually. Working with population data eliminates the need for inferential statistics, and being a correlational design, this study will not make causal claims. Instead, the comprehensive descriptive analysis conducted here will focus on presenting an accessible overview of the broader changes in student, institutional, and system outcomes associated with PBF in Florida.

\section{Summary}

The purpose of the study was to explore the role of PBF in the two public highereducation systems in Florida. In order to understand this role, this study analyzes student success outcome variables over time. This study attends changes in graduation and retention rates, student employment data, student to faculty ratios, and institutional expenditures, variables considered being determinants of degree productivity for both the FCS and SUS. Eleven institutions are included for the SUS and 28 for the FCS. IPEDS data are used to conduct a comprehensive descriptive analysis of these variables. With this analysis, this researcher explored: 1) Institutional-level changes by variable, 2) relative institutional positions (within a system) by variable, 3) overall system changes by 
variable, and 4) overall institutional position within the performance funding system for graduation rates. These four analyses are meant to answer both research questions:

1. What is the role of Performance-Based Funding (PBF) in student success, specifically, as it attends to changes over time on graduation rates, retention rates, and student employment data before and after the implementation of the policy in Florida's public higher education systems?

2. What is the role of Performance-Based Funding (PBF) as it attends to changes over time on student to faculty ratio and institutional expenditures in Florida's public higher education systems? 


\section{CHAPTER IV}

\section{RESULTS}

This study looked at student success outcome variables, student to faculty ratios and institutional expenditures from 2004 to 2016 . The variables considered under the student success included: graduation rates, retention rates, and student employment rates. This research looks at the two public higher education systems in Florida, the SUS and then the FCS. For each system, the chapter presents the variables related to student success first, and then the student to faculty ratio and institutional expenditures. This chapter ends with a comparison between systems.

To better understand the role of PBF on Florida's public higher education system it is important to briefly review how the system was funded and consider this when looking at any changes in trends for any of the variables in this section. Before PBF, Florida's public higher education system was funded based on enrollment. The system had been experiencing budget cuts of up to 22 percent since 2007 (Orozco, 2012). "By 2009-2010, Florida's higher education funding had dropped 26 percent from 20 years earlier, and 40 percent from only three years earlier, to $\$ 6,150$ per FTE (Full Time Equivalent) student (versus \$8,2945 in 1990-1991 and \$10,212 in 2006-2007)” (Orozco,2012, p. 2). PBF brings 20 million in new funding for its first year in 2013 for the SUS and 30 million for the FCS, giving institutions an opportunity to qualify for this new funding based on their performance (Specific funding allocations per institution can be found for the SUS in www.flbog.edu and the FCS on www.floridacollegesystem.com. 


\section{State University System}

\section{Student Success Outcomes: Graduation}

IPEDS defines graduation rates as full-time, first time, degree or certificateseeking students who started and finished at the same institution. Students included in the graduation rate do not represent all students at an institution (https://nces.ed.gov/pubs201 7/2017046.pdf). They calculate graduation rates by dividing the number of students who completed their program within $150 \%$ of the time by the number of student in the entering cohort. In the SUS, (four-year institutions), students who completed their program within $150 \%$ of the time are students who finished their program within six years. Figure two shows descriptive statistics for the SUS graduation rate from 2004 to 2016. The most frequent graduation rate for the SUS was $49 \%$. The average graduation rate for SUS was $55 \%(\mathrm{M}=55 ; \mathrm{SD}=14.27)$. The histogram shows a higher frequency of graduation rates in the lower bottom of the distribution, between $35 \%$ and $54 \%$ for the SUS.

\begin{tabular}{lr}
\hline 2004-2016 SUS Graduation rate \\
\hline Mean & 55 \\
Standard Deviation & 14.27 \\
Median & 49 \\
Mode & 49 \\
Range & 53 \\
Minimum & 35 \\
Maximum & 88 \\
\hline
\end{tabular}

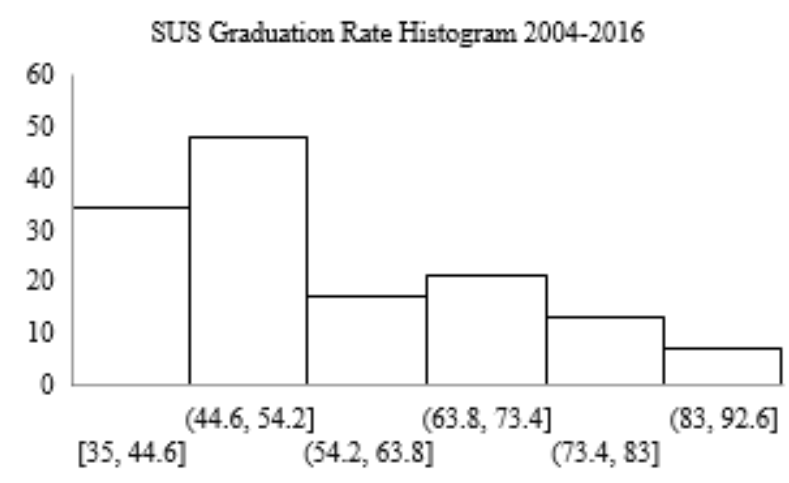

Figure 2: Descriptive Statistics for the SUS Graduation Rate from2004 to 2016 
Figure 3 below shows the graduation rate trend for the SUS. As shown in the trend below, the graduation rate was stable from 2008 to 2011 at 53\%. From 2011 to 2013 , there is an increase of $1 \%$ and $2 \%$ respectively. In 2013, Florida was preparing for the implementation of PBF; one year afterward (2014), the increase in graduation rate was $2 \%$. The graduation rate then stabilizes between 58 and 59 percent for the rest of the years 2015 to 2016 .

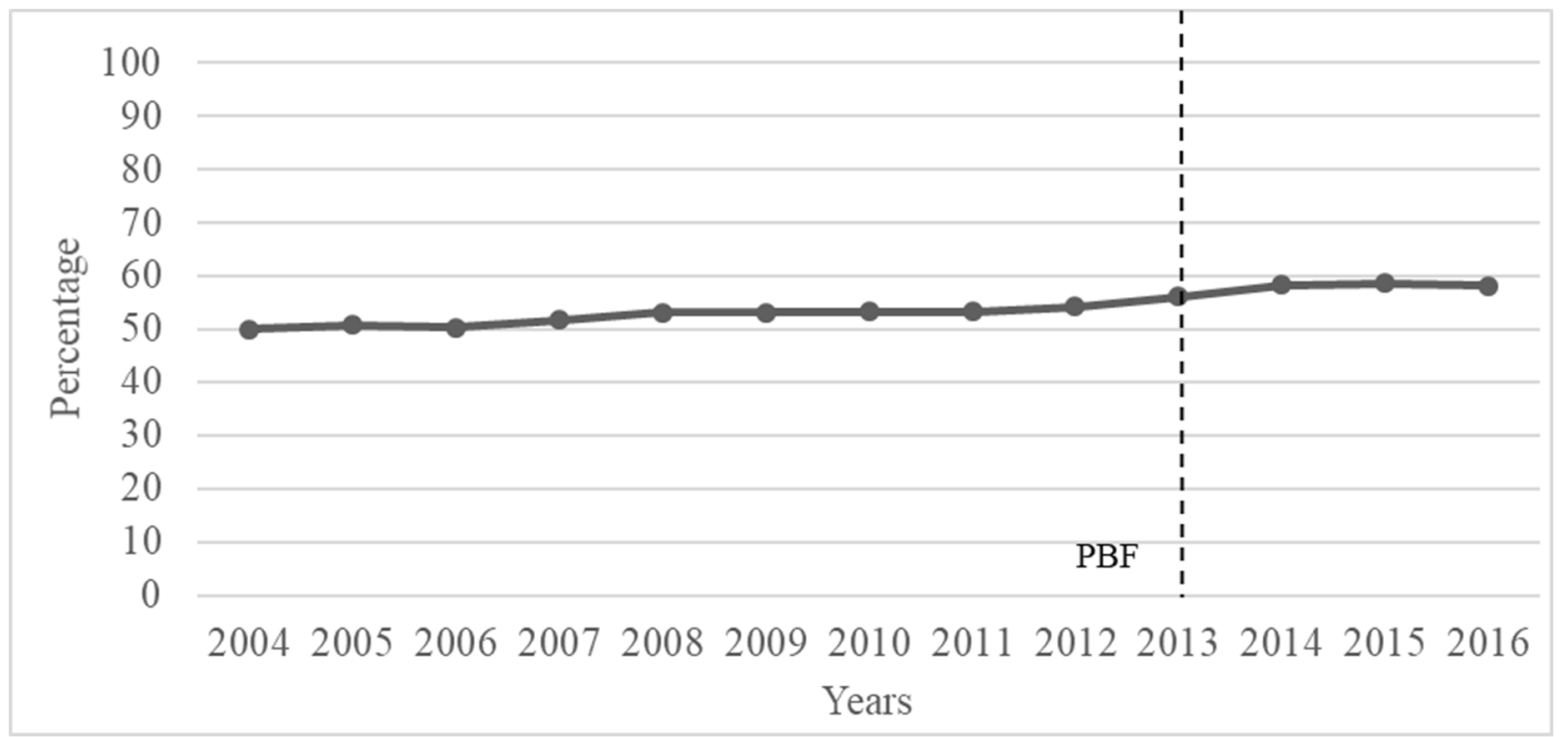

Figure 3. SUS Graduation Rate Trend

Figure 4 below shows the graduation rates trends for each of the institutions in the SUS from 2004 to 2016. Institutions grouped into three categories, high, middle and low. The distinction among these groups became clear after the implementation of PBF when USF performance was closer to UCF and NCF performance forming the middle group. After the implementation of PBF, there were three institutions with graduation rates between $60 \%$ and $70 \%$, University of Central Florida (UCF), New College of Florida (NCF), and University of South Florida (USF). The University of South Florida started with a $47 \%$ graduation rate in 2004, joined the $60 \%$ graduation rate in 2013 and stabilized 
in a $67 \%$ graduation rate in 2014, distancing itself from the rest of the institution in the "lower group." Two institutions remained in the higher end of the percentage trends, above $70 \%$, University of Florida (UF), and Florida State University (FSU) forming the higher group. Six institutions had graduation rates between $30 \%$ and $60 \%$.

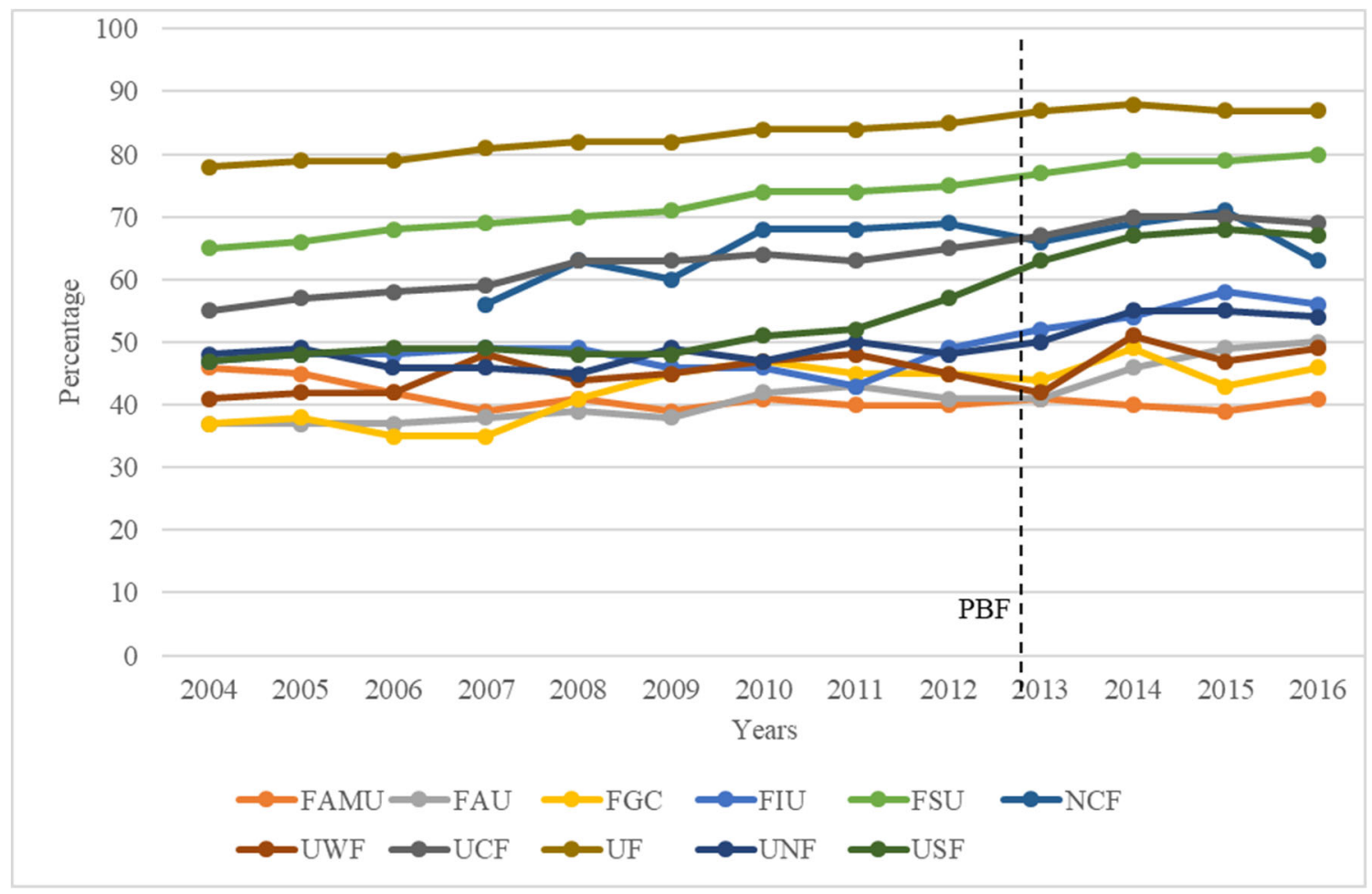

Figure 4. Graduation Rate Trends for the State University System

PBF started in 2013 for the SUS; 2014 was the first year of evaluation for institutions on the PBF program. After the implementation of PBF in 2013, most of the institutions increased graduation rates. Two thousand fourteen shows a higher rate of change for more institutions in the SUS than any other year from 2005 to 2016. Table 3 shows the rates of change for each of the institutions from 2004 to 2016 for the SUS and each of the institutions within the system. 
Table 3. SUS Graduation Rate of Change

\begin{tabular}{lrrrrrrrrrrrr}
\hline & 2005 & 2006 & 2007 & 2008 & 2009 & 2010 & 2011 & 2012 & 2013 & 2014 & 2015 & 2016 \\
\hline SUS & $2 \%$ & $-1 \%$ & $3 \%$ & $3 \%$ & $0 \%$ & $0 \%$ & $0 \%$ & $2 \%$ & $3 \%$ & $4 \%$ & $1 \%$ & $-1 \%$ \\
FAMU & $-2 \%$ & $-7 \%$ & $-7 \%$ & $5 \%$ & $-5 \%$ & $5 \%$ & $-2 \%$ & $0 \%$ & $3 \%$ & $-2 \%$ & $-3 \%$ & $5 \%$ \\
FAU & $0 \%$ & $0 \%$ & $3 \%$ & $3 \%$ & $-3 \%$ & $11 \%$ & $2 \%$ & $-5 \%$ & $0 \%$ & $12 \%$ & $7 \%$ & $2 \%$ \\
FGU & $3 \%$ & $-8 \%$ & $0 \%$ & $17 \%$ & $10 \%$ & $4 \%$ & $-4 \%$ & $0 \%$ & $-2 \%$ & $11 \%$ & $-12 \%$ & $7 \%$ \\
FIU & $2 \%$ & $0 \%$ & $2 \%$ & $0 \%$ & $-6 \%$ & $0 \%$ & $-7 \%$ & $14 \%$ & $6 \%$ & $4 \%$ & $7 \%$ & $-3 \%$ \\
FSU & $2 \%$ & $3 \%$ & $1 \%$ & $1 \%$ & $1 \%$ & $4 \%$ & $0 \%$ & $1 \%$ & $3 \%$ & $3 \%$ & $0 \%$ & $1 \%$ \\
NCF & & & & $13 \%$ & $-5 \%$ & $13 \%$ & $0 \%$ & $1 \%$ & $-4 \%$ & $5 \%$ & $3 \%$ & $-11 \%$ \\
UWF & $2 \%$ & $0 \%$ & $14 \%$ & $-8 \%$ & $2 \%$ & $4 \%$ & $2 \%$ & $-6 \%$ & $-7 \%$ & $21 \%$ & $-8 \%$ & $4 \%$ \\
UCF & $4 \%$ & $2 \%$ & $2 \%$ & $7 \%$ & $0 \%$ & $2 \%$ & $-2 \%$ & $3 \%$ & $3 \%$ & $4 \%$ & $0 \%$ & $-1 \%$ \\
UF & $1 \%$ & $0 \%$ & $3 \%$ & $1 \%$ & $0 \%$ & $2 \%$ & $0 \%$ & $1 \%$ & $2 \%$ & $1 \%$ & $-1 \%$ & $0 \%$ \\
UNF & $2 \%$ & $-6 \%$ & $0 \%$ & $-2 \%$ & $9 \%$ & $-4 \%$ & $6 \%$ & $-4 \%$ & $4 \%$ & $10 \%$ & $0 \%$ & $-2 \%$ \\
USF & $2 \%$ & $2 \%$ & $0 \%$ & $-2 \%$ & $0 \%$ & $6 \%$ & $2 \%$ & $10 \%$ & $11 \%$ & $6 \%$ & $1 \%$ & $-1 \%$ \\
\hline
\end{tabular}

The stack graphic below clearly demonstrates the increase in 2014, with a total increase of 4\% systemwide; 2014 is the year with the highest increase for graduation rates in the SUS. This increase agrees with Dougherty and Hong (2006), Phillips (2002), and Bell's (2005) findings; there is a positive effect of PBF on graduation rates. They also ask for caution when claiming the increase in graduation rates is due to the implementation of PBF. The data for this variable suggests there may be an effect for the first year after implementation of PBF. Future research should explore if such increase was related to the adoption of PBF. 


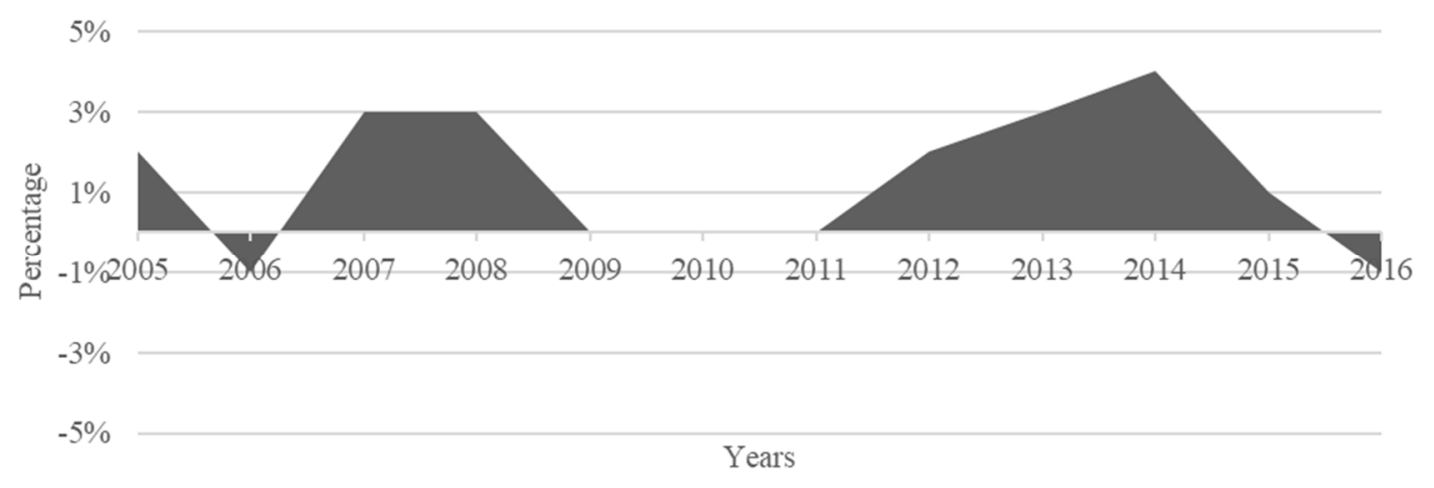

Figure 5. SUS Graduation Rate of Change Stack Graphic

The University of West Florida had the highest rate of change, 21\%, in 2014. The lowest rate of change for 2014 was negative two percent for Florida Agricultural and Mechanical University.

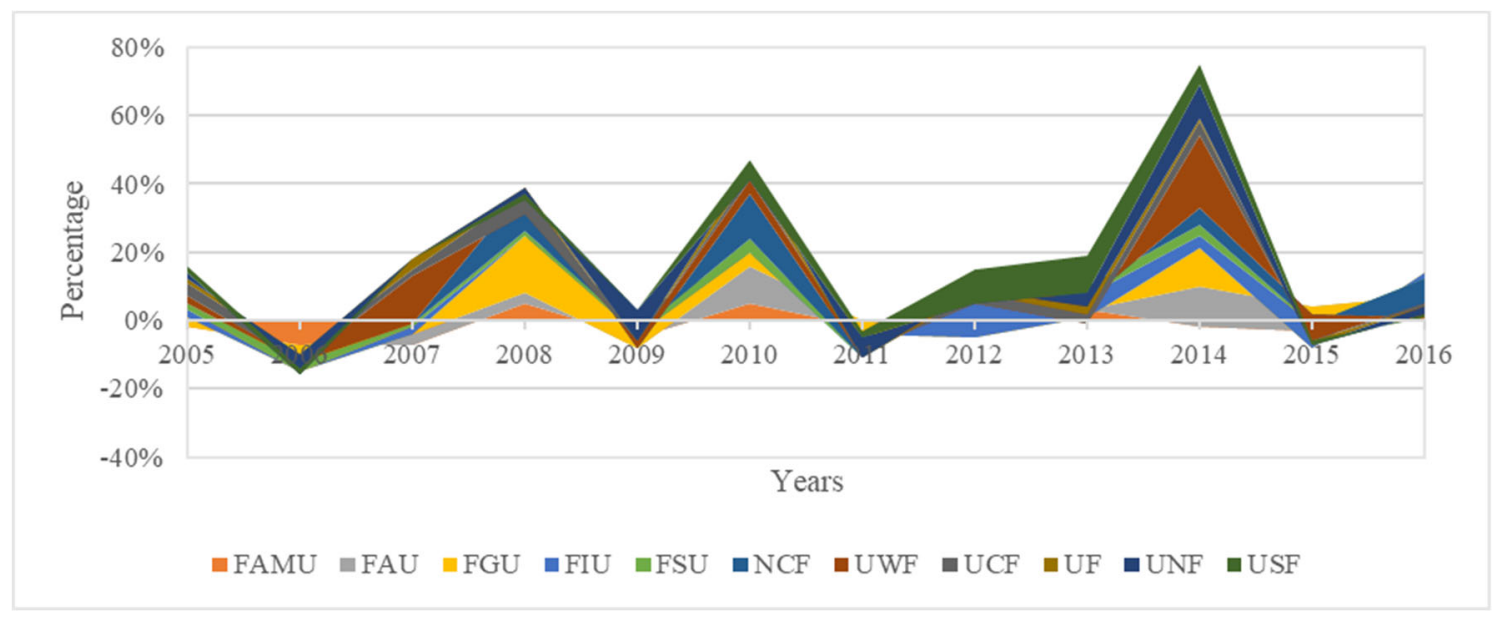

Figure 6. SUS Institutions Graduation Rate of Change Stack Graphic.

Although in 2014 there is an increase in the rate of change, for 2015 and 2016 this increase did not recur. Two thousand sixteen was the year with the highest decrease; six of the 11 institutions decreased graduation rates. 


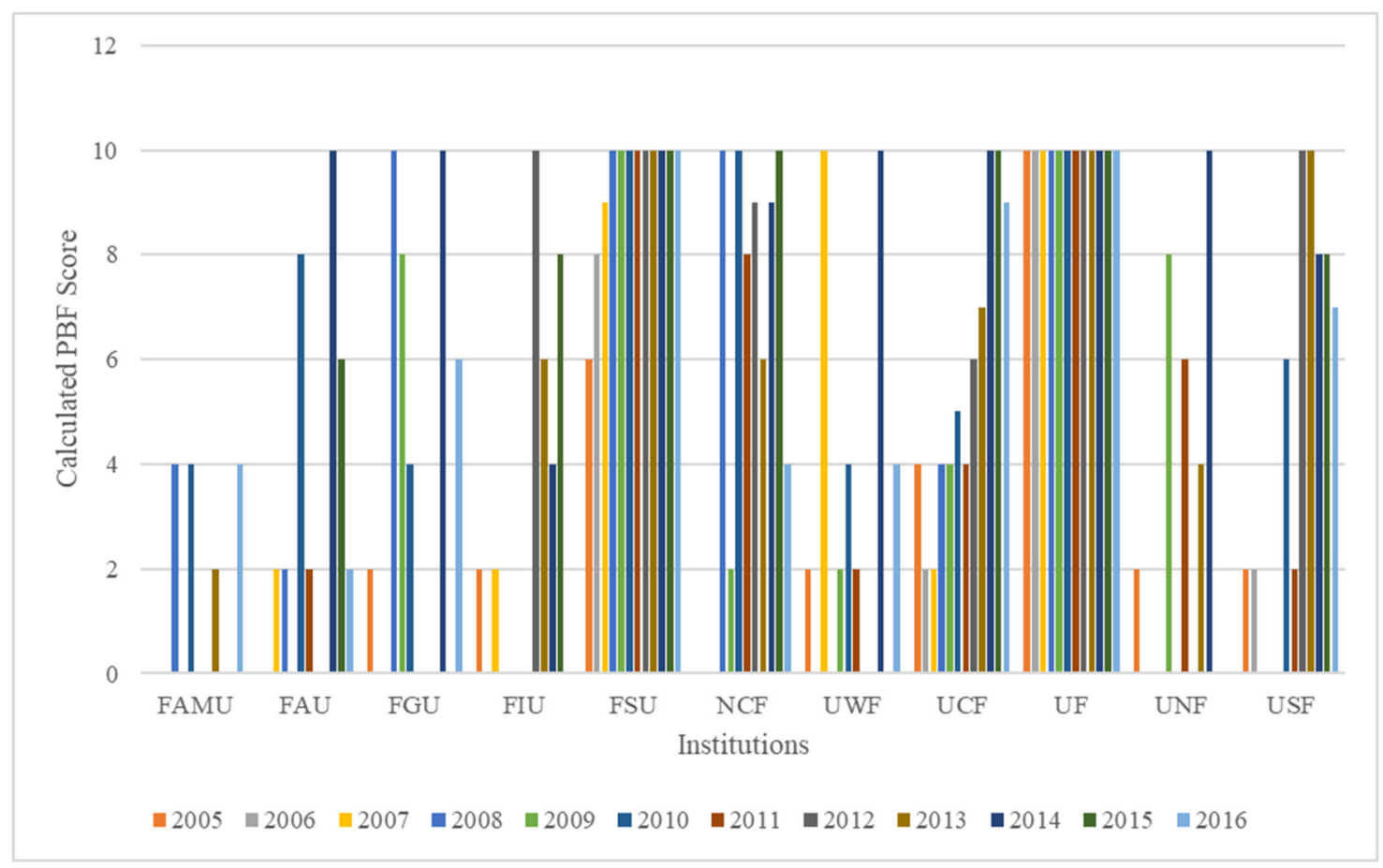

Figure 7: SUS Calculated PBF Score for the Six-Year Graduation Based on IPEDS 20052016 Data

Figure 7 shows the calculated PBF scores for the six-year graduation rate from IPEDS. Six-year graduation rates are one of the few variables in IPEDS that are also a metric in the PBF program, whereas other variables in this study, taken from IPEDs, can help us explore student outcomes but they are not one of the metrics in the PBF program for the SUS. Exploring the graduation rates offers the opportunity to apply the SUS PBF program methodology to the variable to explore how the institutions could have scored under the PBF programs. The BOG excellence and improvement benchmark (see www.fbog.com) were used to assign a PBF score. The excellence score was assigned by comparing the IPEDS six-year graduation rate with the benchmarks apportioned by the BOG for the PBF program. The improvements points were calculated by subtracting the scores and multiplying the difference by 2 . This is the same process used by the BOG to calculate improvements point. The result for such calculation is in figure seven. The 
figure shows FSU and UF performing on top of all the other institutions for the 12 years.

All other institutions have at least one year where they did not score any points except for UCF that managed to score points in all of the years. FAMU and FAU are the two institutions performing in the lower end when compared to the other institutions in the system. Lastly, it is important to note that 2014 is the year where at least eight of the institutions had a higher PBF calculated score for this metric. Since graduation rates may take longer to increase as explained by Shin (2010), who found graduation rates increase by a lower rate than other variables after implementation of PBF, future studies should explore the reasons for the 2014 increase.

\section{Student Success Outcome: Job Placement}

The SUS PBF program contains an employment or continuing education variable. Data for this variable is published by the BOG annually as part of their final metric score sheet for the PBF program. A final metric score sheet is available for each of the five years the PBF program was in place in Florida for the SUS. These are available at the BOG website under the Performance-Based Funding Model page (https://www.flbog.edu/board/office/budget/ performance_funding .php). For this particular variable, the BOG gathers information from three sources, the SUS internal data set for military and post-enrollment data, the national student clearinghouse for postenrollment data, and the Florida education and training placement information program for employment data. The PBF program assigns each institution in the SUS improvement or excellence points. For improvement points, if the institutions increased its current year performance by one percent, it would score one point of improvement, up to a maximum of 10 points. The BOG subtracts the previous year's percentage form the current year 
percentage to calculate the improvement points. Excellence benchmarks for this variable are as follows:

\begin{tabular}{l|rrrrrrrrrr} 
& & & & & & & & & & \\
Point & 10 & 9 & 8 & 7 & 6 & 5 & 4 & 3 & 2 & 1 \\
\hline Benchmark & 72.8 & 70.5 & 68.3 & 66 & 63.7 & 61.4 & 59.2 & 56.9 & 54.6 & 52.3
\end{tabular}

For each two percent improvement in the employment or continuing education variable, the institution gets one excellence point. The total employment or continuing education for the years PBF has been in place in Florida is in figure 8. The minimum rate for the five years was $65 \%$, and the maximum rate was $72 \%$. It is important to consider that this variable only represents between $80 \%$ and $90 \%$ of the SUS graduates, as indicated in the BOG methodology (https://www.flbog.edu/board/ office/ budget /_doc/performance_funding/PBF_FAQs.pdf).

Figure 8 shows an increase in 2015 . The increase in 2015 coincided with a change in methodology. The 2015 revision added to the data from "the Department of Economic Opportunity and Florida Education and Training Placement Information Program (FETPIP) to include military/federal government graduates and graduates employed outside Florida." (Board of Governors Performance-Based Funding Model Changes Approved on November 6, 2014, https://www.flbog.edu/board/office/ budget/_doc/performance_funding/Changes_2015-16.pdf). This change increased the pool for the variable; this could be the reason for the $6 \%$ increase in the employment or continuing education variable in 2015. In 2017, the BOG implemented a second methodology change for this metric. They approved an increase in the wage threshold from minimum wage to $\$ 25,000$ to include a bachelor's degree recipient in the data set 
(https://www.flbog.edu/board/office/budget/_doc/performance_funding/Changes_201718.pdf). This change could be the reason for the six percent decrease in the Employment or continuing education rate. Further research should explore more deeply the changes in 2015 and 2017.

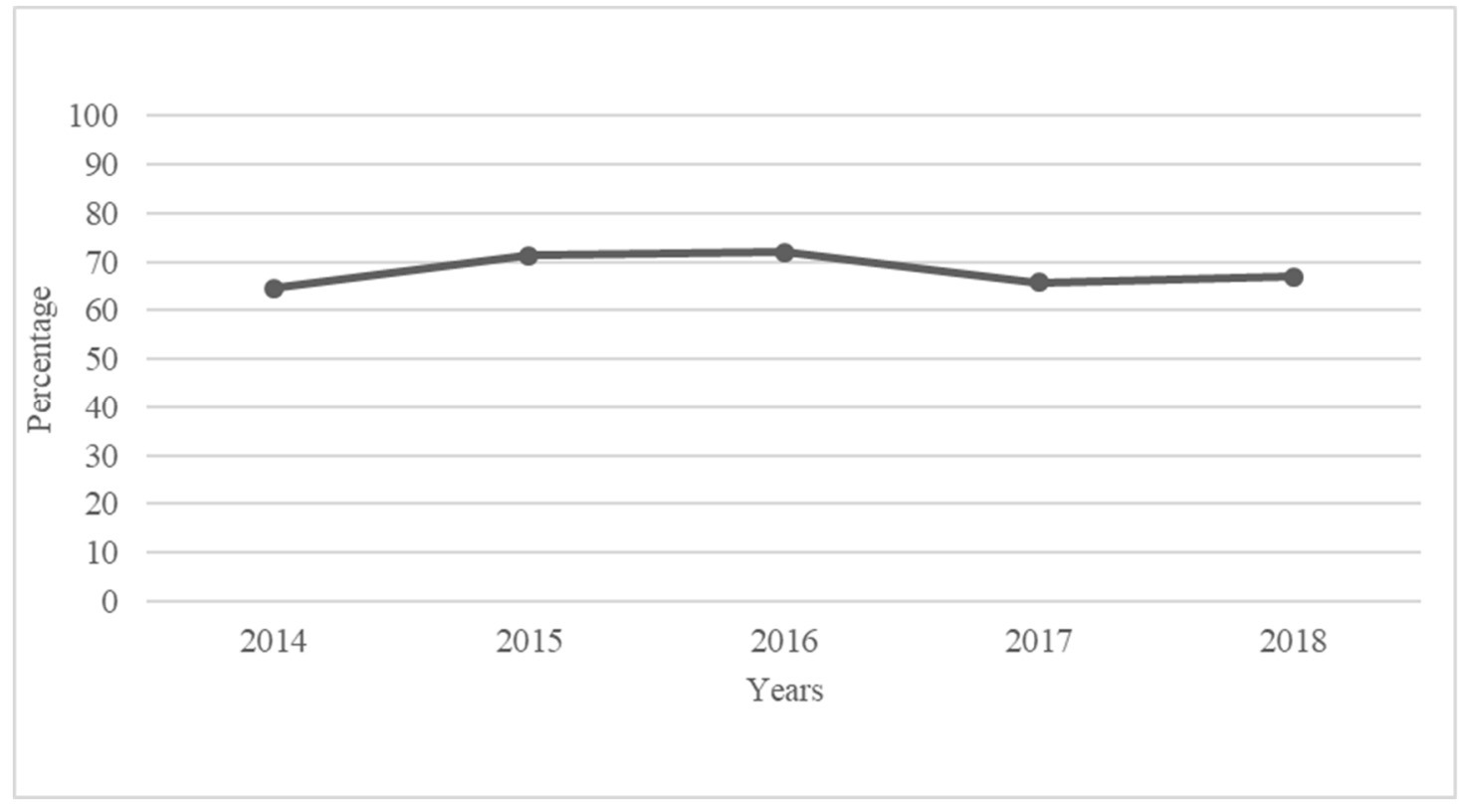

Figure 8. SUS Total Employment or Continuing Education Rates

Figure 9 shows employment or continuing education rates for each of the institutions in the SUS between 2014 and 2018. The trends for 10 of the institutions are very similar; most of them performing between $60 \%$ and $75 \%$. The years with the highest employment rates are 2015 and 2016. There is one institution that separates itself from the rest in the employment or continuing education trend, New College of Florida. This institution employment rate is almost $10 \%$ points lower than the rest of the institutions in the system for 2014 through 2018. 


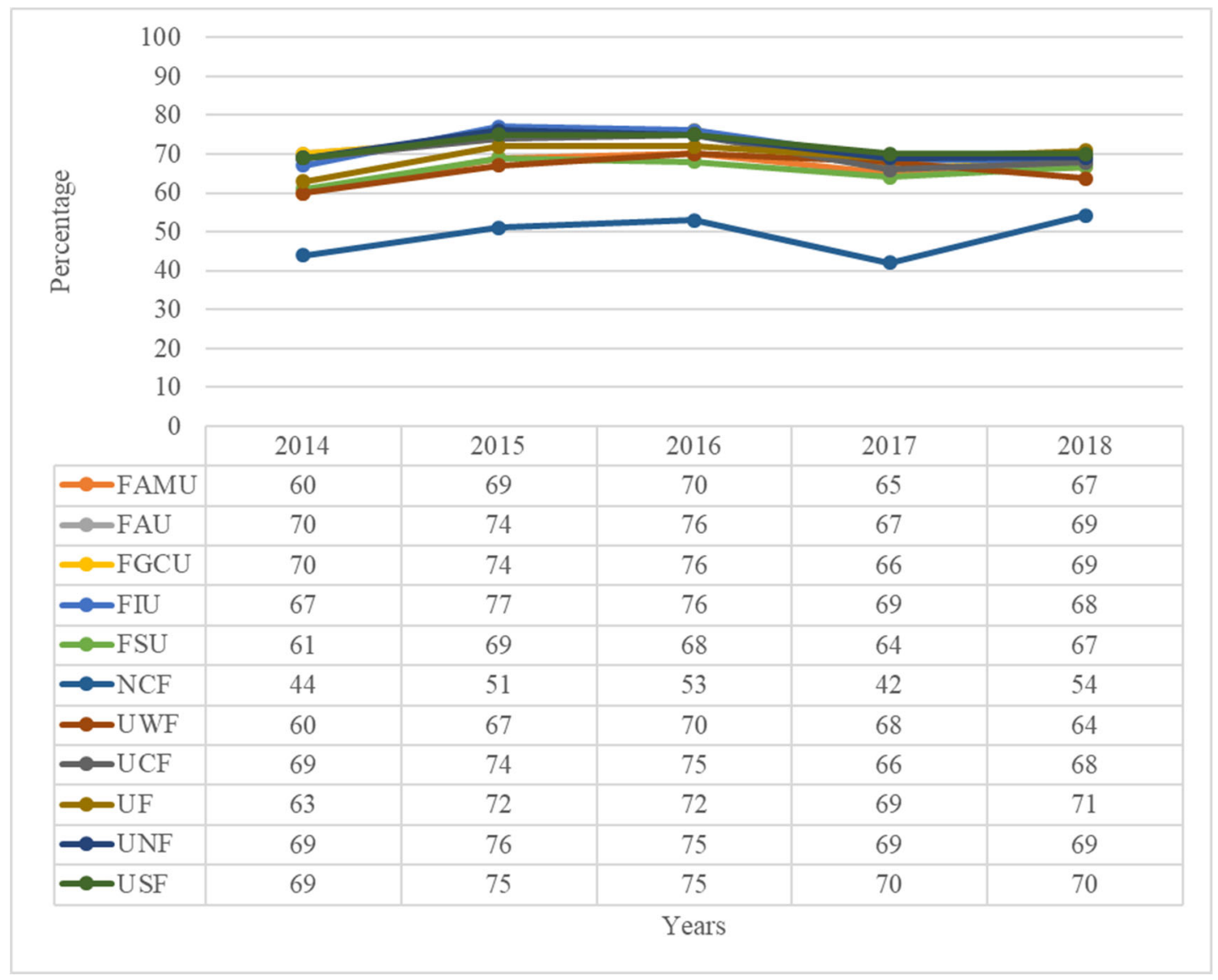

Figure 9. SUS Employment or Continuing Education Rates

Figure10 shows the rate of change of the Employment or continuing education rates from 2014 to 2018 . The year with the highest rate of change was 2015 . The trend line in figure 10 shows the change from 2014 to 2015 was the highest one for all institutions in the SUS. The rate of change was between 7 and 15 percent. In the rate of change by year, New College of Florida had the lowest trend, and also a very different rate of change for 2017 and 2018. In 2017, this institution decreased its employment or continuing education rate by $21 \%$ to improve by $29 \%$ in 2018 .

Further research should explore the particular patterns for employment or continuing education rates in the New College of Florida. Perhaps the institution 
experimented with new strategies to influence this metric during these years.

Nonetheless, future researchers should explore the reasons for such changes.

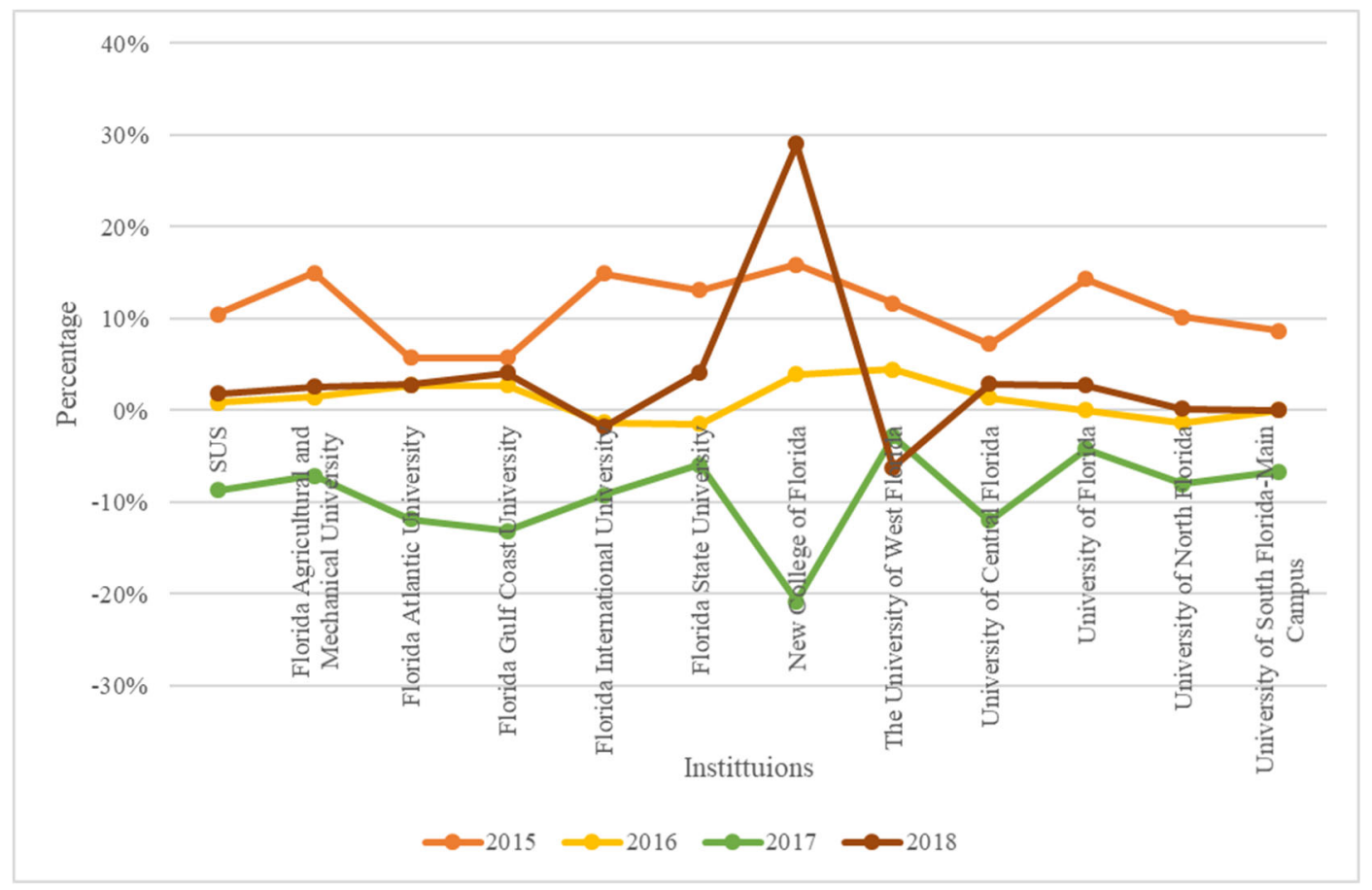

Figure 10. Rate of Change Employment or Continuing Education SUS

\section{Student Success Outcome: Retention}

IPEDS retention rates represent the percentage of first-time, full-time undergraduate students who returned to the same institution the following fall after admissions. Hillman, Tandberg, and Fryar (2015) suggest that even when PBF may have little to no effect on degree completion, it is possible that it has a positive effect on intermediate outcomes such as student retention. In this section, this researcher explores the retention rate trends before and after the implementation of PBF in the SUS.

Figure 11 shows descriptive statistics for the SUS retention rate from 2004 to 2016. The most frequent retention rate for the SUS was $82 \%$. The average retention rate 
for SUS was $82.81 \%(\mathrm{M}=82.81 ; \mathrm{SD}=6.72)$. The histogram shows a higher frequency of retention rates in the middle of the distribution, between $79.0 \%$ and $83.5 \%$ for the SUS.

\begin{tabular}{lr}
\hline \multicolumn{2}{c}{ Full-time Retention Rate } \\
\hline Mean & 82.81 \\
Standard Error & 0.56 \\
Median & 82 \\
Mode & 82 \\
Standard Deviation & 6.72 \\
Range & 27 \\
Minimum & 70 \\
Maximum & 97 \\
\hline
\end{tabular}

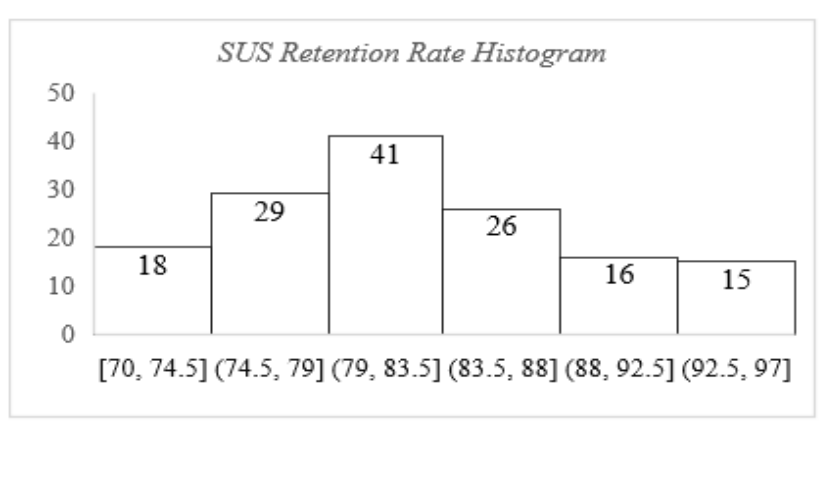

Figure 11: Descriptive Statistics for the SUS Retention Rates from 2004 to 2016

Figure 12 below shows the retention rate trend for the SUS. The retention rate fluctuates between one and two percentage points from 2004 up to 2013 when the state implemented PBF. After 2013, the retention rate gradually increases up to its highest point of $85 \%$ in 2016 . The reasons for such change in the pattern could be many, from new initiatives implemented to increase retention, up to a more stable data reporting methodology. Future research could explain the reasons for this pattern change.

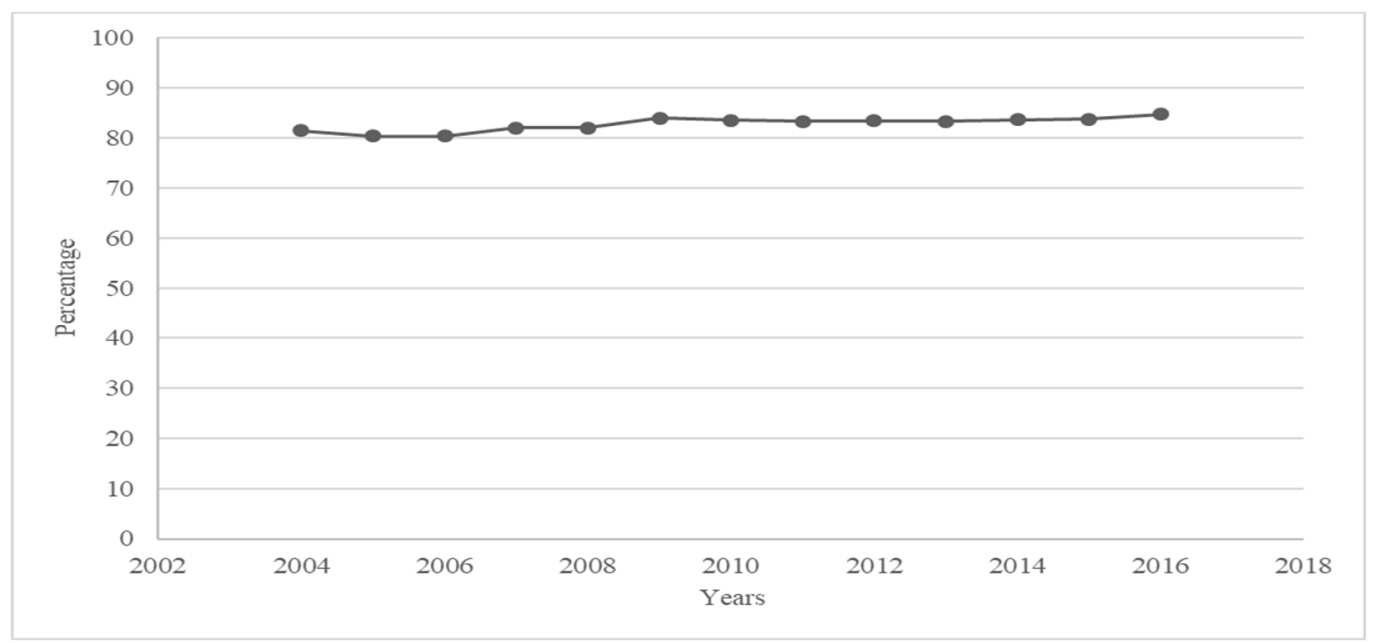

Figure 12. SUS Retention Rate Trend 
Figure 13 below shows retention rate trends for each of the institutions in the SUS from 2004 to 2016 . The 11 institutions in the SUS seem to have similar patterns in retention rate trends from 2004 to 2016 . The rate of change of the retention rate variable generally fluctuated between negative one percent and positive one percent for the 12 years.

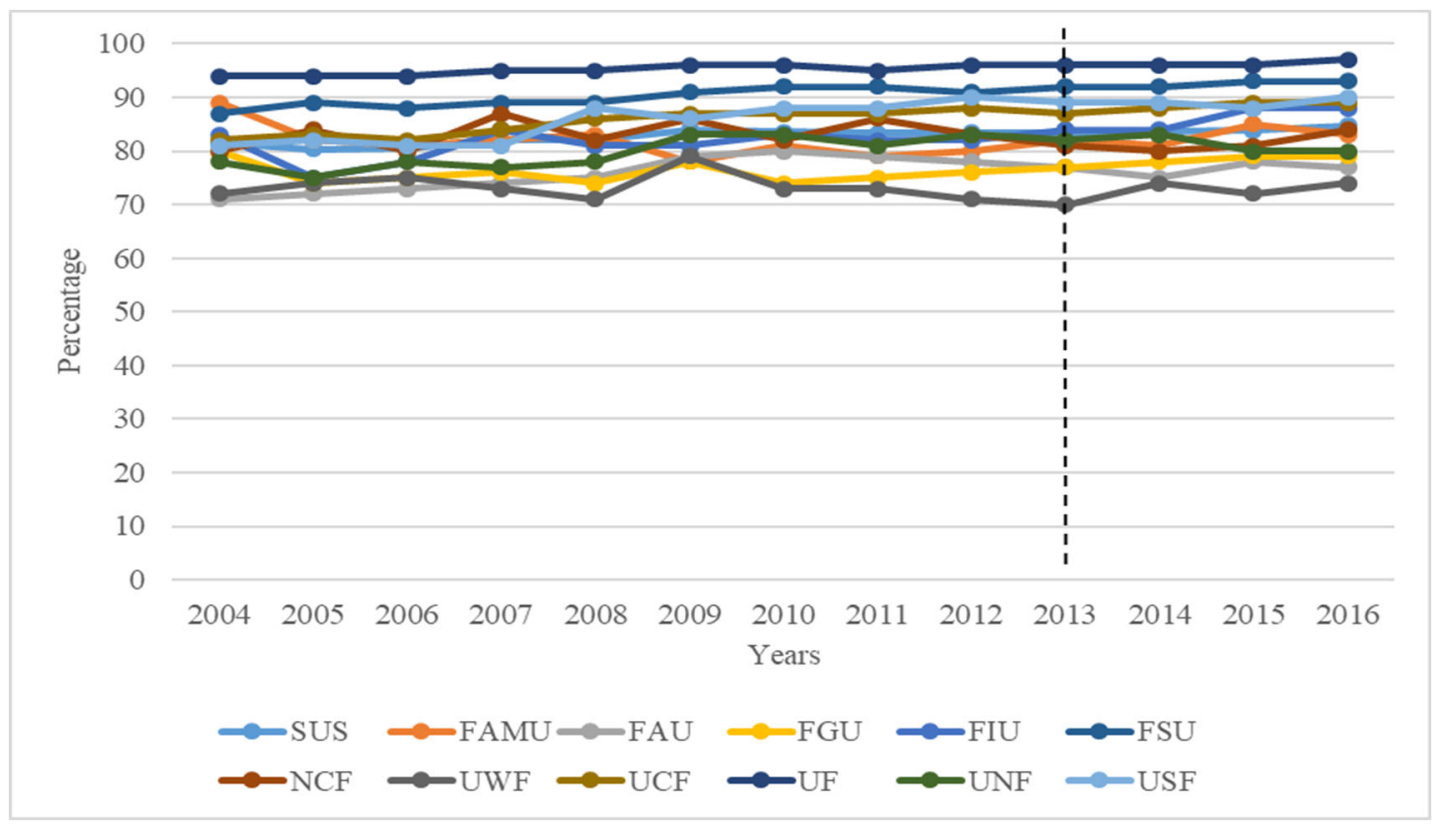

Figure 13: SUS Retention Rates Trends

Table 4 shows with more clarity how the relative institutional position within the SUS was for the 12 years. It is clear from figure 13 that UF retention rate trend positioned this institution above the other 11 institutions with rates ranging in the 90s. The arrows in table 5 show the values for retention rate clustered in three groups. The first icon $(\uparrow)$ represents the top one-third of the values, the second icon $(\rightarrow)$ represents the second third of the values, and the third icon $(\downarrow)$ represents the lowest one-third of the values. UF kept its positioning in the top third for the 12 years. FSU joined UF in the top third in 2005 and USF in 2012. UCF, NCF, FIU, and FAMU kept in the second third for most of the 
years, while UNF, FGU, FAU, and UWF shared the lowest third position. After the implementation of PBF in 2013, the top one-third group increased, and in 2016 four institutions had joined this position.

Table 4. SUS Retention Rates

\begin{tabular}{|c|c|c|c|c|c|c|c|c|c|c|c|c|c|c|}
\hline \multicolumn{15}{|l|}{ SUS } \\
\hline Institutions & 2004 & 2005 & 2006 & 2007 & 2008 & 2009 & 2010 & 2011 & 2012 & 2013 & 2014 & 2015 & 2016 & Total \\
\hline UF & 1. 94 & A 94 & A. 94 & 1 95 & 95 & A 96 & ค 96 & 95 & 1. 96 & 96 & A 96 & ค 96 & ค 97 & ㄱ 95 \\
\hline FSU & $\Rightarrow 87$ & 89 & 588 & 89 & 89 & ค 91 & 92 & 92 & 91 & 92 & 92 & 93 & 93 & 91 \\
\hline USF & $\Rightarrow 81$ & 382 & $\Rightarrow 81$ & $\Rightarrow 81$ & 388 & 586 & $\Rightarrow 88$ & 388 & A 90 & 89 & 89 & 388 & 90 & 586 \\
\hline UCF & $\Rightarrow 82$ & 583 & 582 & $\Rightarrow 84$ & 386 & $\Rightarrow 87$ & $\Rightarrow 87$ & 587 & $\$ 88$ & $\Rightarrow 87$ & 588 & ค 89 & ต 89 & $\Rightarrow 86$ \\
\hline SUS & $\Rightarrow 82$ & $\Rightarrow 80$ & $\Rightarrow 80$ & $\Rightarrow 82$ & $\$ 82$ & $\Rightarrow 84$ & $\Rightarrow 84$ & $\Rightarrow 83$ & $\Rightarrow 83$ & $\Rightarrow 83$ & $\Rightarrow 84$ & $\Rightarrow 84$ & $\Rightarrow 85$ & $\Rightarrow 83$ \\
\hline NCF & $\Rightarrow 80$ & 584 & $\Rightarrow 80$ & $\Rightarrow 87$ & 382 & $\Rightarrow 86$ & 382 & $\Rightarrow 86$ & $\Rightarrow 83$ & $\Rightarrow 81$ & $\Rightarrow 80$ & $\Rightarrow 81$ & $\Rightarrow 84$ & 583 \\
\hline FIU & $\Rightarrow 83$ & 75 & 78 & 384 & 381 & 381 & 383 & 382 & 382 & $\Rightarrow 84$ & 384 & 388 & $\Rightarrow 88$ & 583 \\
\hline FAMU & 1. 89 & 382 & $\Rightarrow 81$ & $\Rightarrow 82$ & $\Rightarrow 83$ & $\sqrt{78}$ & $\Rightarrow 81$ & $\Rightarrow 79$ & $\Rightarrow 80$ & $\Rightarrow 82$ & $\Rightarrow 81$ & $\Rightarrow 85$ & $\Rightarrow 83$ & $\Rightarrow 82$ \\
\hline UNF & $\sqrt{78}$ & $\sqrt{75}$ & $\sqrt{78}$ & 77 & $\sqrt{78}$ & $\Rightarrow 83$ & $\Rightarrow 83$ & $\Rightarrow 81$ & $\Rightarrow 83$ & $\Rightarrow 82$ & $\Rightarrow 83$ & $\Rightarrow 80$ & $\Rightarrow 80$ & $\Rightarrow 80$ \\
\hline FGU & $\Rightarrow 80$ & $\sqrt{74}$ & 75 & $\sqrt{76}$ & $\sqrt{74}$ & 78 & $\sqrt{74}$ & $\sqrt{75}$ & $\sqrt{76}$ & $\sqrt{77}$ & $\sqrt{ } 78$ & $\Rightarrow 79$ & $\Rightarrow 79$ & 》77 \\
\hline FAU & औ 71 & 72 & N3 & 74 & 75 & $\Rightarrow 79$ & $\Rightarrow 80$ & $\Rightarrow 79$ & 78 & 77 & y 75 & 78 & 77 & 76 \\
\hline UWF & 72 & 74 & 75 & 73 & 71 & $\Rightarrow 79$ & $\sqrt{73}$ & 73 & 71 & 70 & 74 & 72 & 74 & 73 \\
\hline
\end{tabular}

\section{Administrative Outcomes: Student to Faculty Ratio}

As Borden (2011) explained, one piece of information required by the Higher

Education Opportunity Act (HEOA) is the student to faculty ratio. "The National Center for Education Statistics (NCES) added the collection of this measure to the Integrated Postsecondary Education Data System (IPEDS) in the Fall Enrollment component for the 2008-09 data collection year" (Borden, 2011, p.1). The official definition for this measure is the ratio of FTE students to FTE instructional staff, as provided by IPEDS 2018-2019 Glossary. As previously mentioned, there were some concerns among the Florida Senate in the last revision of the Florida Excellence in Higher Education Act (2018). Although the Senate did not include the student to faculty ratio in the final verbiage of the Florida Excellence in Higher Education Act of 2018, it was a topic of discussion. Senator Bill Galvano requested an evaluation of a five-year trend on the ratio of student enrollment to faculty (FIU Government relation, personal communication, January 22, 2018). Even 
when the Senate did not include the measure as part of the PBF programs in Florida, the question remains, is the student to faculty ratio increasing or decreasing since the implementation of PBF. In this section, this researcher explores student to faculty ratio trends for SUS system.

Since IPEDS started calculating student to faculty ratios, it has fluctuated between 32 and 10 for the 11 institutions in the SUS participating in the PBF program. This measure has an average of $21.98(\mathrm{M}=21.98, \mathrm{SE} 0.53)$. The histogram below indicates a higher frequency of score between 18 and 22.

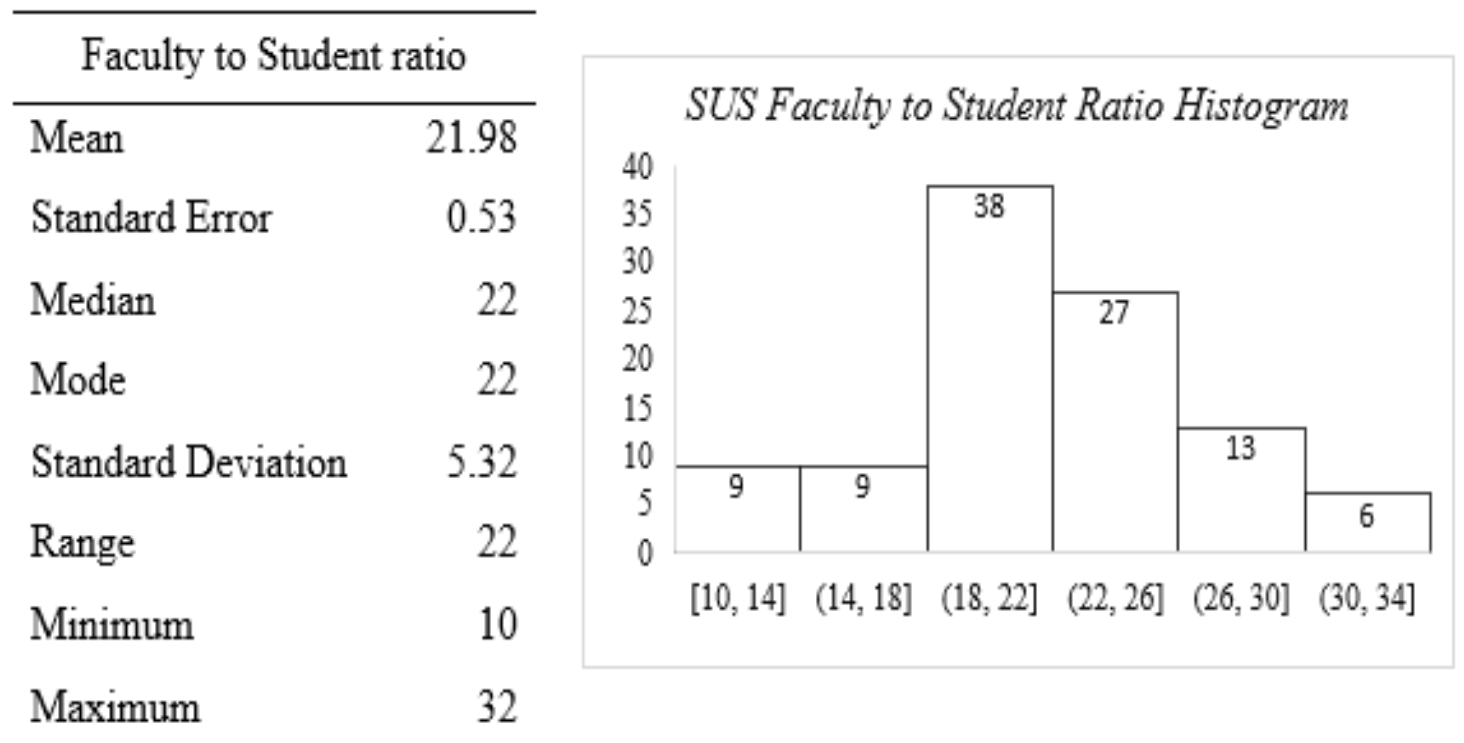

Figure 14: Descriptive Statistic for the SUS Student to Faculty Ratio from 2008 to 2016

Figure 15 contains the trends for the student to faculty ratios. It started around 21.50 in 2008 and fluctuated throughout the years, with the highest ratio in the high 22. In 2013, the year of PBF implementation for the SUS, the student to faculty ratio for the SUS was 22.36. After the implementation of PBF, the rate steadily declined for the SUS with the lowest score of 21.17 in 2016. 


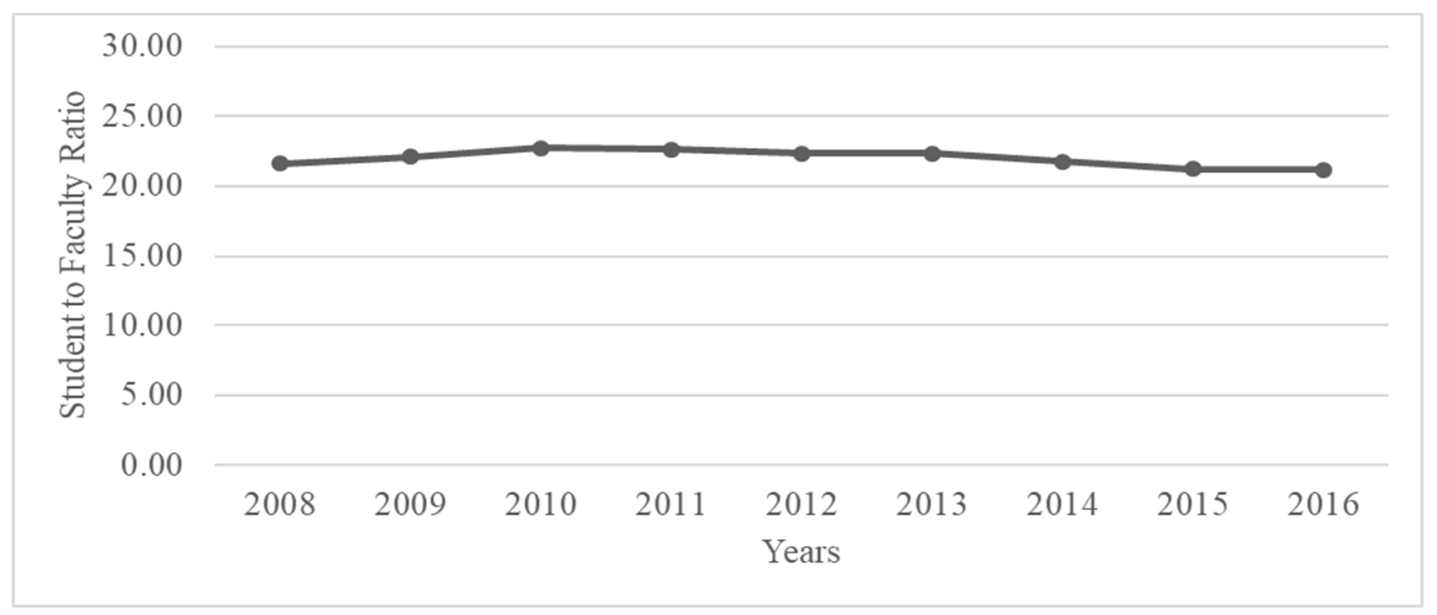

Figure 15. SUS Student to Faculty Ratio.

Figure 16 allowed us to take a closer look at how the student to faculty ratio fluctuates for each institution within the SUS. Two institutions separate themselves from the rest. UCF performed in the higher end with scores in the 30 s, almost $5 \%$ higher than the rest of the group. On the other hand, NCF had the lowest student to faculty ratio throughout the eight years, $5 \%$ lower than the rest of the institutions in the SUS. Lastly, there is a reduction in the spacing among institutions performing in the middle of the distribution, between 25 and 15, since the implementation of PBF in 2013.

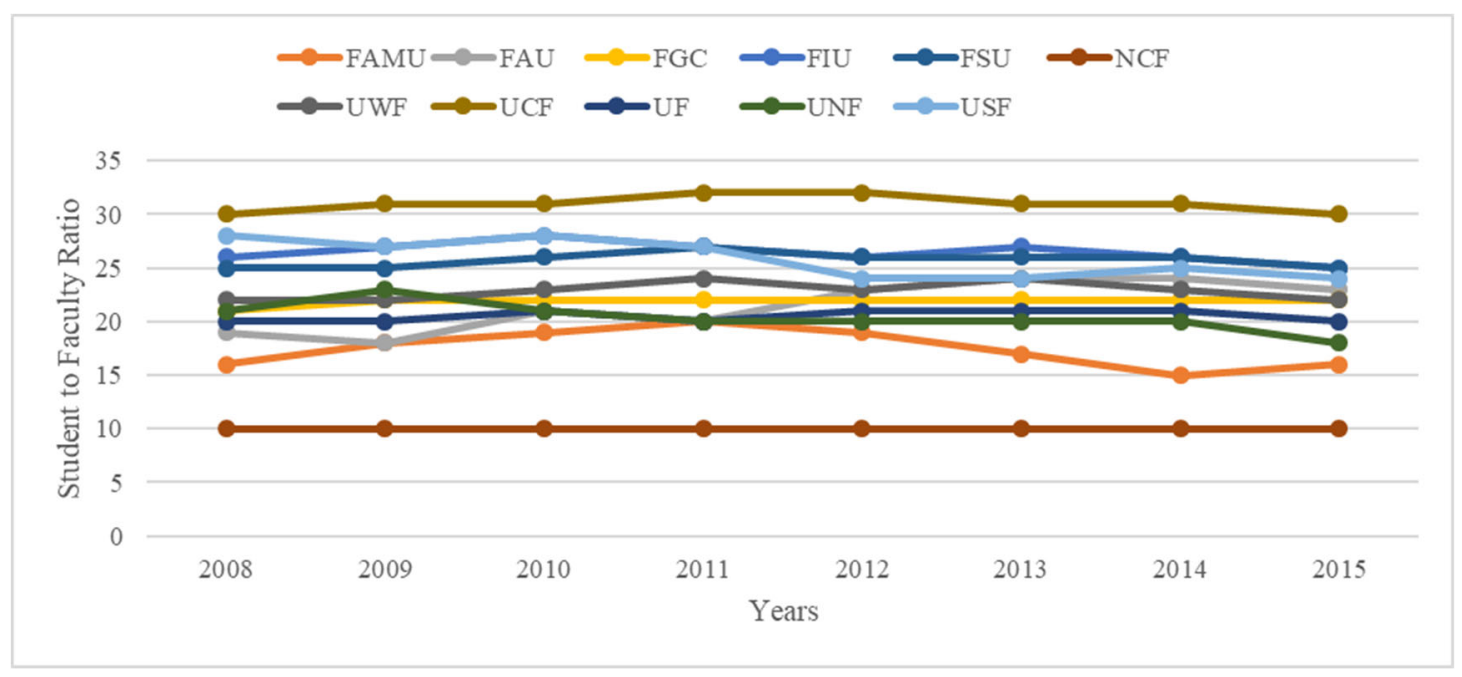

Figure 16. SUS Institutions' Student to Faculty Ratio 
Table 5 shows two institutions with a rate of change close to zero, FGC and NCF. Both institutions have the same student to faculty ratio since 2010. UWF was the only institution decreasing their student to faculty ratio for two consecutive years after the implementation of PBF in 2013. Only three institutions decreased their ratios in 2014, one year after implementation. Two years after implementation 8 of the 12 , institutions decreased their student to faculty ratio.

Table 5. SUS Student to Faculty Ratio Rate of Change

\begin{tabular}{l|lllllllll}
\hline Institutions & 2009 & 2010 & 2011 & 2012 & 2013 & 2014 & 2015 & 2016 & \\
\hline FAMU & 0.13 & 0.06 & 0.05 & -0.05 & -0.11 & -0.12 & 0.07 & -0.06 & $\sim$ \\
FAU & -0.05 & 0.17 & -0.05 & 0.15 & 0.04 & 0.00 & -0.04 & 0.04 & $\sim$ \\
FGC & 0.05 & 0.00 & 0.00 & 0.00 & 0.00 & 0.00 & 0.00 & 0.00 & $\wedge$ \\
FIU & 0.04 & 0.04 & -0.04 & -0.04 & 0.04 & -0.04 & -0.04 & 0.08 & $\sim$ \\
FSU & 0.00 & 0.04 & 0.04 & -0.04 & 0.00 & 0.00 & -0.04 & -0.04 & $\sim$ \\
NCF & 0.00 & 0.00 & 0.00 & 0.00 & 0.00 & 0.00 & 0.00 & 0.00 & $\sim$ \\
UWF & 0.00 & 0.05 & 0.04 & -0.04 & 0.04 & -0.04 & -0.04 & 0.00 & $\sim$ \\
UCF & 0.03 & 0.00 & 0.03 & 0.00 & -0.03 & 0.00 & -0.03 & 0.00 & $\sim$ \\
UF & 0.00 & 0.05 & -0.05 & 0.05 & 0.00 & 0.00 & -0.05 & 0.00 & $\sim$ \\
UNF & 0.10 & -0.09 & -0.05 & 0.00 & 0.00 & 0.00 & -0.10 & 0.06 & $\sim$ \\
USF & -0.04 & 0.04 & -0.04 & -0.11 & 0.00 & 0.04 & -0.04 & -0.08 & $\sim$ \\
\hline
\end{tabular}

The rates of change and the percentage trends for the SUS student to faculty ratio show they have been decreasing as times goes by. This tendency seems to remain unaffected by the implementation of PBF in Florida for the SUS. The data did not support concerns about sudden increases in students' course sections in the SUS institutions.

\section{Administrative Outcomes: Institutional Expenditures}

IPEDS collects higher education financial information through the Finance Survey. As explained by IPEDS, this annual survey describes the financial condition of postsecondary education in the nation. To explore Florida's higher education financial 
condition and its relation to $\mathrm{PBF}$, this researcher looked at the seven types of institutional expenditures collected in the IPEDS financial survey from 2004 to 2016.

The SUS adopted the PBF in 2013. Figure 17 shows an average for each of the seven institutional expenditures from 2004 to 2016 in the SUS Instruction expenses, research expenses, public service expenses, academic support, institutional support, other core expenses, and student services expenses. IPEDS calculates all the expenses based on FTE (Full-time Equivalent). Six of the expenses trends ranged between $\$ 1,000$ and $\$ 3,500$ per FTE. The average instruction expense is the only one with a range of $\$ 6,000$ \$9,000 per FTE for 2004 to 2016 .

After implementation of BPF in 2013, all the expenses increased for 2014 and 2015 except for "All other core expenses per FTE" which decreased nine percent in 2013 and eight percent in 2014. The most noteworthy increase after the implementation of PBF in 2015 was institutional support expenses by FTE; it had a 43\% increase. Based on IPEDS glossary this expense references:

Expenses for the day-to-day operational support of the institution. [It] includes expenses for general administrative services, central executive-level activities concerned with management and long-range planning, legal and fiscal operations, space management, employee personnel and records, logistical services such as purchasing and printing, and public relations and development. Also includes information technology expenses related to institutional support activities (NCES, 2018, p. 3).

Student Services expenses increased by $31 \%$ in 2015 as well as Academic Support Services. Student Services expenses refer to: “expenses for admissions, registrar 
activities, and activities whose primary purpose is to contribute to students' emotional and physical well-being and [ ] their intellectual, cultural, and social development outside the context of the formal instructional program" (NCES, 2018, p. 4). Academic Support Services refers to "expenses of activities and services that support the institution's primary missions of instruction, research, and public service" (NCES, 2018, p. 2). The increase in both types of expenses appears after the implementation of PBF; future research should evaluate the role of PBF in such increases.

In his study, Shin (2010) explained that "performance-based accountability did not contribute to the growth of research funding" (p.63). Shin's finding is consistent with the conclusion in this dissertation. Research expenses only increased by $3 \%$ and $1 \%$ in 2014 and 2015.

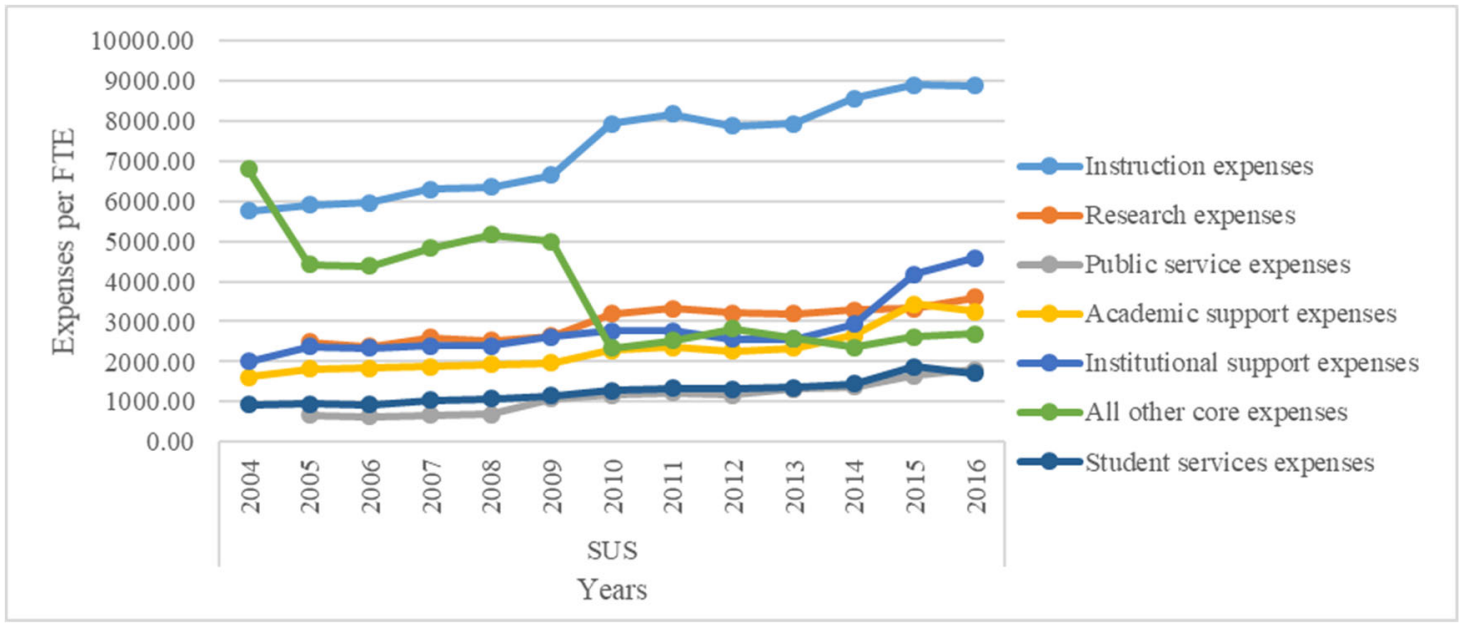

Figure 17: SUS Average Expenses per FTE 2004-2016

Table 6. Change of Percentage SUS Expenses 2005 to 2016

\begin{tabular}{|c|c|c|c|c|c|c|c|c|c|c|c|c|c|}
\hline & 2005 & 2006 & 2007 & 2008 & 2009 & 2010 & 2011 & 2012 & 2013 & 2014 & 2015 & 2016 & $\mathrm{PBF}$ \\
\hline Instruction expenses & $3 \%$ & $1 \%$ & $6 \%$ & $1 \%$ & $5 \%$ & $19 \%$ & $3 \%$ & $-4 \%$ & $1 \%$ & $8 \%$ & $4 \%$ & $0 \%$ & \\
\hline Research expenses & & $-4 \%$ & $9 \%$ & $-2 \%$ & $4 \%$ & $21 \%$ & $4 \%$ & $-3 \%$ & $-1 \%$ & $3 \%$ & $1 \%$ & $9 \%$ & \\
\hline Public service expenses & & $-5 \%$ & $7 \%$ & $2 \%$ & $54 \%$ & $9 \%$ & $5 \%$ & $-5 \%$ & $14 \%$ & $4 \%$ & $19 \%$ & $10 \%$ & \\
\hline Academic support expenses & $13 \%$ & $1 \%$ & $2 \%$ & $2 \%$ & $2 \%$ & $16 \%$ & $3 \%$ & $-4 \%$ & $3 \%$ & $13 \%$ & $30 \%$ & $-5 \%$ & \\
\hline Institutional support expenses & $19 \%$ & $-1 \%$ & $2 \%$ & $0 \%$ & $9 \%$ & $6 \%$ & $0 \%$ & $-7 \%$ & $0 \%$ & $14 \%$ & $43 \%$ & $10^{\circ}$ & \\
\hline All other core expenses & $-35 \%$ & $-1 \%$ & $10 \%$ & $7 \%$ & $-3 \%$ & $-53 \%$ & $8 \%$ & $11 \%$ & $-9 \%$ & $-8 \%$ & $11 \%$ & & \\
\hline Student services expenses & $1 \%$ & $-1 \%$ & $12 \%$ & $3 \%$ & $7 \%$ & $11 \%$ & $4 \%$ & $-1 \%$ & $3 \%$ & $6 \%$ & $31 \%$ & $-10^{\circ}$ & \\
\hline
\end{tabular}


When going into each institution trend for the expenses, they all follow a similar pattern (see figure 18). All the institutions present a higher trend for Instruction expenses. Also, they increased the academic support expense and the institutional support expense after the PBF implementation in 2013. There were three institutions increasing research expense after the implementation of PBF, FSU, UF, and USF. NCF presented the highest trend for student services expenses when compared with the other institutions in the SUS.

Figure 18 shows the SUS institutions and their expense trends from 2004 to 2016.
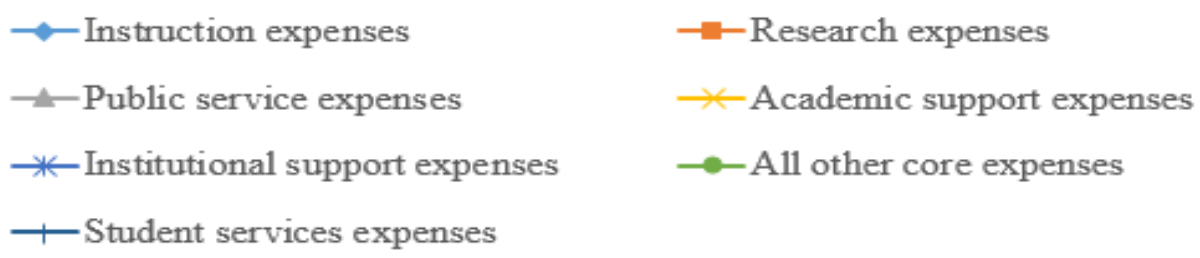

- Student services expenses

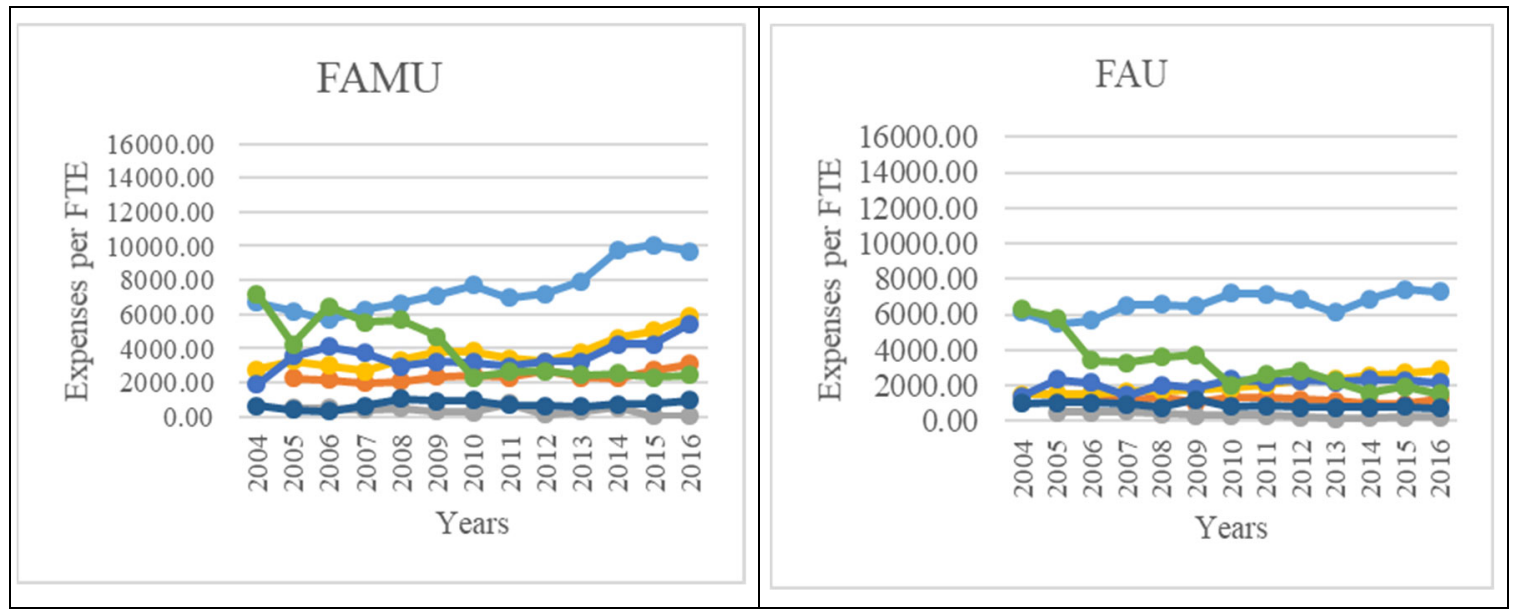




\begin{tabular}{|c|c|c|c|}
\hline 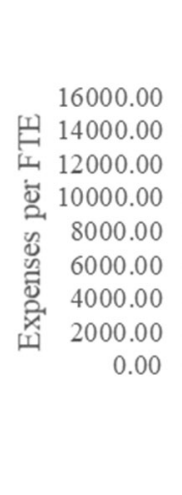 & 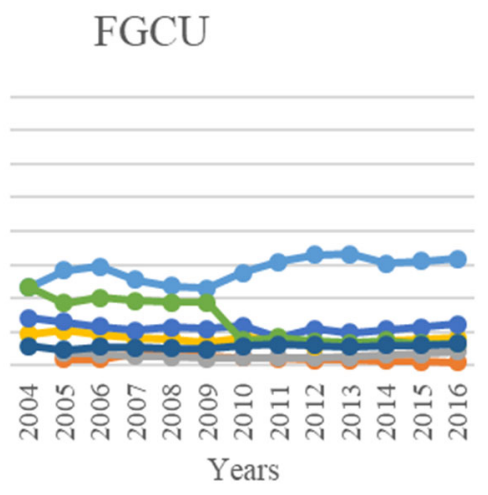 & 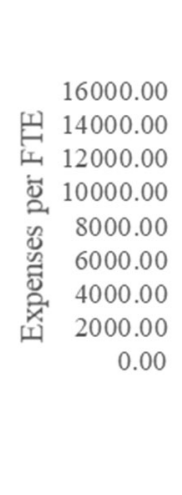 & Years \\
\hline 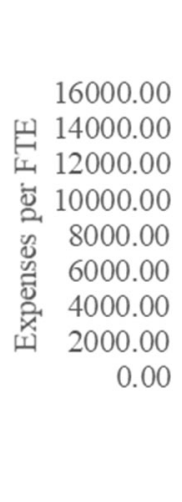 & 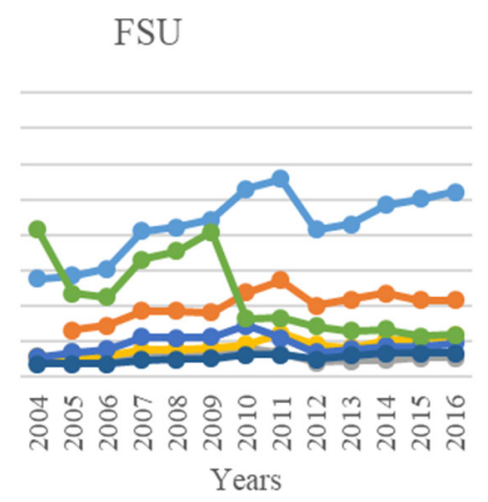 & 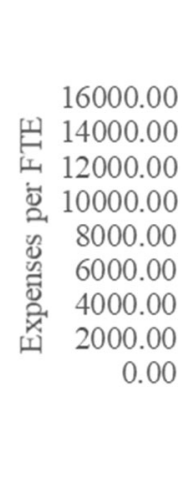 & Years \\
\hline 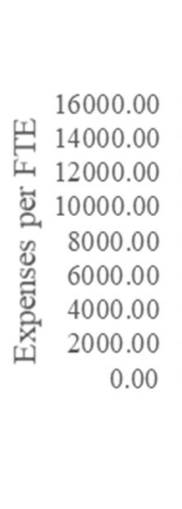 & 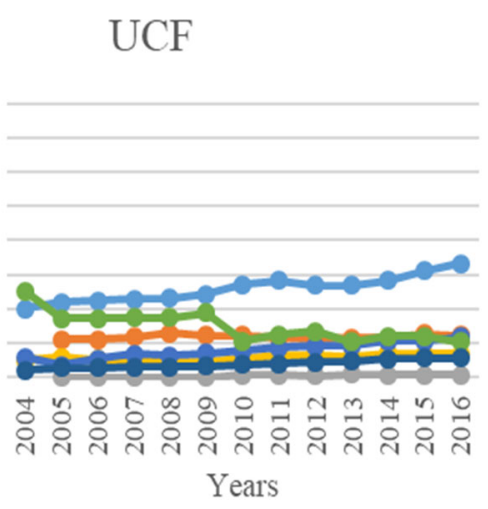 & 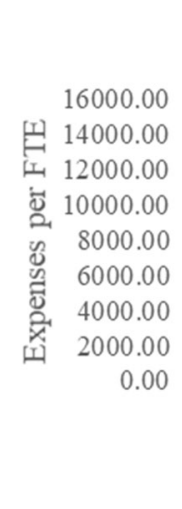 & Years \\
\hline
\end{tabular}




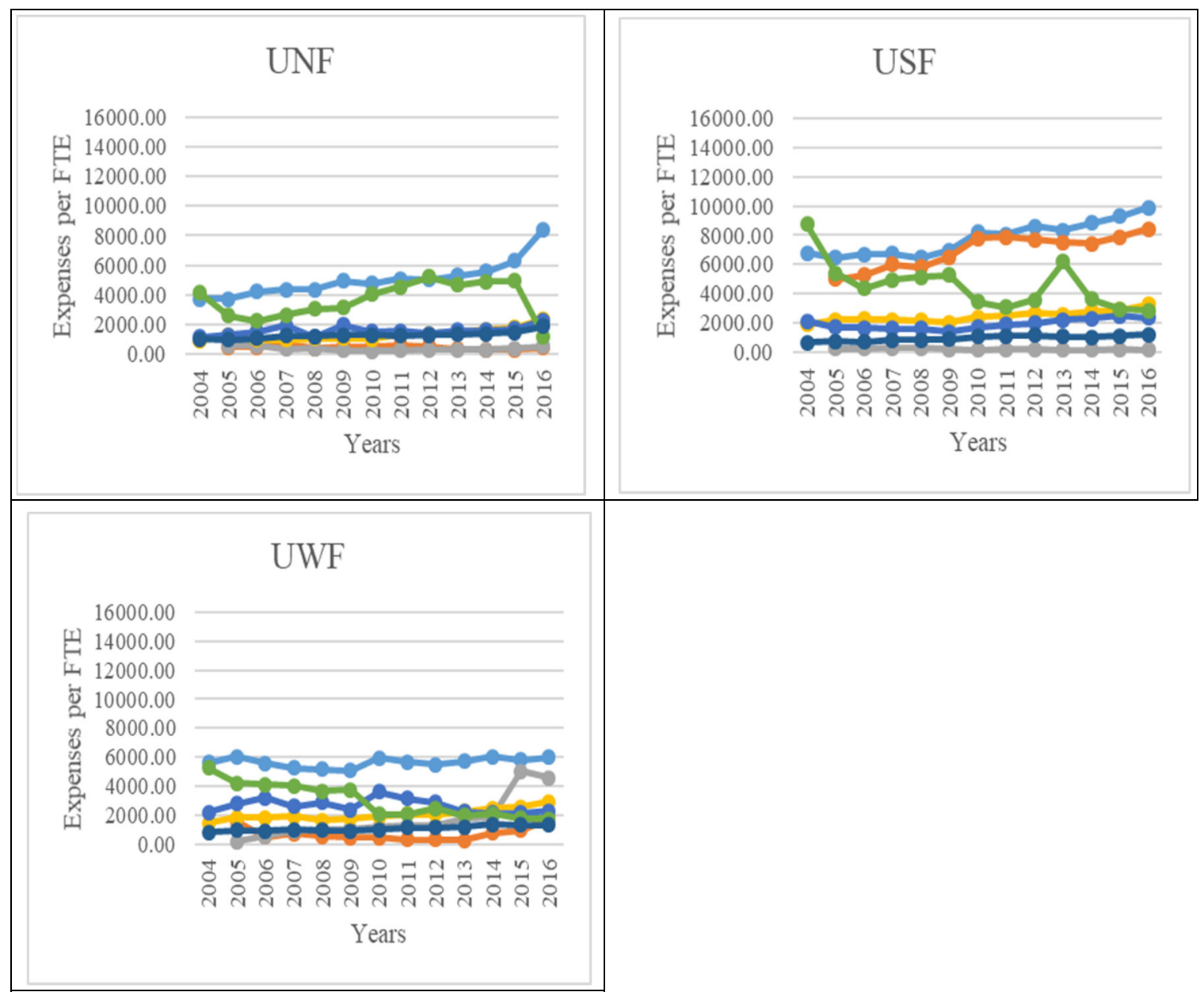

Figure 18: SUS institutions Expenses 2004-2016

In this section, the researcher presented the SUS trends for the graduation rate, employment rates, retention rates, student to faculty ratio, and institutional expenditures. The next section includes FCS data results, specifically, the graduation rates trends for the system and each institution. Employment rates, retention rate, student to faculty ratio, and institutional expenditures for the FCS as well as each institution within the system will also be discussed. 


\section{Florida College System}

\section{Student Success Outcomes: Graduation}

The Florida College System adopted its PBF program in 2015. Figure 19 shows descriptive statistics for the FCS graduation rate from 2004 to 2016 . The most frequent graduation rate for the FCS was 31\%. The average graduation rate for FCS was 35\% $(\mathrm{M}=35 ; \mathrm{SD}=7.08)$. The histogram shows a higher frequency of graduation rates in the lower bottom of the distribution, between $24 \%$ and $38 \%$ for the FCS. There are some graduation rates in the $49 \%$ to $56 \%$ region.

\begin{tabular}{lr}
\hline \multicolumn{2}{c}{ 2004-2016 FCS } \\
\hline Mraduation rate \\
Median & 35 \\
Mode & 34 \\
Standard Deviation & 7.08 \\
Range & 40 \\
Minimum & 21 \\
Maximum & 61 \\
\hline
\end{tabular}

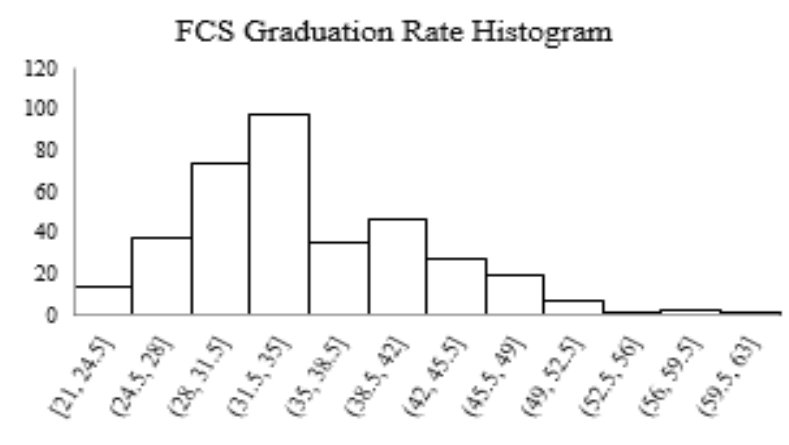

Figure 19: Descriptive Statistics for the FCS Graduation Rate from2004 to 2016

Figure 20 below shows the graduation rate trend for the FCS. As shown in the trend below, the graduation rate fluctuated between 33\% and 35\% percent from 2004 to 2016. There is an increase in 2013 from $35 \%$ to $38 \%$, the highest increase in the 12 years. Graduation rates for the FCS were in the 33\% to 35\% range after 2013 and stayed stable in $35 \%$ for 2015 and 2016. From 2011 to 2013, there is an increase of one percent and two percent respectively. In 2013, when Florida was preparing for implementation of PBF in SUS, the increase in graduation rate for FCS was two percent for a total graduation rate of $38 \%$, the highest in the last 13 years. The graduation rate then stabilizes at $35 \%$ for 2015 and 2016. 


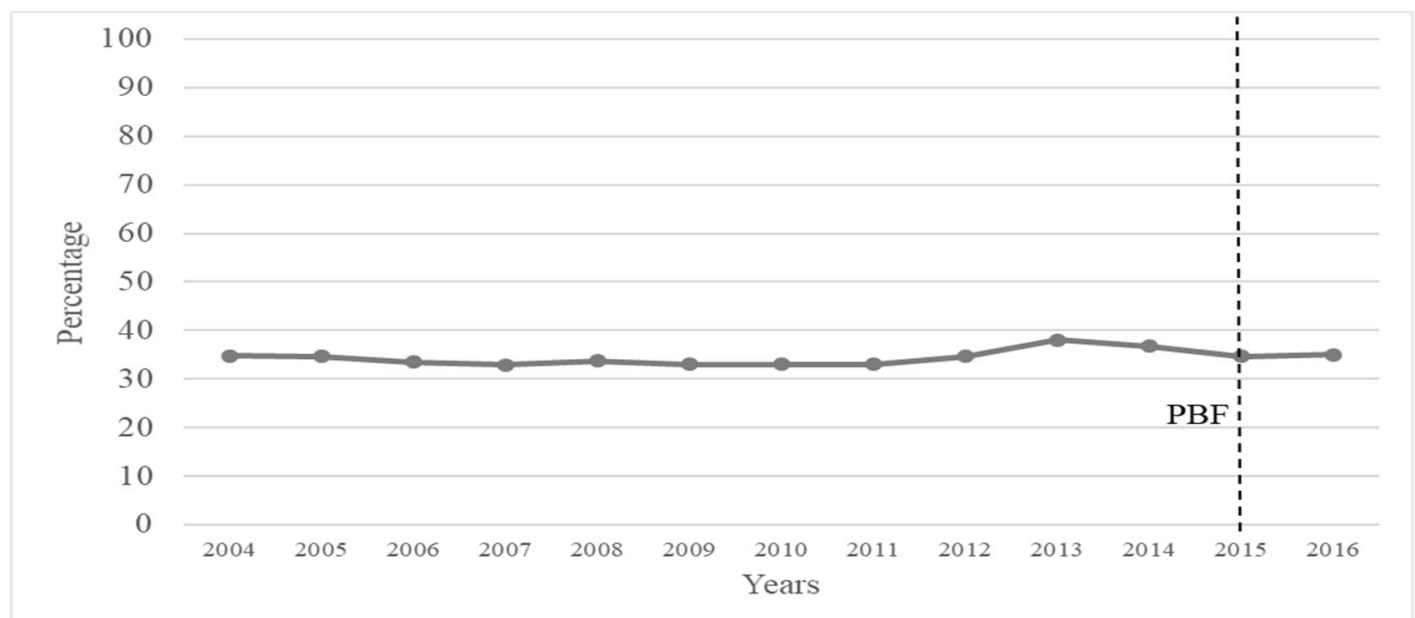

Figure 20. FCS Graduation Rate Trend

FCS PBF program classifies institutions based on their performance in three groups, gold, silver, and bronze. Figure 21 shows its graduation trends from 2004 to 2016. One year after implementation of the PBF program graduation rates for the gold, silver and bronze groups were 39\%, 38\%, and 35\% respectively. Differences in the trends for these three groups are very subtle, between one and two percent throughout the years.

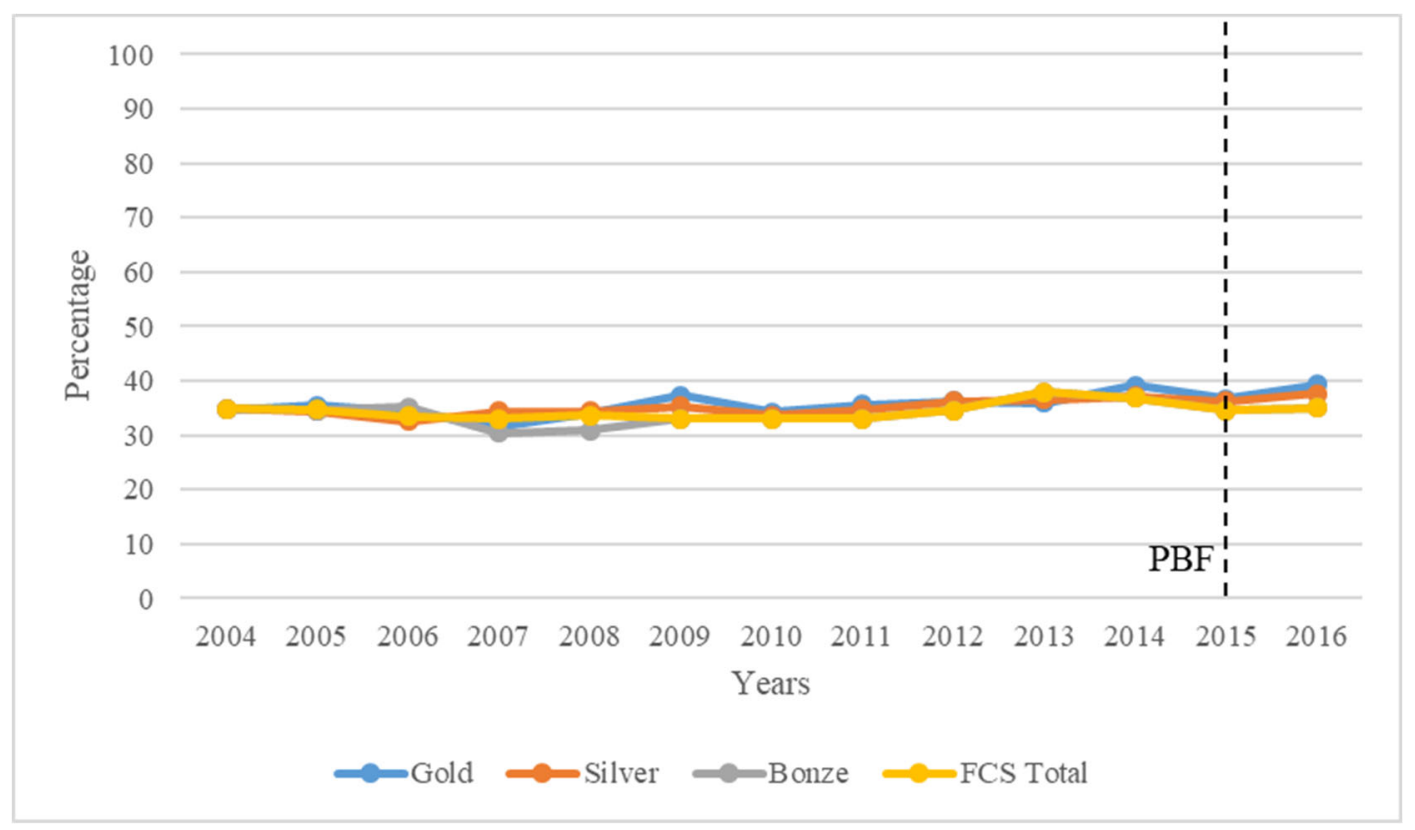

Figure 21. FCS Graduation Rate Trend for Each Classification in the PBF Program 


\section{FCS-Gold Classification}

The gold group was composed of Florida SouthWestern State College, LakeSumter College, State College of Florida- Manatee Sarasota, Valencia College, Gulf Coast State College, Santa Fe College, and Tallahassee Community College. The college with the highest graduation rates was Santa Fe College. From the seven colleges under this Gold classification, three of them decreased their graduation rates after the implementation of PBF and four of them increased their graduation rates. Figure 22 presents the graduation trend for each of the institutions in the gold group. As previously discussed, Santa Fe College performed above the rest of the institutions in this classification.

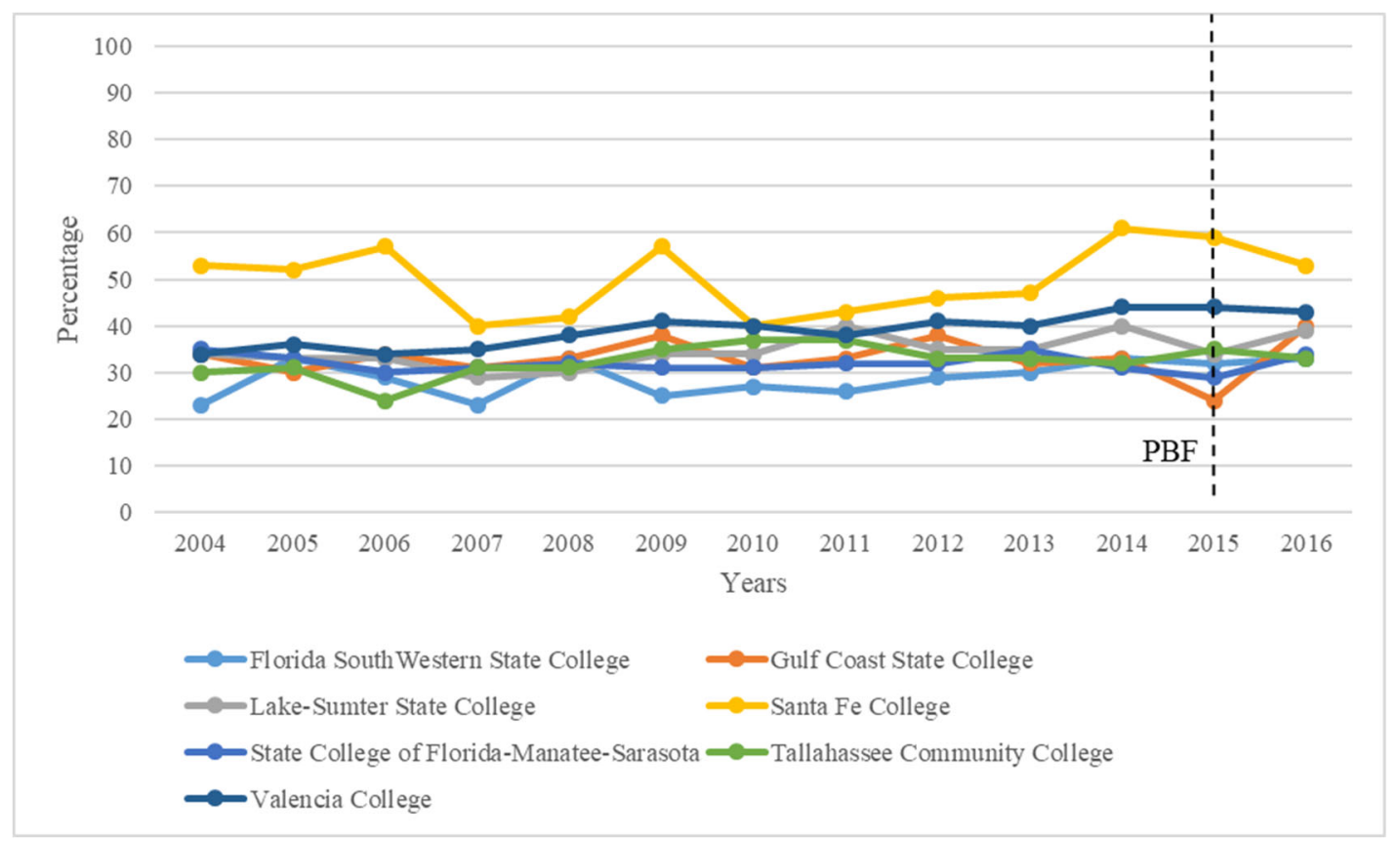

Figure 22: Graduation Rate Trends for the FCS Gold Classification

\section{FCS-Silver Classification}

The FCS Silver classification consists of 16 colleges. Figure 23 shows the graduation rates for the top eight colleges and figure 24 shows the eight colleges in the 
bottom. Differently from the Gold classification, the silver top classification does not have a single college that separates itself from the rest regarding the graduation rates trends. Instead, two colleges seem to perform above the rest in this classification and one college that occasionally reaches the top two colleges. These two top colleges are Chipola College and Eastern Florida State College. Florida Gateway College presents drastic decreases in 2010, 2013, and 2015.

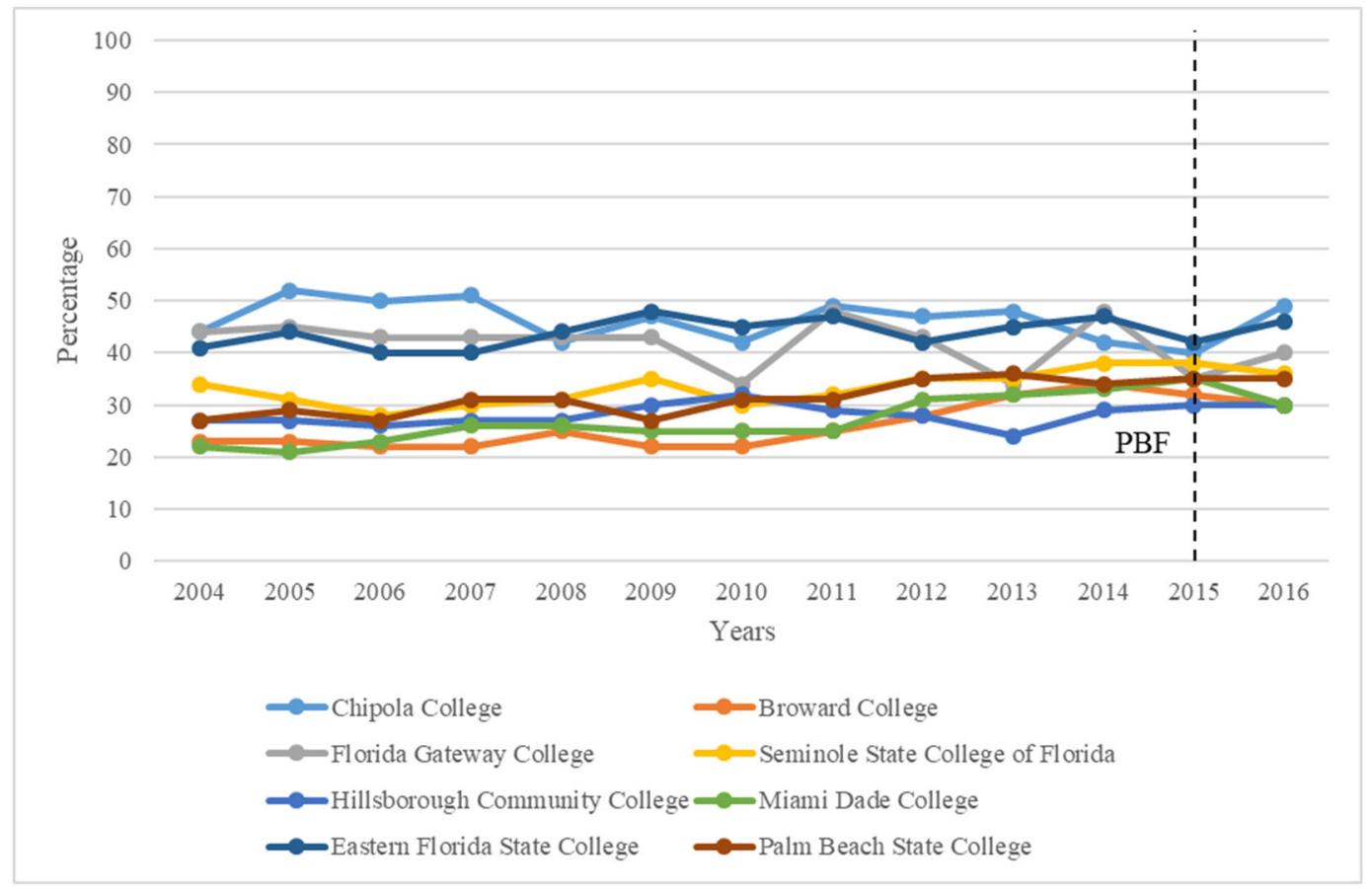

Figure 23: Graduation Rate for the FCS Silver Classification Upper 8 Institutions

These three years have particular events that may be influencing the graduation rate for this institution. For example, 2010 is the year IPEDS adopted methodological changes in their surveys, 2013 is the year Florida adopted PBF for the SUS, and 2015 is the year the FCS adopted PBF. Future researches should investigate if these three events had anything to do with the changes in trends, specifically if the adoption of PBF in the SUS created a statewide effect affecting the FCS and perhaps the private higher 
education system in Florida as well.

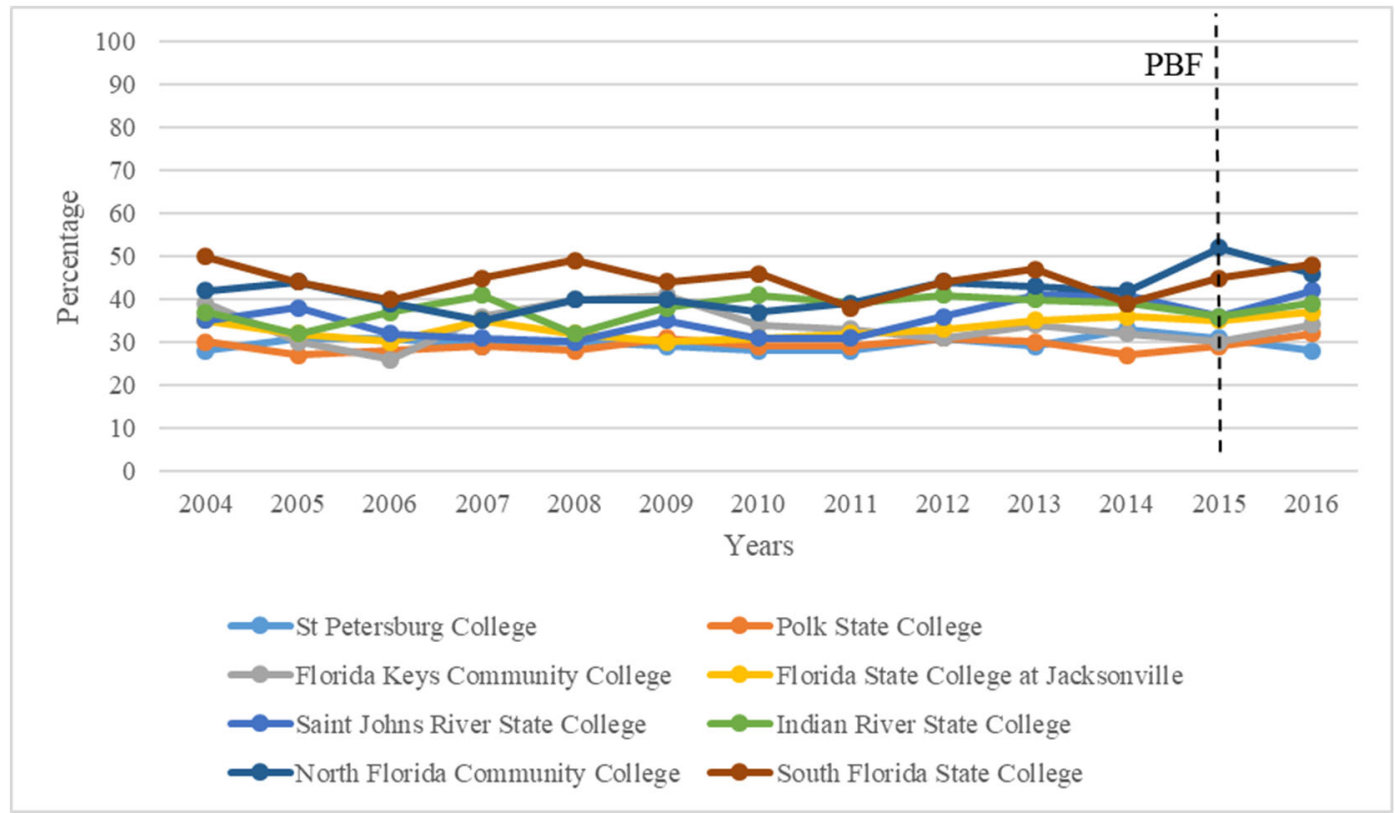

Figure 24: Graduation Rate for the FCS Silver Classification Lower 8 Institutions

\section{FCS- Bronze Classification}

The Bronze classification consists of those institutions that performed in the lower end for the FCS PBF program. There were five institutions in this classification, College of Central Florida, Northwest Florida State College, Pensacola State College, Daytona State College, and Pasco-Hernando State College. The graduation rate trends from 2004 to 2016 are in figure 25 . For the bronze classification, none of the institutions separated from the rest. Instead, all five showed similar trends, with decreases in the graduation rates from 2013 to 2015 and a slight increase from 2015 to 2016, after the implementation of PBF. 


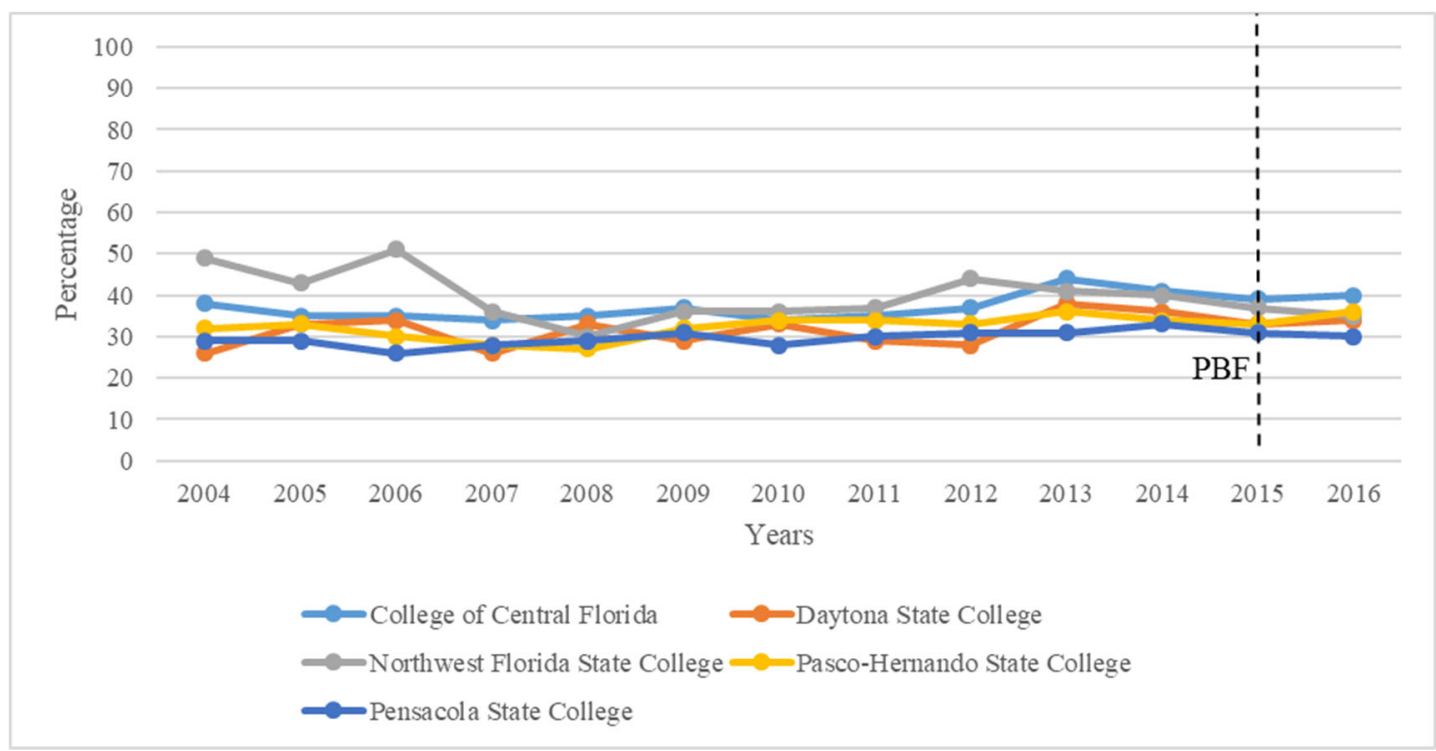

Figure 25: Graduation Rate for the FCS Bronze Classification

\section{FCS-Rate of Change}

Table 7 demonstrates the rate of change for the FCS from 2005 to 2016 . The FCS showed a higher variability for the rate of change than the SUS. Changes in this system go from $-27 \%$ to $67 \%$. From 28 institutions in the system, 10 of them had a negative rate of change for the year after the implementation of PBF and 18 had an increase. The institution with the highest increase in the FCS after the implementation of PBF was Gulf Coast State College. This institution increased its graduation rate 67 percent, placing itself among the gold classification for 2016. On the other hand, the institution with the highest decrease in the FCS after the implementation of PBF was Miami Dade College. This institution decreased its graduation rate by $17 \%$, placing itself among the silver classification for 2016.

The FCS is composed mostly of two-year institutions. Students attending a twoyear institution may do so for reasons other than attaining a degree. Zarkesh and Beas (2004) reviewed performance indicators in community colleges and assessed their effect 
on the institutions. They collected data from 47 states using a semi-structured interview and found that community colleges were being evaluated using some of the performance indicators generally used to evaluate four-year institutions. Zarkesh and Beas (2004) claimed that those performance indicators did not reflect the value of community colleges, whose missions are different from four-year institutions. The authors argued that even when "this indicator [i.e., graduation rates] can be used correctly to measure the success of a university, it does not similarly reflect the value of a community college due to the many two-year college students who take classes for reasons other than simply to attain a degree" (p. 654). Other authors argued against using graduation rates to evaluate colleges as well (Burke \& Minassians, 2004; Christopher, 2010). The data presented for the FCS $(M=35)$ clearly shows there is a gap in graduation rate when compared with the SUS graduation rates $(M=55)$. Future research should evaluate other measures of quality within the FCS, and their changes, if any, during, before, and after the adoption of PBF. It is important to consider that graduation rates are still a metric used to evaluate FCS within the new PBF program. 


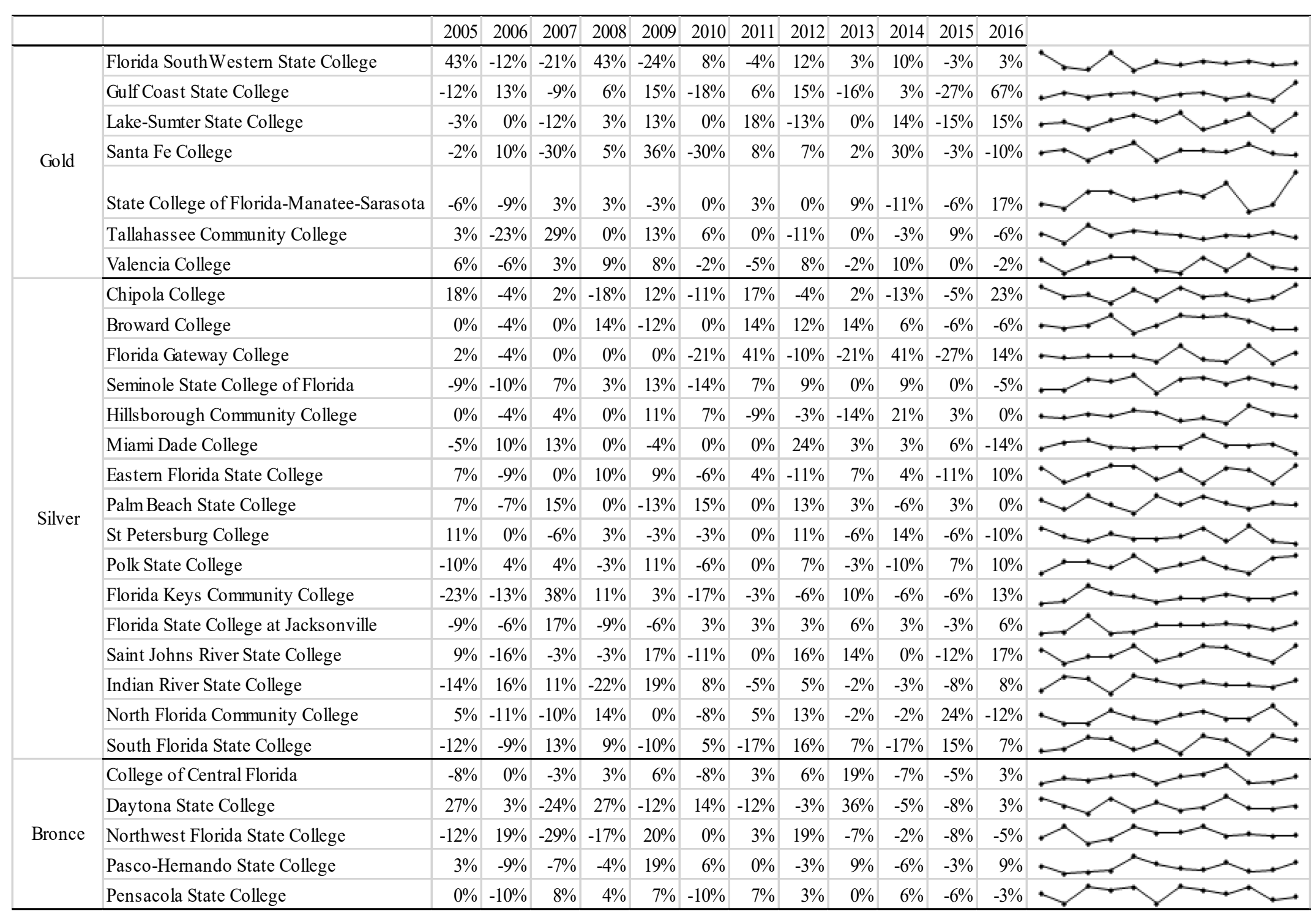

Table 7. Rate of Change for the Florida College System from 2005 to 2016 
Figure 26 shows the stacked line chart for the FCS PBF calculated scores for sixyear graduation rates from 2005 to 2016. These scores were calculated using the FCS PBF methodology. Excellence points were calculated using the system average for the previous two years and the standard deviation as explained in the 2017-18 Florida College system PBF model (https://www.floridacollegesystem .com/resources/ publications /performance_funding_model_2017-18.aspx). The improvement points were calculated using the percentage change formula [(CY -PY Avg.) / PY Avg]. Points were awarded based on the percentage change table in the 017-18 Florida College system PBF model. The graph shows an increase in the cumulative value of the calculated PBF score for graduation rates in the FCS for 2009 followed by a decrease from 2010 to 2013. Reasons for the decrease in 2010 are not clear, although 2010 was a year for methodological changes in IPEDS, which may have affected the data for that particular year. In 2013, Florida was preparing to adopt PBF in the SUS; further research should explore how the SUS adoption of PBF may indirectly affect other public and private systems in Florida.

Finally, 2016 shows a cumulative increase for the calculated PBF score. Two thousand sixteen was the first year after the FCS adopted the PBF program in 2015. The six-year graduation rate for the FCS considers a three-year allowable time for students in two-year programs and a 6-year allowable time for students in four-year programs to graduate from the institution. Therefore, the direct effect of PBF in such a metric should not be visible until 2019. Reasons for the 2016 graduation rates increase are not clear, but an extended investigation into the FCS reaction to PBF may reveal more information as to why an increase did occur. Future researchers should also explore to what extent the 
increase was due to the methodology used to assign PBF scores and if this increase translates into more students completing their programs.

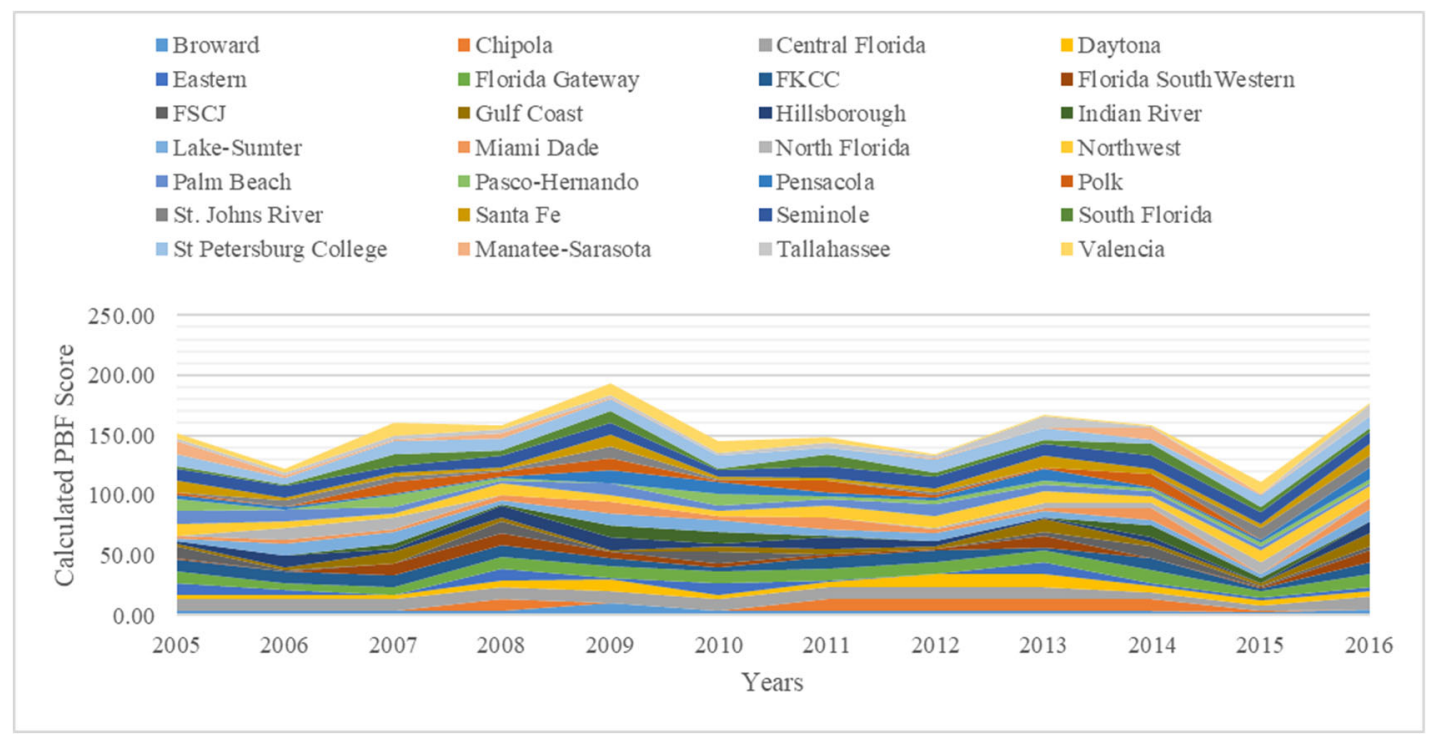

Figure 26: Stacked Line Chart for the FCS PBF Calculated Scores-Six-Year Graduation Rates from 2005 to 2016.

\section{Student Success Outcome: Job Placement}

The FCS PBF program contains an employment or continuing education variable. Data for this variable is published by the FCS in their web page (https://www.floridacolle gesystem.com/Default.aspx?page=resources $\% 2$ Fpublications $\% 2$ Fperformance_funding model_2017-18). For this particular variable the FCS gathers information from five sources, Community College and Technical Center Management Information System (CCTCMIS), Department of Education (DOE), Florida Department of Revenue (DOR), National Student Clearinghouse (NSC), U.S. Office of Personnel Management (OPM), and Wage Record Interchange System 2 (WRIS2). In the FCS PBF program, excellence points were determined based on each college's most recent year of data. Each college receives 0.1 points for each $2 \%$ of completers employed or continuing their education. 
For the improvement points, they also compare each college's most recent year available rate of change to the mean of the three to two prior years for that college alone. Then they assign points on a scale from low $(.25 \%)$ to high $(2.50 \%)$ in ten increments (JobPlacementContinuingEducation_1718Model.pdf., p.3). From the two scores, excellence and improvement, they then choose the highest and multiply it by two for a maximum of 10 points in this metric.

Figure 27 shows the total Job Placement or Continuing education for the FCS 2012 graduates to 2016 graduates. The data represents the percentage of students who graduated in 2012 to 2016 and one year after graduation have a job or are studying. The range for FCS Job Placement or continuing education was $88 \%$ to $95 \%$, which is higher than the range of employment continuing education for the SUS (65\% to $72 \%)$. There is an evident decrease in the student's employment for 2015 graduates. The State Board of Education (SBOE) changed the formula to calculate the excellence points for the FCS PBF program in 2016-2017, which could have affected the rates for the 2015 graduates. This metric had a second review in methodology in 2017-2018 that included adding a data set to track more students. This change in methodology may have contributed to the increase for the 2016 graduates' employment rate. Although both explanations for the 2015 and 2016 changes in employment rate are possible, further research should explore FCS employment rates in order to understand what the causes of these changes were. 


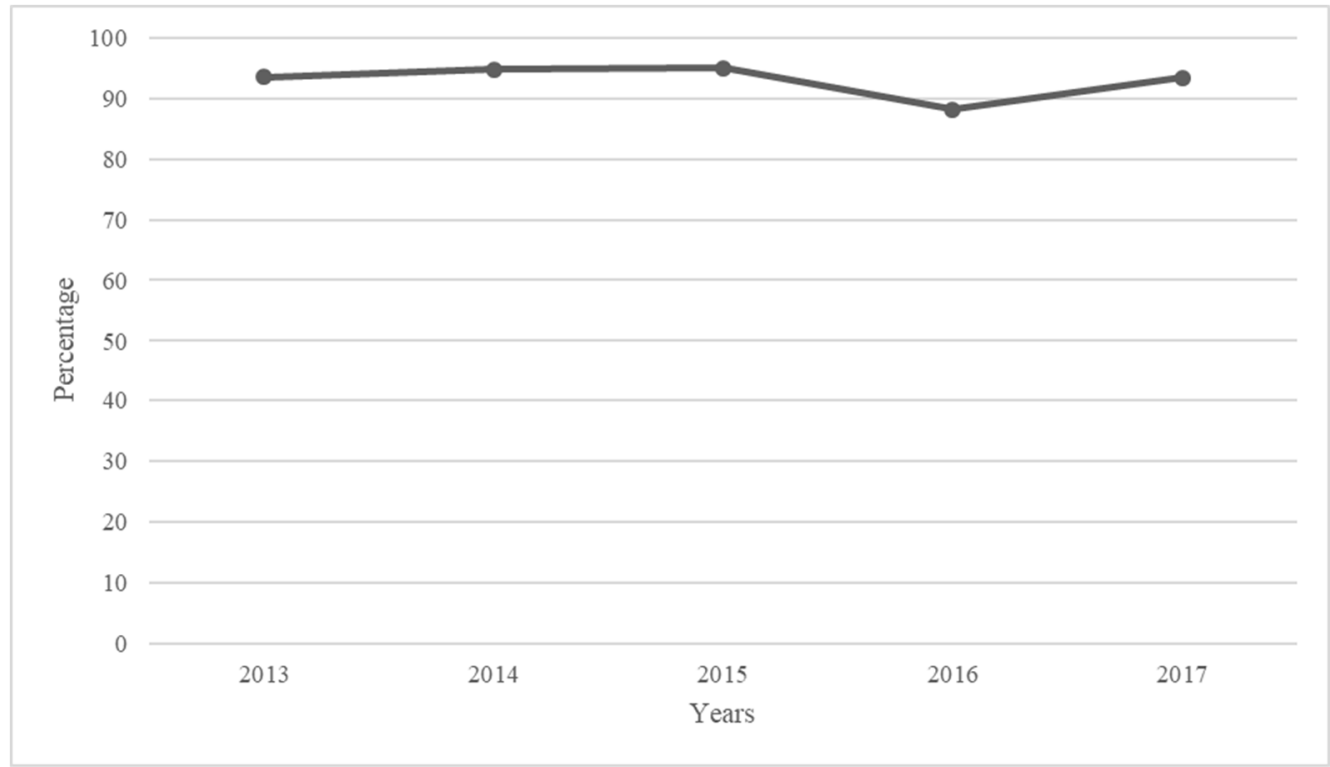

Figure 27. FCS Total Job Placement or Continuing Education Rates

Figure 28 shows the Job Placement or continuing education trends for each institution in the system. Most of the institutions in the system had similar trends for five years. Institutions that underperformed during this period were Pensacola State College, Florida SouthWestern State College, and Chipola College. Pensacola State College and Florida SouthWestern State College had the lowest Job Placement or continuing education score for the 2015 cohort of students, which is consistent with the Total Job Placement or continuing education rates presented in figure 27. Chipola College had the lowest score for the 2016 cohort of students. 


\begin{tabular}{|c|c|c|c|c|c|c|}
\hline \multirow{6}{*}{$\begin{array}{r}\text { Valencia College } \\
\text { Tallahassee Community College } \\
\text { State College of Florida-Manatee-Sarasota } \\
\text { St Petersburg College } \\
\text { South Florida State College } \\
\text { Seminole State College of Florida }\end{array}$} & 95 & 97 & 97 & 92 & 97 & 96 \\
\hline & 96 & 97 & 97 & 92 & 97 & 96 \\
\hline & 96 & 96 & 96 & 91 & 95 & 95 \\
\hline & 94 & 95 & 96 & 88 & 95 & 94 \\
\hline & 94 & 94 & 95 & 88 & 94 & 93 \\
\hline & 94 & 96 & 96 & 90 & 96 & 94 \\
\hline \multirow{8}{*}{$\begin{array}{r}\text { Santa Fe College } \\
\text { Saint Johns River State College } \\
\text { Polk State College } \\
\text { Pensacola State College } \\
\text { Pasco-Hernando State College } \\
\text { Palm Beach State College } \\
\text { Northwest Florida State College } \\
\text { North Florida Community College }\end{array}$} & 95 & 97 & 96 & 90 & 96 & 95 \\
\hline & 94 & 95 & 96 & 89 & 95 & 94 \\
\hline & 96 & 97 & 95 & 92 & 97 & 95 \\
\hline & 89 & 90 & 90 & 81 & 90 & 88 \\
\hline & 93 & 95 & 96 & 88 & 95 & 93 \\
\hline & 94 & 94 & 96 & 89 & 94 & 93 \\
\hline & 92 & 92 & 94 & 84 & 92 & 91 \\
\hline & 92 & 96 & 94 & 87 & 96 & 93 \\
\hline \multirow{3}{*}{$\begin{array}{r}\text { Miami Dade College } \\
\text { Lake-Sumter State College } \\
\text { Indian River State College }\end{array}$} & 93 & 95 & 95 & 90 & 95 & 94 \\
\hline & 95 & 97 & 97 & 90 & 97 & 95 \\
\hline & 93 & 94 & 95 & 88 & 94 & 93 \\
\hline \multirow{2}{*}{$\begin{array}{r}\text { Hillsborough Community College } \\
\text { Gulf Coast State College }\end{array}$} & 94 & 96 & 95 & 90 & 96 & 94 \\
\hline & 94 & 95 & 96 & 88 & 95 & 94 \\
\hline \multirow{2}{*}{$\begin{array}{l}\text { Florida State College at Jacksonville } \\
\text { Florida SouthWestern State College }\end{array}$} & 91 & 94 & 94 & 86 & 94 & 92 \\
\hline & 96 & 96 & 96 & 92 & 62 & 88 \\
\hline \multirow{2}{*}{$\begin{array}{r}\text { Florida Keys Community College } \\
\text { Florida Gateway College }\end{array}$} & 91 & 94 & 92 & 83 & 93 & 91 \\
\hline & 92 & 95 & 95 & 84 & 95 & 92 \\
\hline \multirow{2}{*}{$\begin{array}{r}\text { Eastern Florida State College } \\
\text { Day tona State College }\end{array}$} & 93 & 94 & 94 & 88 & 94 & 93 \\
\hline & 92 & 93 & 94 & 86 & 93 & 92 \\
\hline \multirow{2}{*}{$\begin{array}{r}\text { College of Central Florida } \\
\text { Chipola College }\end{array}$} & 93 & 96 & 94 & 86 & 96 & 93 \\
\hline & 93 & 88 & 95 & 88 & 87 & 90 \\
\hline & 94 & 96 & 96 & 90 & 96 & 94 \\
\hline FCS & 94 & 95 & 95 & 88 & 93 & 93 \\
\hline 2013 Grads & 2014 Grads & $\square 2$ & 5 Grads & $=201$ & 6 Grads & Grand Total \\
\hline
\end{tabular}

Figure 28. FCS Job Placement or Continuing Education Rates

The rate of change (figure 29) confirms the trends shown in figure 28. Florida SouthWestern College and Chipola College separate themselves from the rest of the institutions. Florida SouthWestern College had a 33\% decrease for the 2016 cohort while Chipola College had an 8\% increase for the 2014 cohorts and a 1\% decrease for the 2016 cohort. The rest of the institutions had decreased for the 2015 cohort. The 2015 cohort is the only cohort that shows a decrease for all the institution in the system. 
Further research should evaluate the reasons for this decrease. The 2015 cohort represents students who graduated in 2015, and therefore this metric is calculated in 2016 one year after graduation. It is interesting that 2015 is the official year for the adoption of PBF in the FCS and 2016 is the first year of performance evaluation for the system.

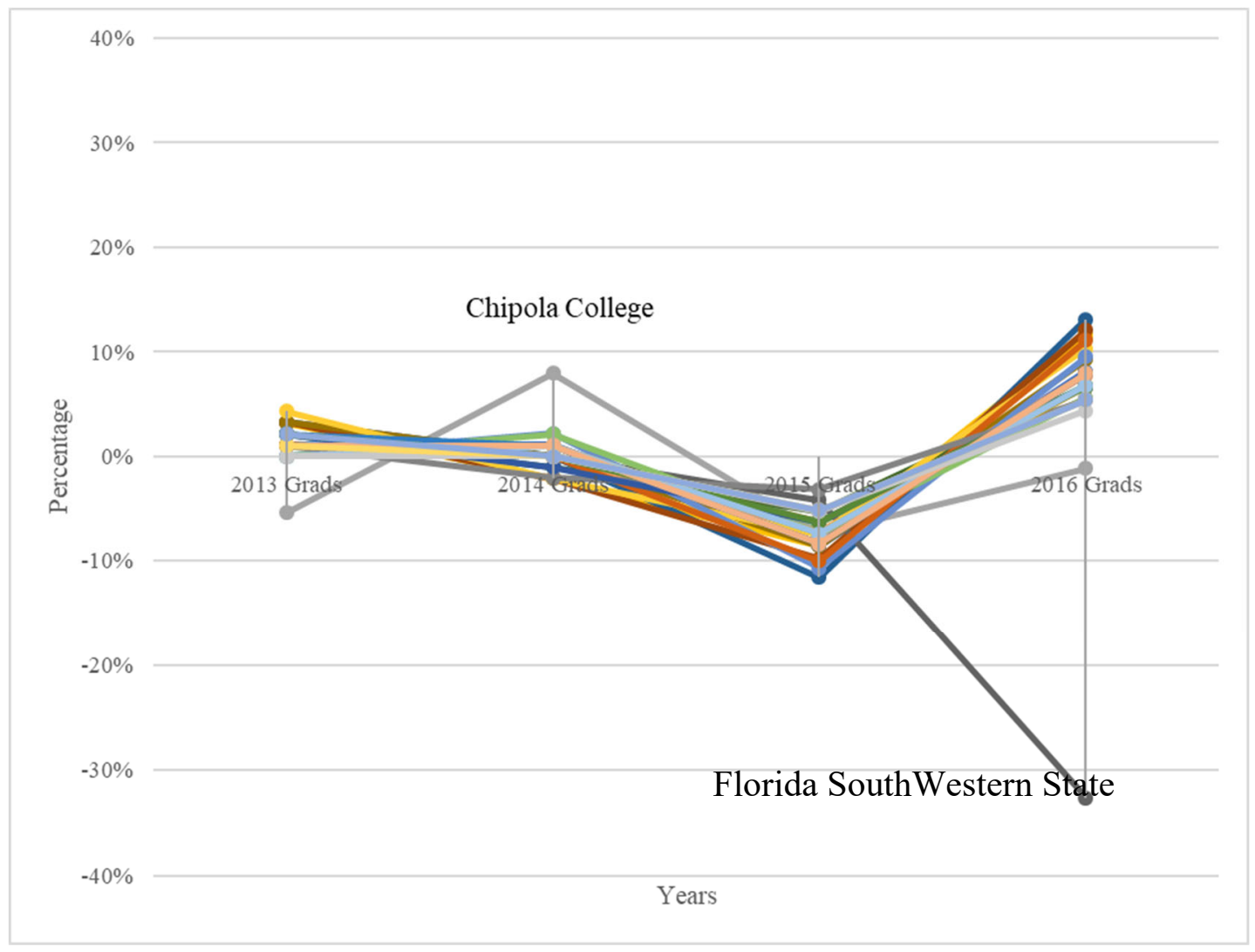

Figure: 29. Rate of Change FCS Job Placement /Continuing Education

The analysis performed for the FCS Job Placement or continuing education variable clearly shows the 2015 cohort as a point of interest. Not only did all the institutions decrease in performance for this cohort, showing a negative rate of change, but also 2015 is the year of implementation for the PBF. Future researchers should explore if there were possible connections between the implementation of PBF and the decrease in FCS Job Placement or continuing education rates. 


\section{Student Success Outcome: Retention}

As explained in the SUS results section, retention rates provided by IPEDS represent the percentage of first-time, full-time undergraduate students who returned to the same institution the following fall. Hillman, Tandberg, and Fryar (2015) suggest that even when the effect of PBF may have little to no effect on degree completion, it is possible that it has a positive effect on intermediate outcomes such as student retention. In this section, this researcher explores the relation between $\mathrm{PBF}$ and retention for the FCS.

Figure 30 shows descriptive statistics for the FCS retention rate from 2004 to 2016. The most frequent retention rate for the FCS was $66 \%$. The average graduation rate for FCS was $61.4 \%(M=61.4 ; \mathrm{SD}=13.06)$. The histogram shows a higher frequency of retention rate in the middle of the distribution, between $62.8 \%$ and $66.0 \%$ for the FCS.

\begin{tabular}{lr}
\hline \multicolumn{2}{c}{ FCS Retention Rate } \\
\hline Mean & 61.4 \\
Median & 64 \\
Mode & 66 \\
Standard Deviation & 13.06 \\
Range & 75 \\
Minimum & 50 \\
Maximum & 75 \\
\hline
\end{tabular}

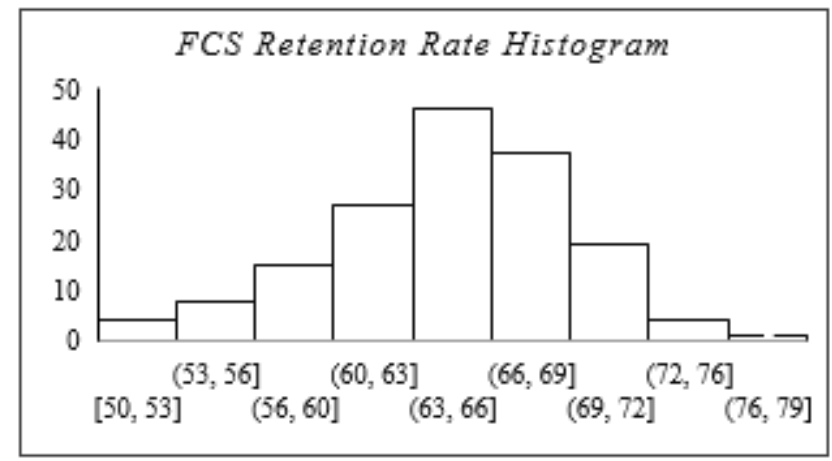

Figure 30: Descriptive Statistics for the FCS Retention Rate from 2004 to 2016

Figure 31 shows the retention rate trend for the FCS. As shown in the trend below, the retention rate fluctuated between 54\% and 68\% from 2004 to 2016 . There is an increase in 2016 from $65 \%$ to $68 \%$, the highest retention rate in the twelve years and one year after implementation of PBF in 2015 for the FCS. The rate of change in the 
retention rates generally fluctuated between negative one percent and one percent for the 12 years.

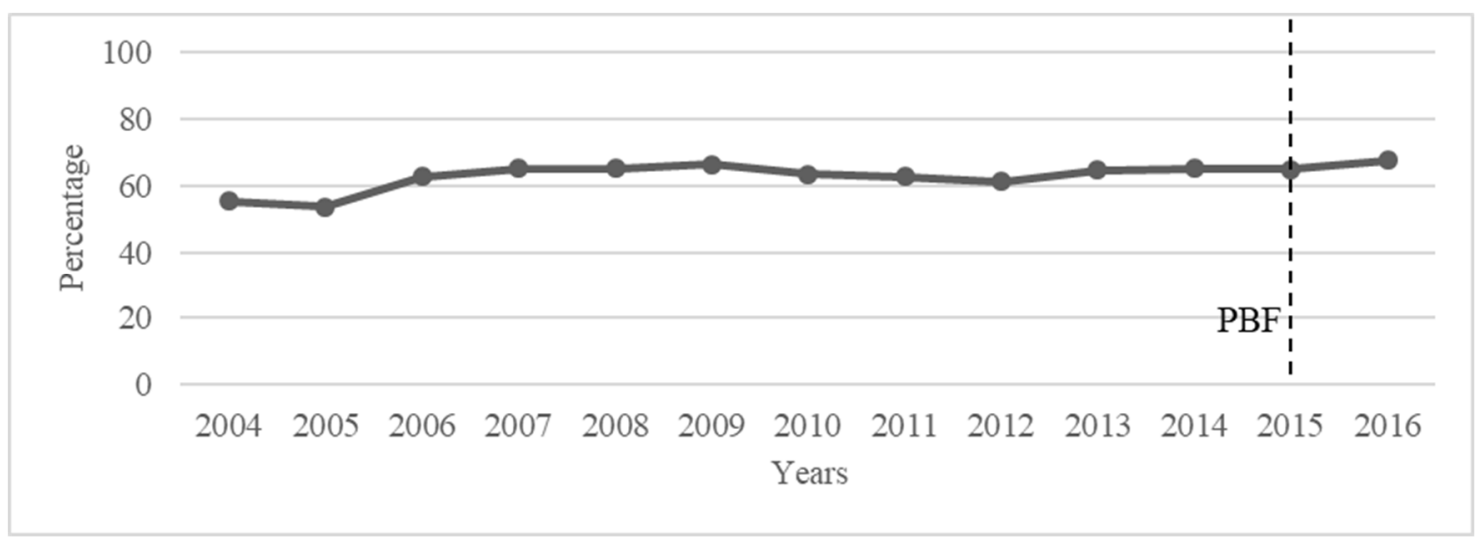

Figure 31. Retention Rate FCS

The FCS institutions' retention rates fluctuate from $54 \%$ to $68 \%$. There is an increase after the implementation of PBF in 2015. This increase seems to be true for all the institutions within the FCS. Nonetheless, when looked at closely, figure 32 presents that at least four institutions decreased retention rates after PBF implementation in 2015, (Broward College, Daytona State College, Florida Keys Community college, and Miami Dade College). Figure 33 confirms that these four institutions decreased retention rates after 2015, resulting in a negative rate of change in 2015 . 


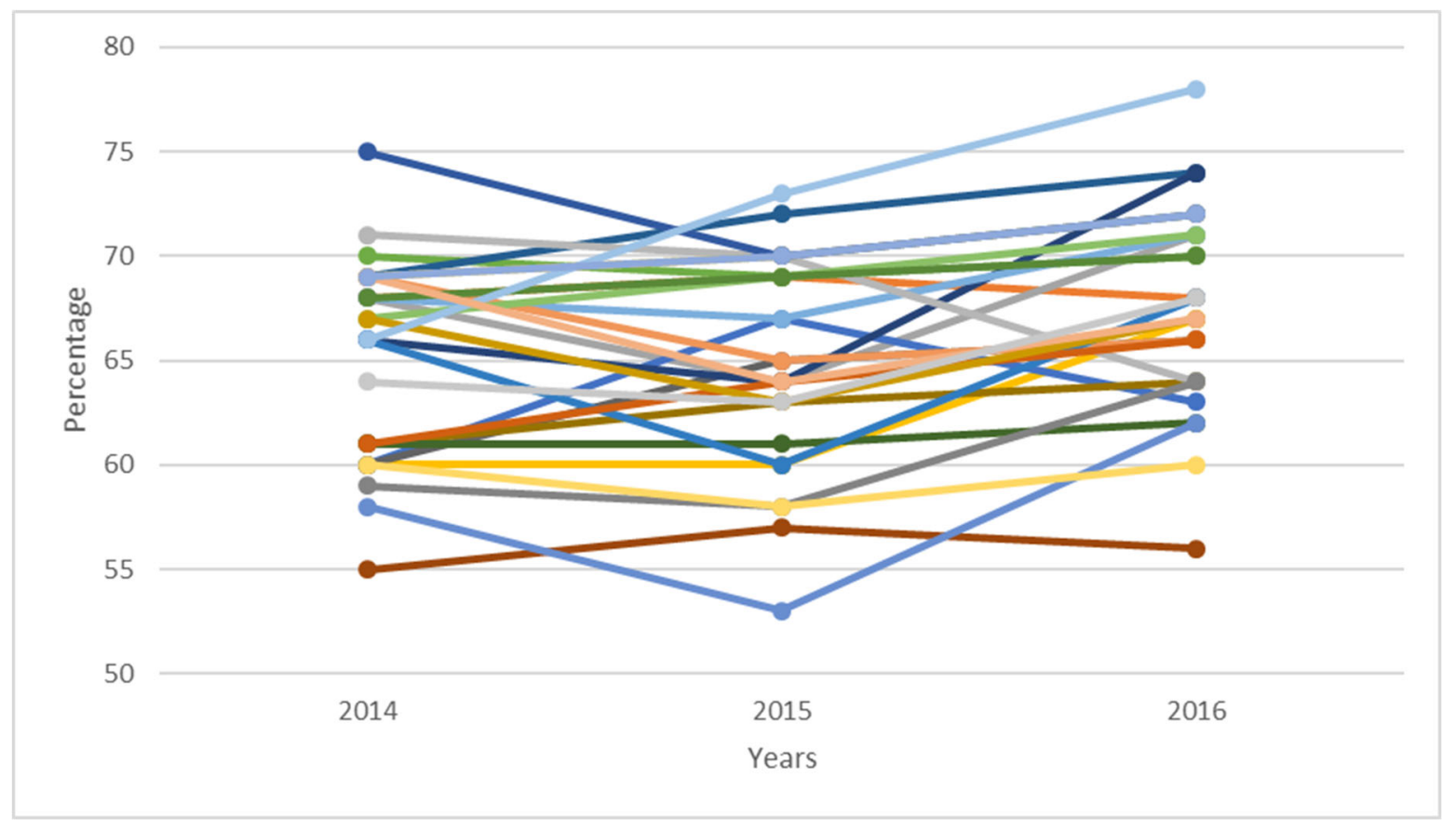

Figure 32. Retention Rates for Institutions within the FCS

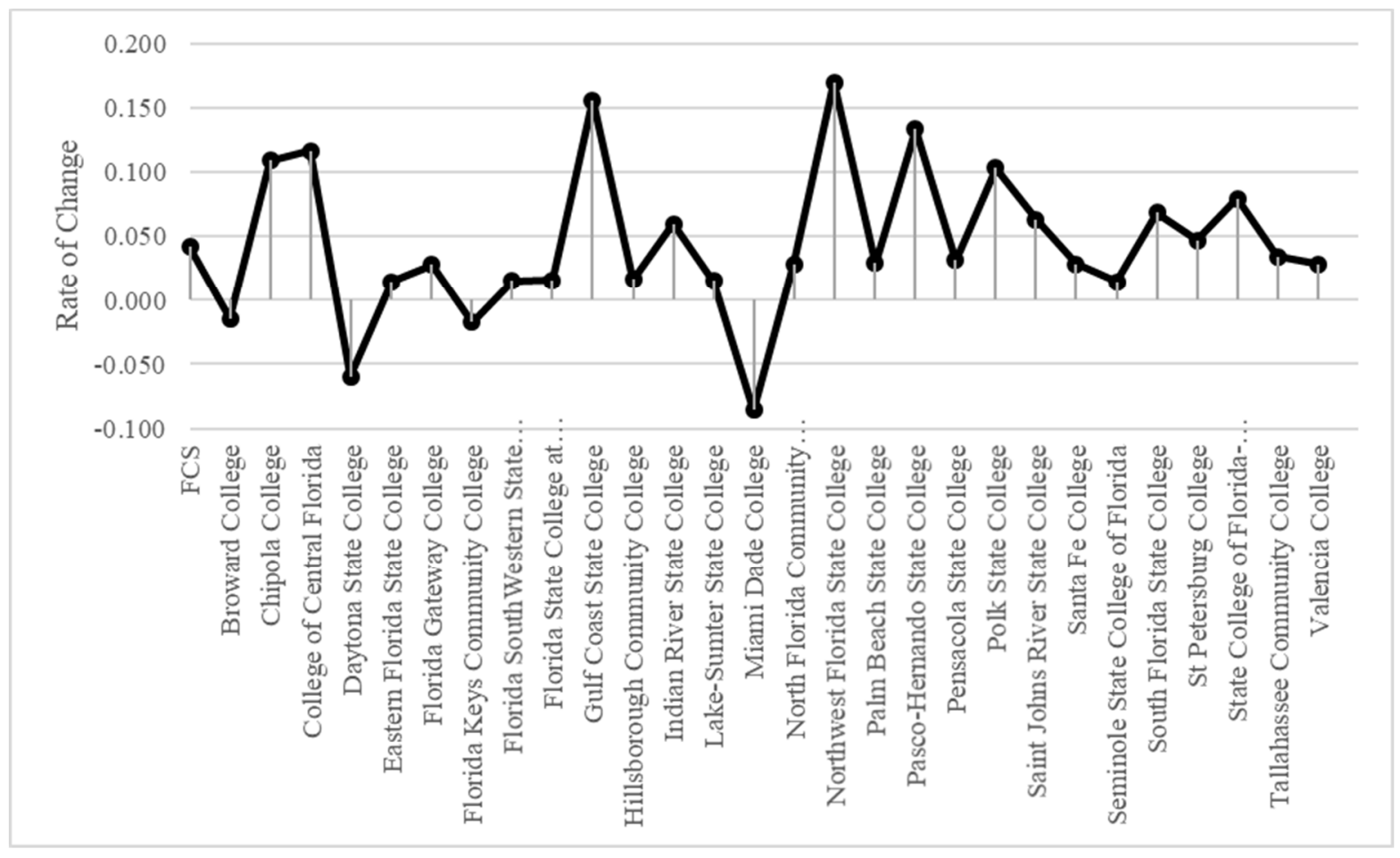

Figure 33: FCS Retention Rate of Change One Year after the Implementation of PBF 
Table 8 shows with more clarity the relative institutional positions within the FCS for the 12 years. The arrows in table 8 show the values for three retention rate groups. The first icon ( $\uparrow$ ) represents the top one-third of values, the second icon $(\rightarrow)$ represents the second third of values, and the third icon $(\downarrow)$ represents the lowest one-third of values. Valencia College, Santa Fe College, Eastern Florida State College, and North Florida Community College seem to stand out from the rest, as they are on the top one-third for the last three years (2014 to 2016). The following institutions kept themselves in the middle or second third of the distribution for the last three years, State College of Florida Manatee-Sarasota, Pasco Hernando State College, Saint John River State College, Pensacola State College, College of Central Florida, Hillsborough Community College, Lake Summer State College, Daytona State College, Florida State College at Jacksonville, and Florida SouthWestern State College. Lastly, Florida Keys Community College was the only institution in the lowest one-third of values for the last three years (2014 to 2016). Some institutions fluctuated positions in the last two years (2015 to 2016) with three of them going from the low one-third to the second third (Polk State College, Tallahassee Community college, and North West Florida State College), and four of them going from the second third to the first one-third (Indian River, Gulf Coast, Chipola College, and Broward College). The rest went down one position, either from top to middle or from middle to bottom. 
Table 8. FCS Retention Rates 2004 to 2016

\begin{tabular}{|c|c|c|c|c|c|c|c|c|c|c|c|c|c|c|}
\hline FCS Institution & 2004 & 2005 & 2006 & 2007 & 2008 & 2009 & 2010 & 2011 & 2012 & 2013 & 2014 & 2015 & 2016 & Total \\
\hline Santa Fe College & 74 & $\$ 65$ & $\$ 68$ & 968 & $\$ 66$ & 70 & 968 & $\$ 65$ & 965 & 71 & 75 & 70 & 72 & 14 69 \\
\hline Valencia College & $\$ 68$ & $\$ 68$ & 69 & 71 & 69 & 72 & 70 & $\$ 67$ & $\Rightarrow 65$ & 567 & 69 & 70 & 72 & 69 \\
\hline Broward College & $\Rightarrow 66$ & $\Rightarrow 64$ & $\Rightarrow 64$ & $\Rightarrow 68$ & 71 & 75 & 72 & 72 & $\Rightarrow 67$ & 70 & 568 & 69 & $\Rightarrow 68$ & 69 \\
\hline Palm Beach State College & $\Rightarrow 65$ & $\Rightarrow 65$ & $\Rightarrow 64$ & $\Rightarrow 68$ & $\Rightarrow 67$ & 71 & 70 & $\Rightarrow 66$ & $\Rightarrow 66$ & 71 & $\Rightarrow 67$ & 69 & 71 & $\Rightarrow 68$ \\
\hline Indian River State College & $\$ 65$ & $\Rightarrow 63$ & $\$ 66$ & ค 69 & $\Rightarrow 67$ & $\Rightarrow 66$ & $\Rightarrow 64$ & $\Rightarrow 65$ & $\Rightarrow 64$ & 567 & $\Rightarrow 68$ & 567 & 71 & $\Rightarrow 66$ \\
\hline Seminole State College of Florida & $\Rightarrow 62$ & $\Rightarrow 62$ & $\$ 64$ & $\Rightarrow 67$ & $\Rightarrow 67$ & $\Rightarrow 66$ & $\Rightarrow 67$ & $\Rightarrow 67$ & $\Rightarrow 65$ & $\Rightarrow 68$ & $\Rightarrow 68$ & 69 & 70 & $\Rightarrow 66$ \\
\hline Gulf Coast State College & $\$ 68$ & $\$ 65$ & $\$ 66$ & $\$ 66$ & $\rightrightarrows 65$ & 69 & $\rightrightarrows 61$ & 567 & $\rightrightarrows 61$ & $\$ 68$ & $\rightrightarrows 66$ & 564 & 74 & $\Rightarrow 66$ \\
\hline Lake-Sumter State College & $\$ 66$ & $\Rightarrow 64$ & $\Rightarrow 60$ & $\$ 64$ & $\rightrightarrows 65$ & $\Rightarrow 68$ & $\Rightarrow 62$ & $\Rightarrow 63$ & $\Rightarrow 65$ & $\Rightarrow 63$ & 69 & $\Rightarrow 65$ & $\Rightarrow 66$ & $\Rightarrow 65$ \\
\hline State College of Florida-Manatee-Sarasota & $\Rightarrow 68$ & $\Rightarrow 65$ & $\Rightarrow 67$ & $\Rightarrow 67$ & $\xi 67$ & $\Rightarrow 63$ & $\sqrt{59}$ & $\Rightarrow 61$ & $\Rightarrow 62$ & $\Rightarrow 65$ & $\Rightarrow 64$ & $\Rightarrow 63$ & $\Rightarrow 68$ & $\Rightarrow 65$ \\
\hline Pasco-Hernando State College & $\Rightarrow 66$ & $\Rightarrow 61$ & $\$ 61$ & $\Rightarrow 65$ & $\$ 68$ & 70 & $\Rightarrow 66$ & $\Rightarrow 62$ & $\sqrt{59}$ & $\Rightarrow 64$ & $\Rightarrow 66$ & $\Rightarrow 60$ & $\Rightarrow 68$ & 564 \\
\hline North Florida Community College & $\$ 63$ & $\$ 60$ & $\sqrt{49}$ & $\Rightarrow 63$ & 50 & 263 & $\Rightarrow 66$ & 365 & $\Rightarrow 64$ & 367 & 69 & 70 & ค1 72 & $\Rightarrow 64$ \\
\hline Saint Johns River State College & $\$ 63$ & $\Rightarrow 62$ & $\Rightarrow 63$ & $\$ 64$ & $\Rightarrow 66$ & $\rightrightarrows 67$ & $\Rightarrow 63$ & $\Rightarrow 65$ & $\sqrt{56}$ & $\Rightarrow 65$ & $\Rightarrow 67$ & $\Rightarrow 63$ & $\Rightarrow 67$ & $\Rightarrow 64$ \\
\hline South Florida State College & $\Rightarrow 60$ & $\Rightarrow 62$ & $\Rightarrow 68$ & $\Rightarrow 62$ & $\Rightarrow 65$ & $\Rightarrow 60$ & $\sqrt{58}$ & $\sqrt{59}$ & & $\Rightarrow 64$ & $\Rightarrow 66$ & 73 & 78 & $\Rightarrow 64$ \\
\hline Pensacola State College & $\$ 64$ & $\Rightarrow 61$ & $\$ 65$ & $\$ 66$ & $\$ 66$ & $\$ 68$ & $\Rightarrow 61$ & $\Rightarrow 63$ & 59 & $\$ 60$ & $\Rightarrow 61$ & $\Rightarrow 64$ & $\Rightarrow 66$ & 963 \\
\hline FCS & $\sqrt{55}$ & $\sqrt{54}$ & $\$ 63$ & $\$ 65$ & $\$ 65$ & $\$ 67$ & 363 & 563 & $\$ 61$ & $\$ 65$ & $\$ 65$ & 565 & 368 & $\Rightarrow 63$ \\
\hline College of Central Florida & ค. 72 & 456 & 57 & $\Rightarrow 63$ & $\Rightarrow 66$ & $\Rightarrow 65$ & $\Rightarrow 61$ & $\Rightarrow 62$ & $\Rightarrow 61$ & $\Rightarrow 63$ & $\Rightarrow 60$ & $\Rightarrow 60$ & $\Rightarrow 67$ & $\Rightarrow 63$ \\
\hline Polk State College & $\Rightarrow 68$ & $\Rightarrow 63$ & $\$ 64$ & $\Rightarrow 65$ & $\$ 66$ & $\Rightarrow 62$ & $\Rightarrow 67$ & $\Rightarrow 62$ & $\sqrt{55}$ & $\Rightarrow 60$ & $\sqrt{59}$ & 58 & $\Rightarrow 64$ & $\Rightarrow 63$ \\
\hline Hillsborough Community College & $\Rightarrow 60$ & $\Rightarrow 60$ & $\$ 60$ & $\$ 65$ & $\Rightarrow 65$ & $\$ 66$ & $\Rightarrow 62$ & $\Rightarrow 61$ & $\Rightarrow 62$ & $\$ 63$ & $\Rightarrow 61$ & 561 & $\$ 62$ & $\Rightarrow 62$ \\
\hline Daytona State College & $\$ 61$ & $\sqrt{59}$ & $\sqrt{59}$ & 57 & $\$ 68$ & 69 & $\Rightarrow 62$ & $\sqrt{57}$ & 58 & $\$ 60$ & $\$ 60$ & $\$ 67$ & 363 & $\Rightarrow 62$ \\
\hline Florida State College at Jacksonville & $\$ 63$ & $\Rightarrow 61$ & $\sqrt{58}$ & $\Rightarrow 60$ & $\Rightarrow 61$ & $\Rightarrow 65$ & 59 & $\Rightarrow 62$ & $\sqrt{58}$ & $\Rightarrow 64$ & $\Rightarrow 61$ & $\Rightarrow 63$ & $\Rightarrow 64$ & $\Rightarrow 61$ \\
\hline Florida SouthWestern State College & $\sqrt{56}$ & $\$ 60$ & $\sqrt{56}$ & $\Rightarrow 61$ & $\sqrt{58}$ & $\$ 65$ & 58 & $\Rightarrow 61$ & $\sqrt{59}$ & $\$ 60$ & $\Rightarrow 60$ & $\$ 65$ & $\Rightarrow 66$ & $\Rightarrow 60$ \\
\hline Tallahassee Community College & $\$ 62$ & $\Rightarrow 61$ & 59 & $\rightrightarrows 64$ & 362 & $\Rightarrow 61$ & 56 & 56 & $\sqrt{56}$ & 59 & $\Rightarrow 60$ & 58 & $\$ 60$ & $\Rightarrow 60$ \\
\hline Miami Dade College & & & $\$ 62$ & $\$ 66$ & $\rightrightarrows 67$ & $\$ 67$ & 72 & $\Rightarrow 65$ & 69 & 72 & A 71 & 70 & $\rightrightarrows 64$ & 57 \\
\hline St Petersburg College & & & $\$ 67$ & $\$ 66$ & $\$ 66$ & ค 69 & 72 & 69 & $\$ 66$ & 567 & 69 & 564 & $\Rightarrow 67$ & 57 \\
\hline Florida Keys Community College & $\$ 61$ & $\sqrt{57}$ & 53 & $\$ 61$ & 564 & 56 & 55 & $\sqrt{50}$ & 50 & 58 & 55 & $\sqrt{57}$ & 56 & 56 \\
\hline Chipola College & & & $\$ 66$ & 69 & 70 & $\Rightarrow 64$ & $\Rightarrow 64$ & $\Rightarrow 64$ & $\Rightarrow 67$ & $\Rightarrow 61$ & $\Rightarrow 68$ & $\Rightarrow 64$ & 71 & 56 \\
\hline Northwest Florida State College & & & $\Rightarrow 62$ & $\$ 63$ & $\Rightarrow 67$ & $\Rightarrow 65$ & $\Rightarrow 61$ & $\sqrt{59}$ & $\sqrt{59}$ & $\Rightarrow 60$ & $\sqrt{58}$ & $\sqrt{53}$ & $\Rightarrow 62$ & 51 \\
\hline
\end{tabular}


In summary, the relationship between PBF and Retention rates is more visible when looking at the systems as a whole. Both systems, SUS and FCS, did show an increase in their total retention rates after the adoption of the PBF. When looking at individual institutions, none of the systems had sudden changes in patterns. Therefore, future research should explore this lack of reaction to PBF in term of the retention rates.

This section presented the data for FCS student success outcomes, including graduation rates trends, employment data, and retention rates. Next section will discuss the student to faculty ratio and institutional expenditures for the FCS, concluding with a comparison of both systems (SUS and FCS).

\section{Administrative Outcomes: Student to Faculty Ratio}

Since 2008, the student to faculty ratio for the FCS has fluctuated between 37 and 9, with higher frequency on rates between 19.8 and 25.21 as shown in the histogram below. The average student to faculty ratio was $22.48(\mathrm{M}=22.49, \mathrm{SE} 4.95)$ with a mode and median of 22.

\begin{tabular}{lr}
\hline \multicolumn{2}{c}{ Faculty-Stent Ratio } \\
\hline Mean & 22.49 \\
Standard Error & 0.31 \\
Median & 22 \\
Mode & 22 \\
Standard Deviation & 4.95 \\
Range & 28 \\
Minimum & 9 \\
Maximum & 37 \\
\hline
\end{tabular}

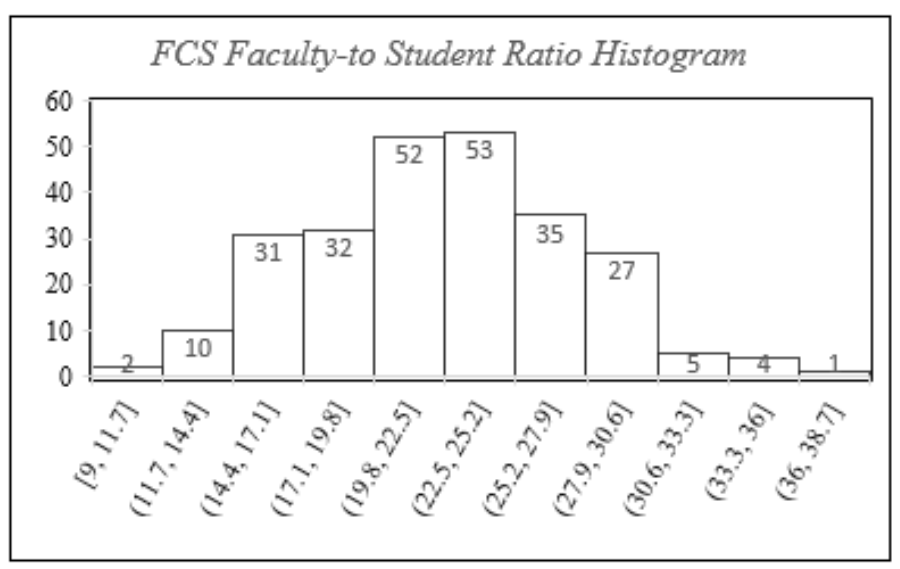

Figure 34: Descriptive Statistics for the FCS Student to Faculty Ratio from 2008 to 2016 
The trend for the FCS student to faculty ratio stabilized between 21 and 24 in 2009. Since 2012, the trend has indicated a small but constant decrease. The implementation of PBF for the FCS occurred in 2015. The trend for this particular variable shifted in 2013. At this time, the student to faculty ratio decrease continued until 2016. The decrease is also visible in the rate of change for this variable (figure 26). Future research could evaluate the reasons for such a pattern. Similarly, knowing this seems to be the standard pattern for this variable may aid in future studies looking into a deviation of the pattern and the reasoning behind it.

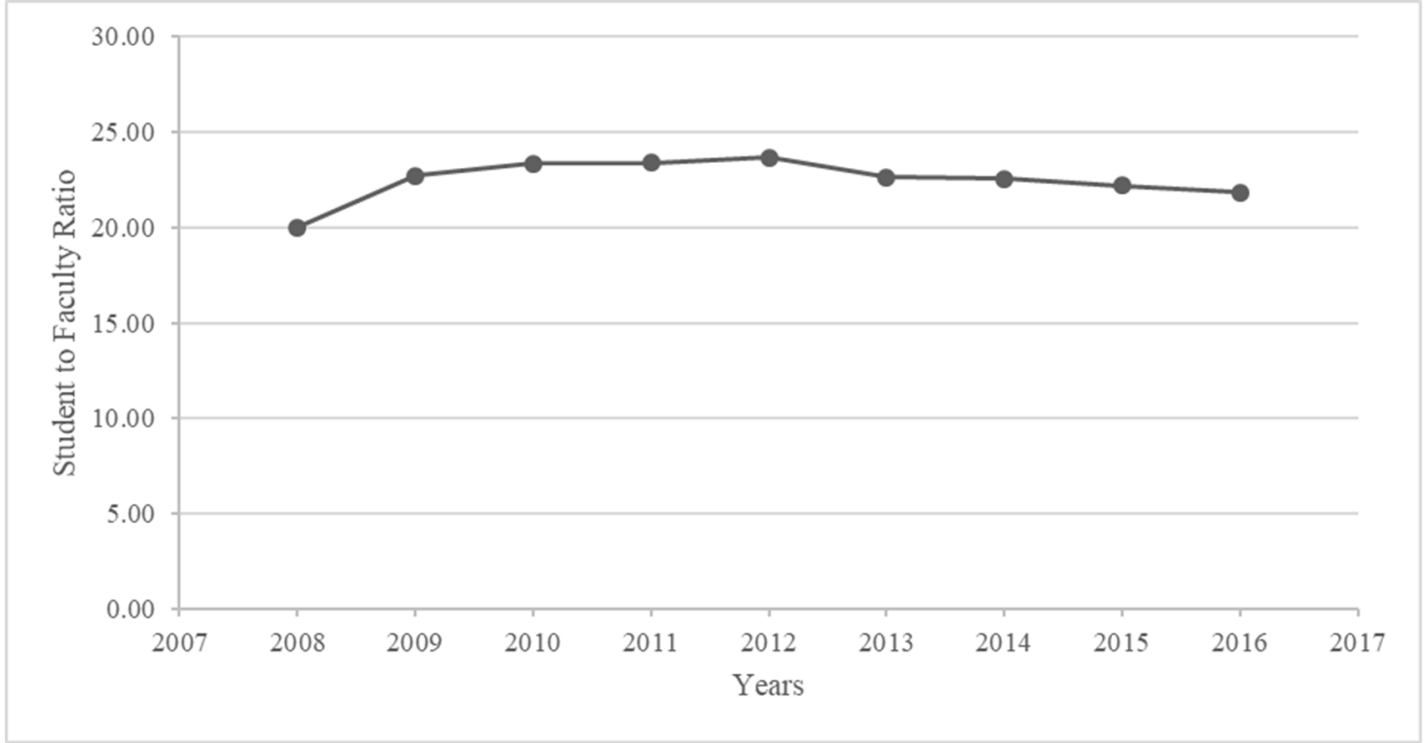

Figure 35. FCS Total Student to Faculty Ratio. 


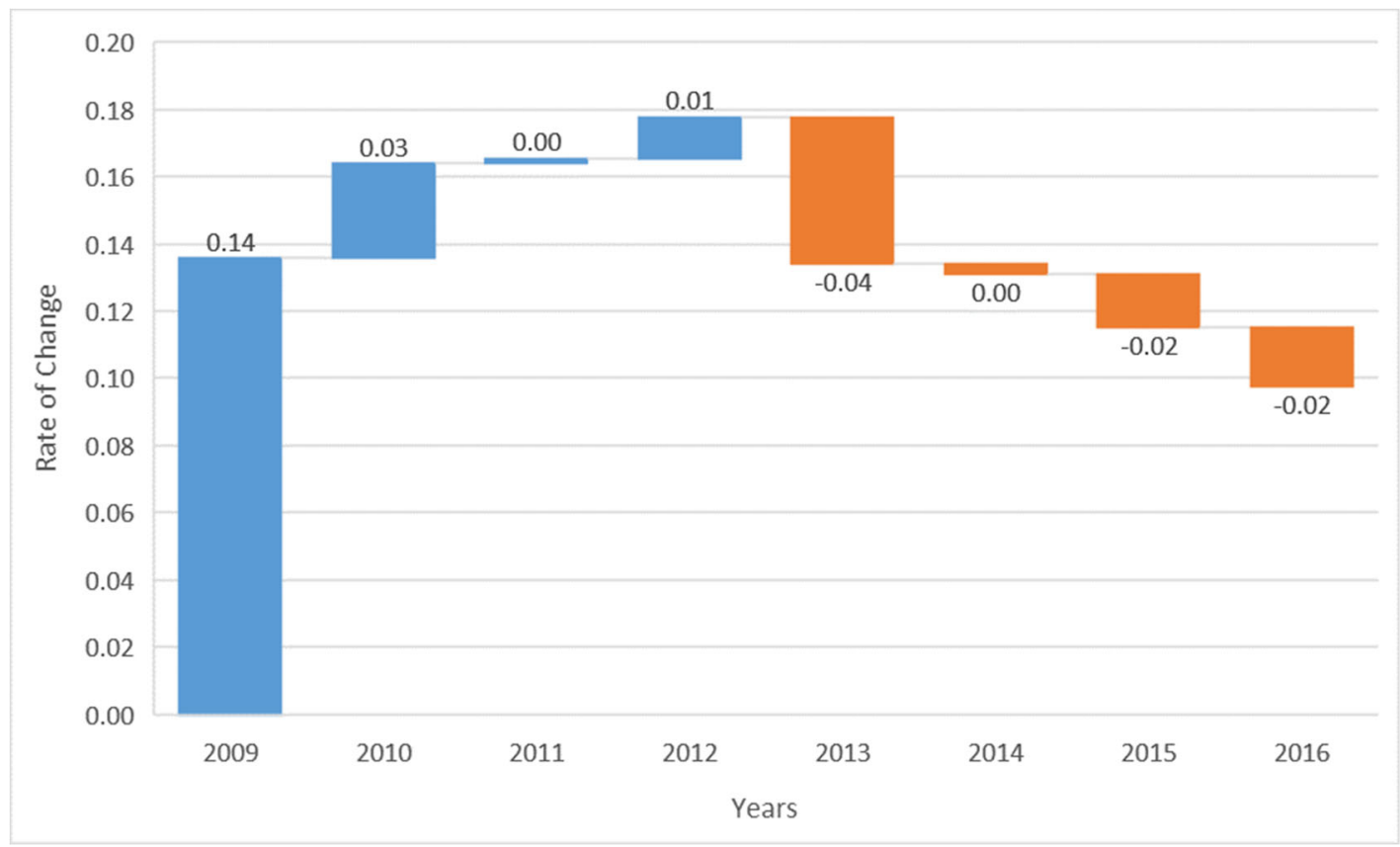

Figure 36: FCS Student to Faculty Ratio, Rate of Change

Figure 37 shows the student to faculty ratio trend for each institution in the FCS.

All institutions in the system seem to follow the same pattern, presenting ratios between 18 and 25. Nonetheless, a closer look indicates there are a few institutions that separate themselves from the rest. For example, South Florida State College and Florida Keys Community College performed in the 10 to 15 region for the eight years. These two institutions not only have a low student to faculty ratio but they kept it throughout the years.

However, Valencia Community College has a student to faculty ratio in the $30 \mathrm{~s}$. The institution kept this ratio for the eight years. Lastly, there are some out of the norm patterns. For example, Santa Fe College started with a 25 student to faculty ratio, increased to 30 in 2012, then decreased and stayed in the 20 regions for 2013 to 2016. Future research could evaluate the reasons for such patterns. 
The student to faculty ratio is a measure to evaluate how many students there could be per instructor in institutions. It implies that a small student to faculty ratio is a signal of a smaller teaching group and a higher quality of education. There is an effort to decrease this ratio. This pattern is visible in the change of percentage for the system as well as individual institution trends. Figure 37 shows how trends for this variable tend to conglomerate in the lower range after 2013. The tendency to decrease the student to faculty ratio is visible in the FCS and in the SUS. It seems the effort for smaller course sections is a statewide effort.

This section presented student outcome variables and their relationship with PBF. Some of those variables are also part of the metrics used in Florida's PBF programs (i.e., Graduation rate, and employment data). It also explored other administrative outcomes, such as the student to faculty ratio. Next section presents the last administrative outcome for the FCS, institutional expenditures and the changes in trends before and after the adoption of PBF in Florida. 
- Broward College

$\rightarrow$-Daytona State College

-Florida Keys Community College

-Gulf Coast State College

*-Lake-Sumter State College

- Northwest Florida State College

- -Pensacola State College

* Santa $\mathrm{Fe}$ College

-St Petersburg College

- Valencia College
-Chipola College

- Eastern Florida State College

_Florida SouthWestern State College

- Hillsborough Community College

- Miami Dade College

_Palm Beach State College

-Polk State College

- Seminole State College of Florida

S State College of Florida-Manatee-Saraso $\longleftarrow$ College of Central Florida

-Florida Gateway College

—Florida State College at Jacksonville

*Indian River State College

- North Florida Community College

$\_$Pasco-Hernando State College

$*$ Saint Johns River State College

+ South Florida State College

$\longrightarrow$ Tallahassee Community College

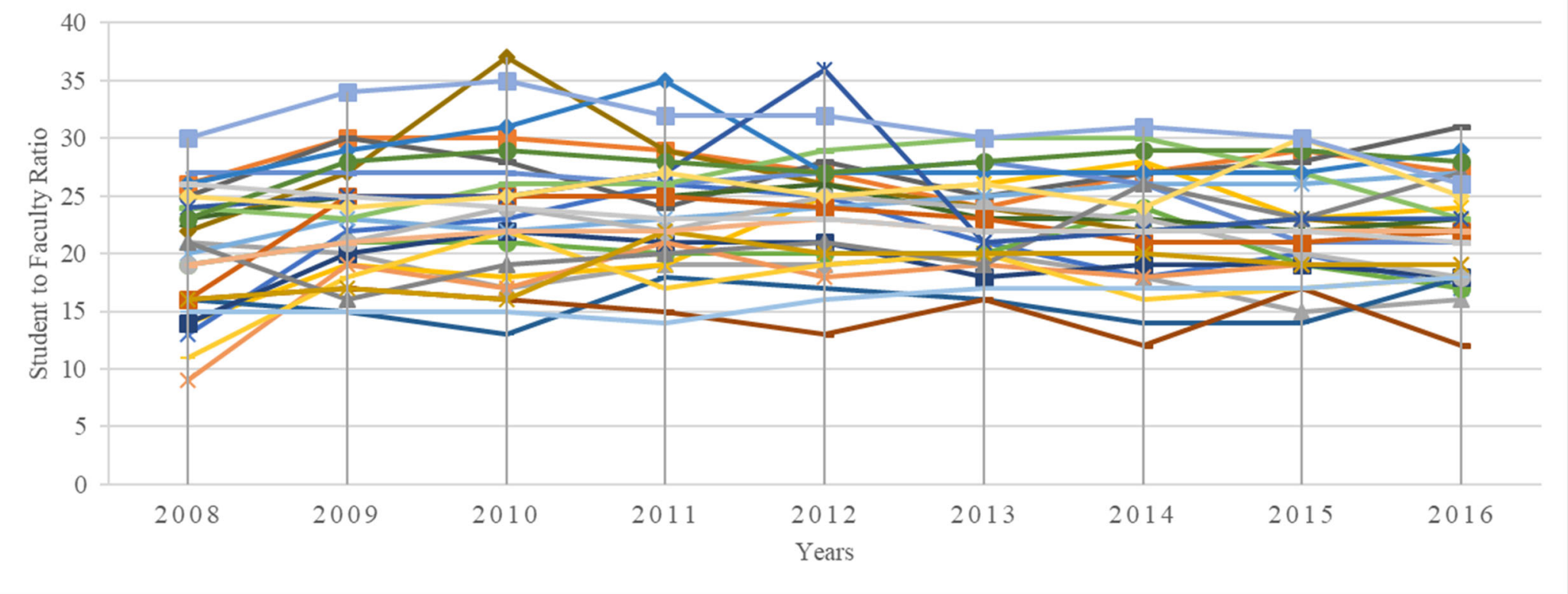

Figure 37. FCS Student to Faculty Ratio 


\section{Administrative Outcomes: Institutional Expenditures}

The FCS adopted PBF in 2015. Figure 38 shows an average for each of the seven expenditures from 2004 to 2016 in the FCS, instruction expenses, public service expenses, academic support, institutional support, other core expenses, and student services expenses. IPEDS provides this expense data per FTE (Full-time Equivalent). The FCS did not report research expenses, remaining at zero for 2004 to 2016. Public service expenses also remained at zero for most of the years except for 2006 when Valencia Community College reported an expense of $\$ 23.00$ per FTE for this category. For the other five categories, expenses ranged between $\$ 500$ and $\$ 2,000$ per FTE. Instruction expense is the only one between $\$ 2,500$ and $\$ 5,000$ per FTE for 2004 to 2016 .

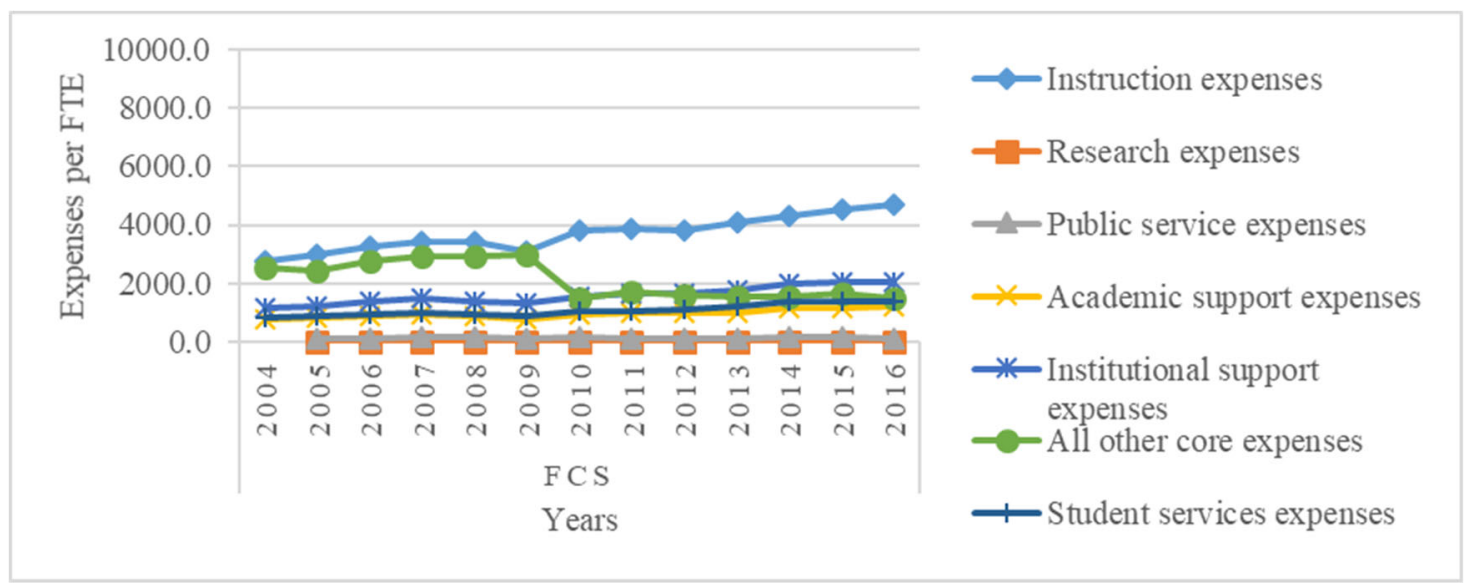

Figure 38: FCS Average Expenses per FTE 2004-2016

After implementation of BPF in 2015, academic, support, instruction expenses, institutional support, and student services increased for 2016 and all other core expenses decreased. The most noteworthy increase after implementation of PBF in 2015 was instruction expenses with a $10 \%$ increase, followed by institutional support with a seven percent increase, and academic support with a six percent increase. Instruction includes 
everything related to teaching, institutional support related to the day-to-day operations and academic support expenses dedicated to supporting the academic mission of the institution.

The most noteworthy decrease after implementation of PBF was in all other core expenses, with an $11 \%$ decrease. Table 9 shows the percentage change for all seven expenses from the FCS from 2005 to 2016.

Table 9. Change of Percentage FCS Expenses from 2005 to 2016

\begin{tabular}{|c|c|c|c|c|c|c|c|c|c|c|c|c|}
\hline & 2005 & 2006 & 2007 & 2008 & 2009 & 2010 & 2011 & 2012 & 2013 & 2014 & 2015 & 2016 \\
\hline Instruction expenses & $7 \%$ & $5 \%$ & $10 \%$ & $-12 \%$ & $-2 \%$ & $17 \%$ & $-1 \%$ & $2 \%$ & $10 \%$ & $4 \%$ & $-3 \%$ & $10 \% \leadsto$ \\
\hline \multicolumn{13}{|l|}{ Research expenses } \\
\hline Public service expenses & & & $-100 \%$ & & & & & & & & & \\
\hline Academic support expenses & $-7 \%$ & $8 \%$ & $-10 \%$ & $-10 \%$ & $-12 \%$ & $18 \%$ & $-1 \%$ & $-1 \%$ & $13 \%$ & $13 \%$ & $11 \%$ & $6 \% \wedge$ \\
\hline Institutional support expenses & $8 \%$ & $7 \%$ & $9 \%$ & $7 \%$ & $-3 \%$ & $-6 \%$ & $1 \%$ & $-3 \%$ & $24 \%$ & $0 \%$ & $-3 \%$ & $7 \%$ and \\
\hline All other core expenses & $21 \%$ & $-11 \%$ & $-4 \%$ & $15 \%$ & $5 \%$ & $-52 \%$ & $36 \%$ & $-5 \%$ & $-10 \%$ & $11 \%$ & $-14 \%$ & $-11 \%$ \\
\hline Student services expenses & $3 \%$ & $3 \%$ & $3 \%$ & $-2 \%$ & $-4 \%$ & $22 \%$ & $-1 \%$ & $5 \%$ & $10 \%$ & $13 \%$ & $1 \%$ & $2 \% \ldots$ \\
\hline
\end{tabular}

There is an important decrease in 2010 for all other core expenses. The change in percentage table shows 2010 was the year for the highest decrease in all other core expenses. In 2016 one year after the implementation of PBF for the FCS, there is an increase in all the expenses except in all other core expenses. In 2015 the FCS decreased expenses for instruction and institutional support, two areas that were increasing since 2011. Both areas then increased for 2016.

Finally, when going into each institution's trend for the expenses, they all follow a similar pattern when compared to the total FCS trend in figure 38. All the institutions present a higher trend for instruction expenses followed by institutional support expenses, with some exceptions. There is no definite change in trends after the adoption of PBF. All changes seem to be subtle. Further researchers should evaluate if the trend presented in these results holds true and whether PBF is a changing point in the trends. 
$\neg$ Instruction expenses

$\_$Public service expenses

*-Institutional support expenses

-Student services expenses $\rightarrow-$ Research expenses

$\rightarrow$ Academic support expenses

$\rightarrow$ All other core expenses

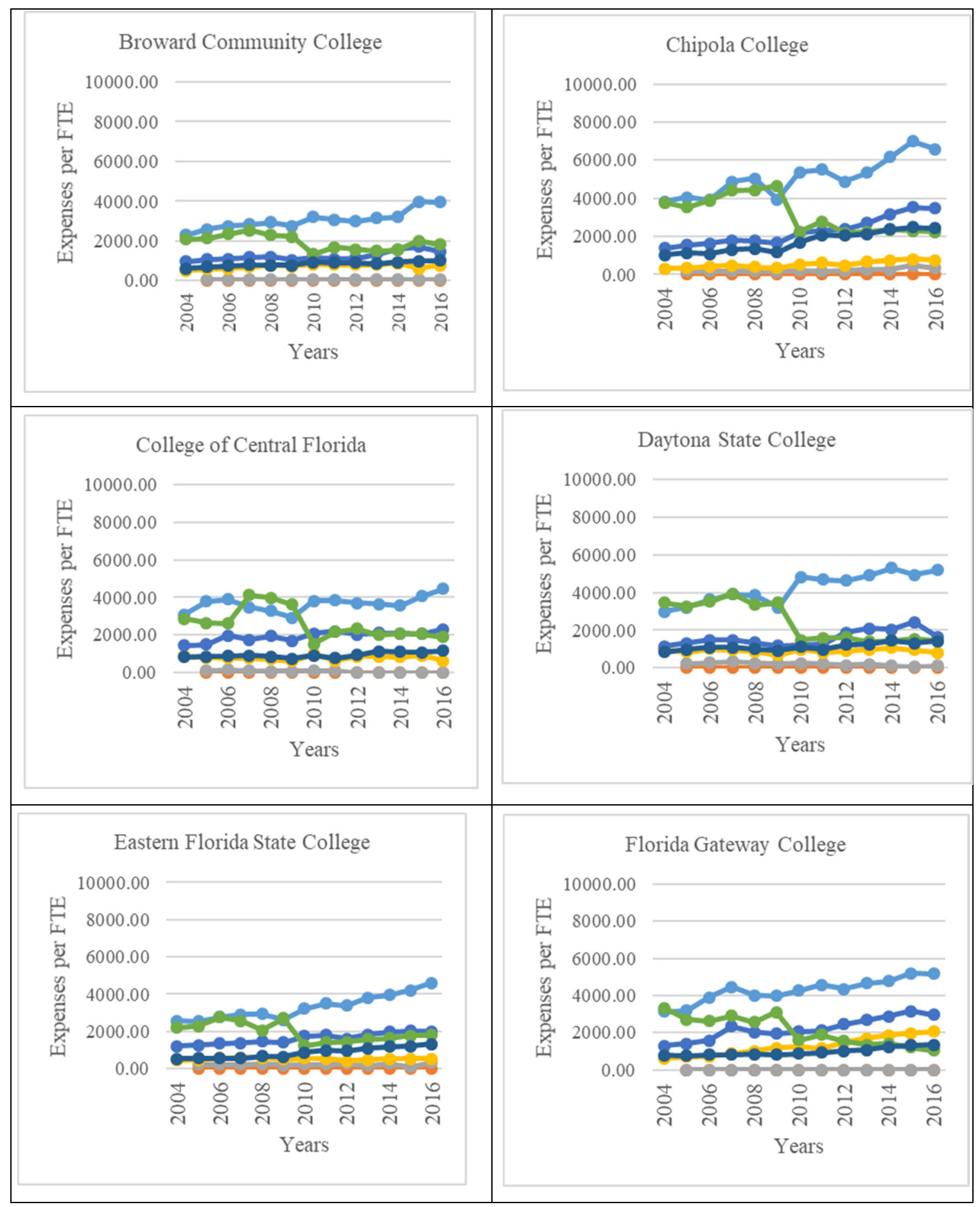




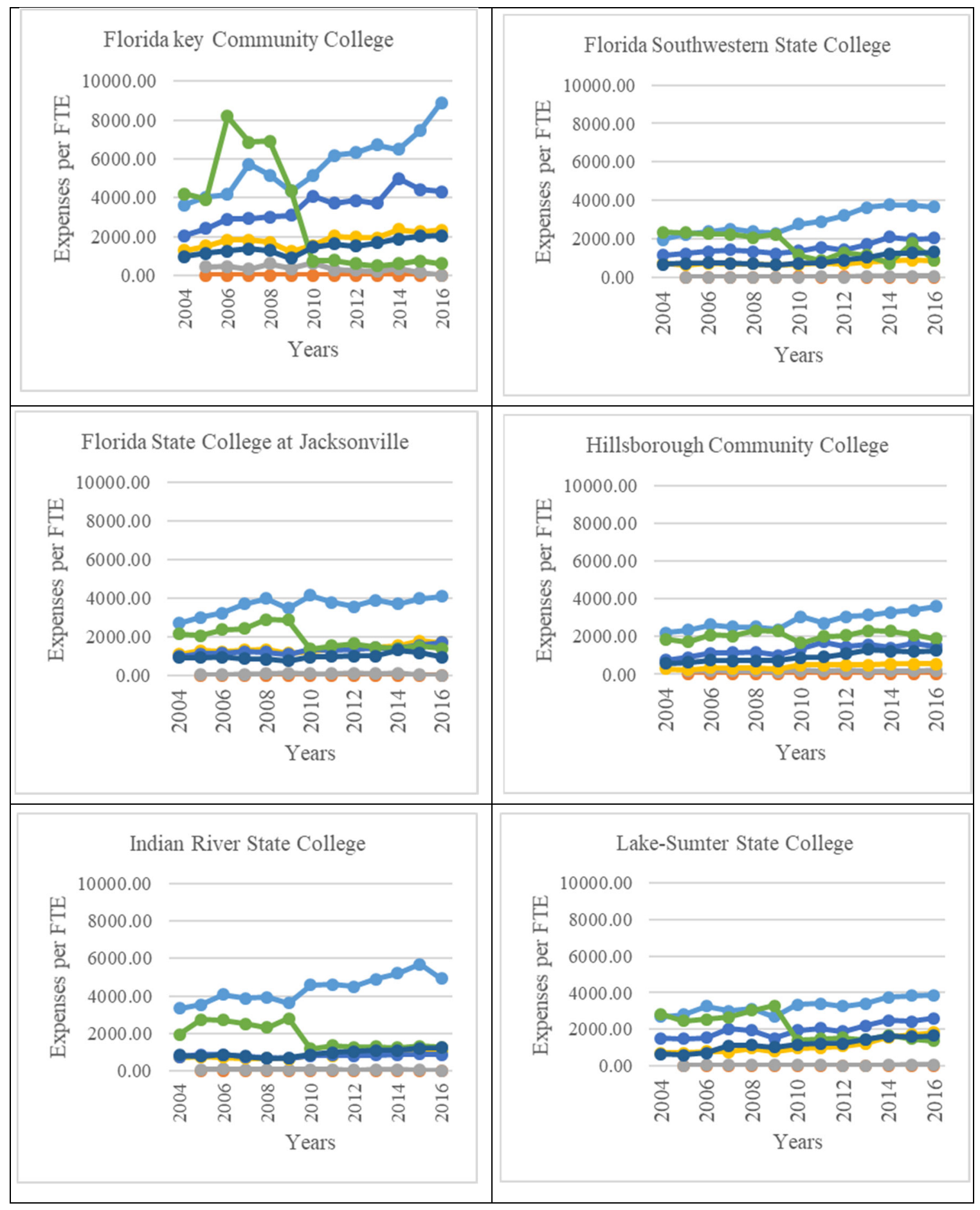




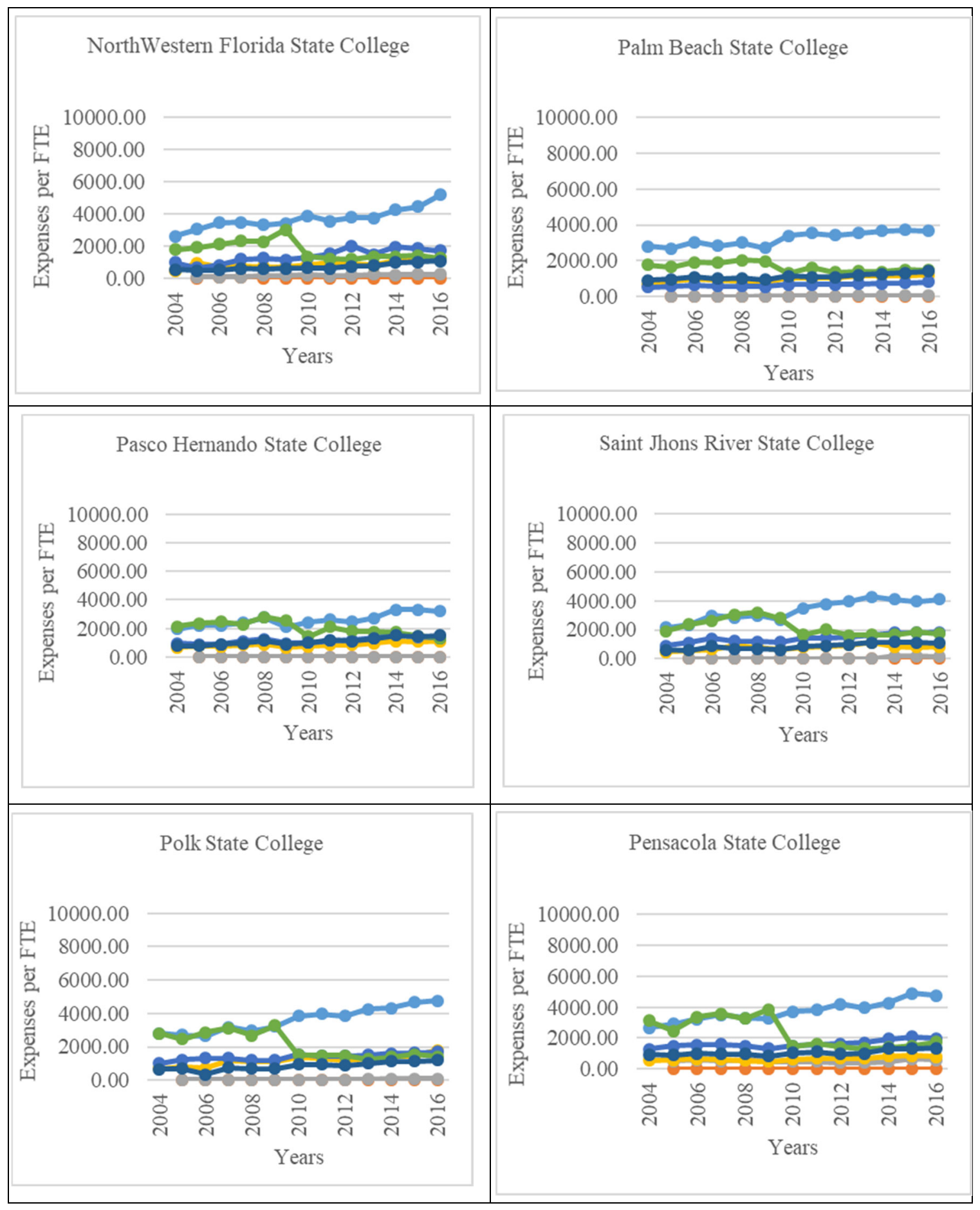




\begin{tabular}{|c|c|}
\hline Santa Fe College & Seminole State College of Florida \\
\hline 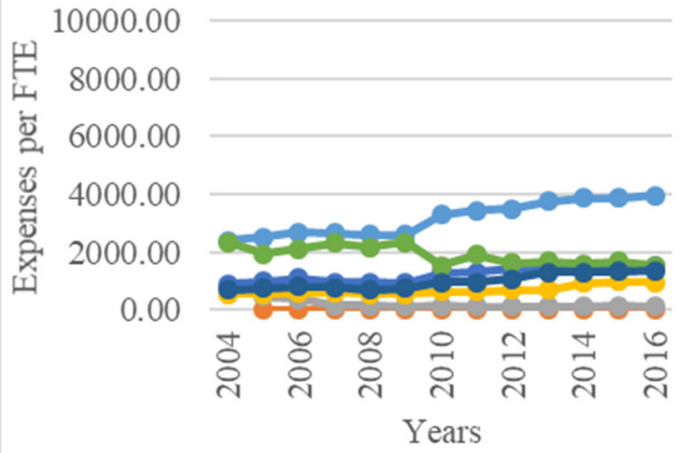 & 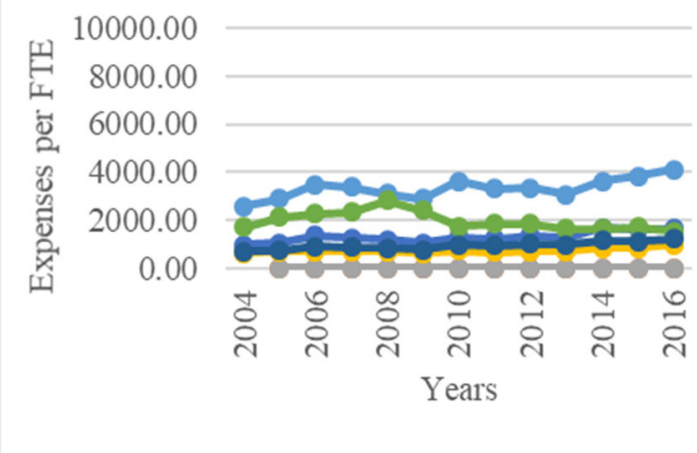 \\
\hline 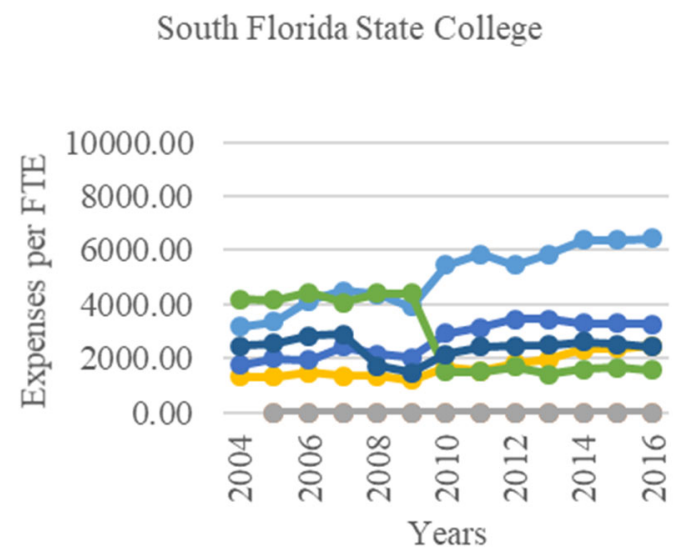 & 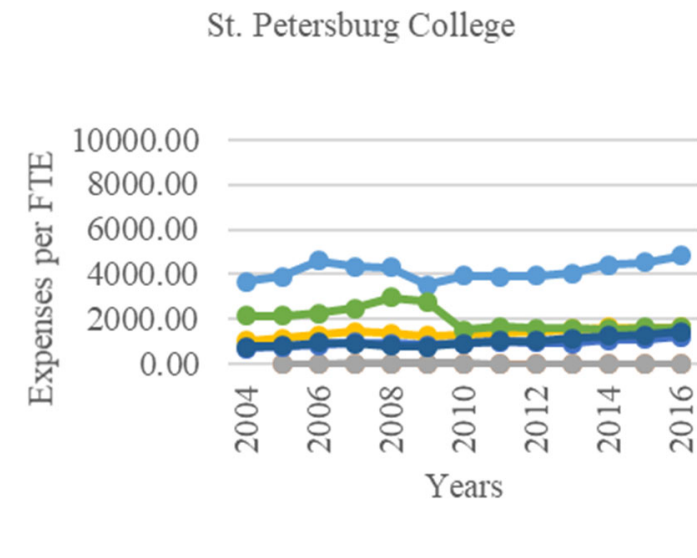 \\
\hline 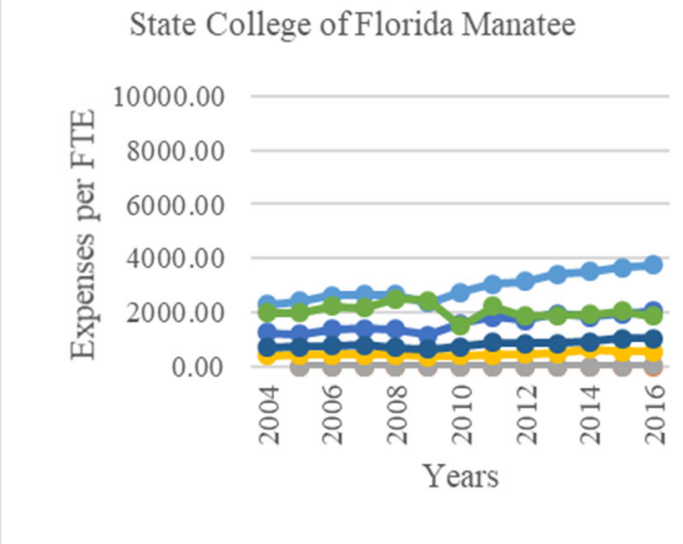 & 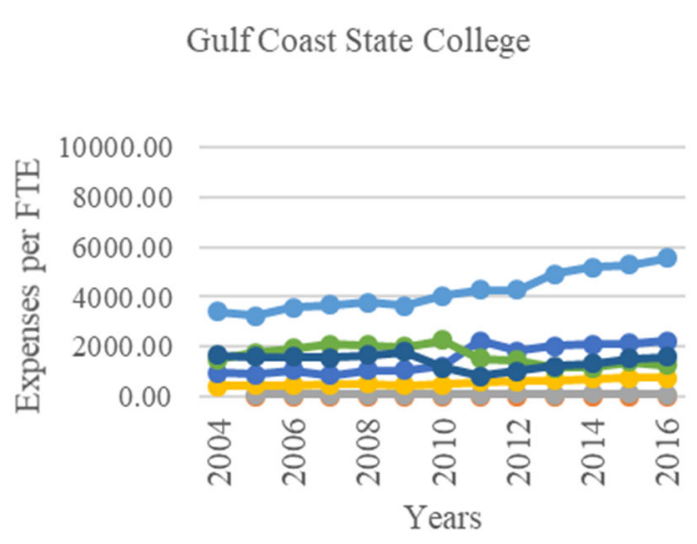 \\
\hline
\end{tabular}




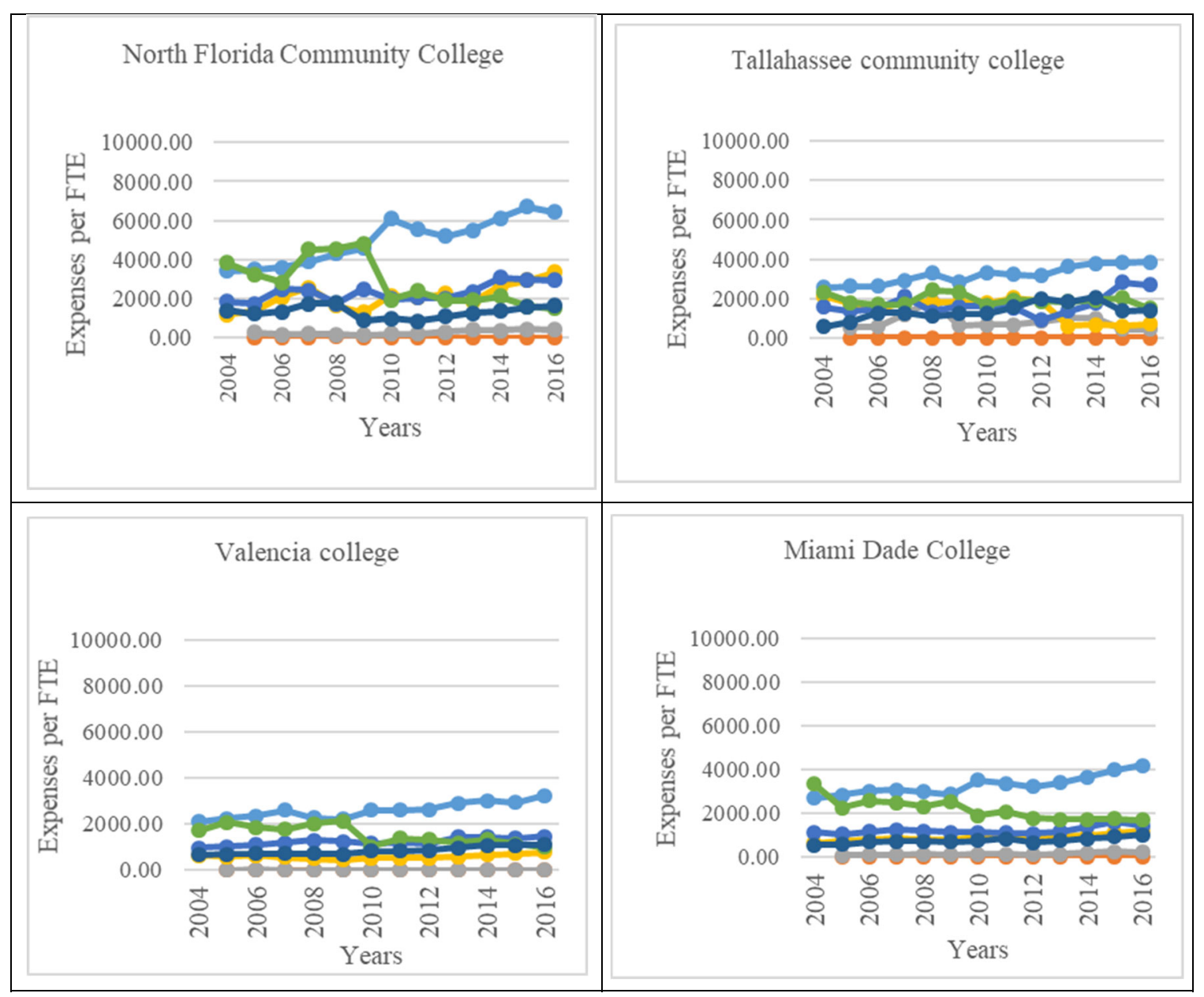

Figure 39: FCS Institutions Expenses 2004 - 2016

In the end, it seems both systems' most noteworthy expense is instructional. This type of expense includes "expenses of the colleges, schools, departments, and other instructional divisions of the institution" that involve instruction (NCES, 2018, p. 18). The relationship between PBF and SUS is very different from the relationship between PBF and FCS regarding expenses. While in the SUS the most prominent increase after the adoption of PBF was institutional support expense, for the FCS it was instruction expense. Future research could explore the differences between both systems and how they invest their funds per FTE. 
The data presented explored how PBF relates to both Florida public higher education systems concerning student outcomes (graduation rates, employment, and retention rates) and administrative outcomes such as student to faculty ratio and expenses. The next section explores some of the similarities and differences between both systems concerning the graduation rates, employment data, retention rate, student to faculty ratio, and institutional expenditures.

\section{SUS and FCS: A Comparison}

As previously explained, graduation rates for the FCS were between $33 \%$ and $35 \%$. Graduation rates for the SUS system were between $50 \%$ and $58 \%$. There is a difference between both systems, with the SUS holding a higher graduation rate. One interesting point in the data is the graduation rate for the FCS in 2013. In 2013, Florida was preparing for the implementation of PBF in the SUS; the increase in the graduation rate for the FCS was two percent for a total graduation rate of 38\%, the highest in the last 13 years. The graduation rate then stabilizes at $35 \%$ for 2015 and 2016. Researchers in the field of higher education field should evaluate if there was a connection between the adoption of the PBF program in the SUS and the increase in the FCS graduation rate for 2013.

The research about PBF and type of institution concentrates on graduation rates as an unfit performance outcome to evaluate two-year institutions. Zarkesh and Beas (2004) claimed that graduation rates do not reflect the value of community colleges, whose missions are different from four-year institutions. Considering the Zarkesh and Beas (2004) findings, it was expected to find different graduation rates trends for the two systems. Nevertheless, both systems had subtle increases in graduation after the 
implementation of PBF, even though both systems differ in their graduation rate range (SUS in the 50s, FCS in the 30s).

The SUS has a higher graduation rate than the FCS, but the FCS has a higher percentage of students employed than the SUS. The range for the FCS job placement or continuing education was between $88 \%$ and $95 \%$, which is higher than the range of employment or continuing education for the SUS (65\% to 72\%). Zarkesh and Beas (2004) explain that many of the students in two-year institutions are taking classes for reasons other than attaining a degree. One of those reasons could be professional development. By Zarkesh and Beas (2004) logic, students coming into the FCS already have jobs or want to acquire some education to get a job following graduation, which contributes to the higher job placement or continuing education.

The last student outcomes variable explored was retention. Authors such as Hillman, Tandberg, and Fryar (2015) argue that even when PBF has little to no effect on degree completion, it is possible that it has a positive effect on intermediate outcomes such as retention rates (Hillman, Tandberg \& Fryar, 2015). Authors such as Sanford and Hunter (2011) then contradict this argument. These researchers found that PBF policies had no impact on retention. The retention rates trends in this study seem to reflect more Sanford and Hunter's (2011) findings to a higher degree. Although both systems, the SUS and the FCS, increased their retention rate after the implementation of the PBF program, the increase was minimal. The retention rate trend after the implementation of the PBF program followed the trend before the implementation of PBF. In the case of the FCS, whose PBF program started in 2015, future researchers should keep evaluating FCS retention rates trends. The data in this study, although sufficient to establish a trend 
before and immediately after the implementation of PBF, does not include enough years to establish a final response to whether PBF in the FCS positively affects retention rates.

This research also looked at two administrative outcomes, student to faculty ratio, and institutional expenditures trends before and after the implementation of PBF for both systems. The student to faculty ratio is a measure to evaluate how many students there are per instructor in institutions. It implies that a small student to faculty ratio is a signal of a smaller teaching group and a higher quality of education. There seems to be an effort to decrease this ratio. The tendency to decrease the student to faculty ratio was visible in the FCS and the SUS. Both systems had a similar trend. It seems the effort for smaller course sections is a statewide effort.

Lastly, let us look at the institutional expenditure variables and the differences between the SUS trends and the FCS trends. Both systems' most noteworthy expense was the instructional throughout the 12 years of data. Nonetheless, the relationship between PBF and the SUS was very different from the relationship between PBF and the FCS regarding expenses. While in the SUS the most prominent increase after the adoption of PBF was institutional support expenses, for the FCS it was still instruction expenses. Researchers such as Ryan (2004) and Gansmeyer-Topf and Schul (2006) found evidence that instruction and academic support expenditures positively affect graduation rates and first-year retention. Future researchers should look at the instructional expenditure for both systems and its relationship with graduation and retention rates before and after the implementation of PBF. As it was mentioned, the most prominent expense for the SUS was institutional support, which could mean this system is focusing on student services after the implementation of PBF. The most prominent expense for the FCS was 
instruction expenses, which means that this system invested more in the teaching aspect after the implementation of PBF.

Future research could explore the differences between both systems and how they invest their funds per FTE, specifically the reasons for the change in trend in the SUS expenses while the FCS kept spending in the same category. This researcher can speculate that the PBF program at the FCS has not been in place long enough for the institution to have a change in the institutional expenditures trend. It is interesting that for the SUS the change in trend was immediately after the implementation of the PBF program, whereas for the FCS it seems it will take more time for changes to occur. The data presented explored how PBF relates to both Florida public higher education systems concerning student outcomes (graduation rates, employment, and retention rates) and administrative outcomes such as student to faculty ratio and expenses. The next chapter offers answers to both the research questions guiding this study and explores implications for practice. 


\section{CHAPTER V}

\section{SUMMARY OF THE STUDY}

Florida consists of two large public higher-education systems: the Florida College System (FCS) and the State University System (SUS). The State funds both systems through Performance-Based Funding (PBF). PBF funds higher education based on specific performance measures such as graduation and retention or progress rates. As Dougherty et al. (2014) explained, PBF "has become a politically attractive way of pursuing better college outcomes" (p. 1). It was established for the SUS in 2013 and FCS in 2015. PBF is controversial primarily because it uses a ranking system in which institutions compete for funding, and because there are questions about whether PBF improves outcomes such as graduation and retention rates (Zarkesh \& Beas, 2004; McKeown-Moak, 2013; Dougherty \& Reddy, 2011). Still, PBF has received significant support from many policymakers, policy groups at the state and federal level, such as the Lumina Foundation, the Complete College America, and the U.S. Department of Education, as a tool for determining progress towards completion and other quality goals (Dougherty, et al. 2016).

The goal of PBF ostensibly is to improve degree productivity to keep pace with changes in the labor market (Hillman, Tandberg \& Fryar, 2015). Some studies of PBF suggest that it has had "little to no effect on degree completion," (Hillman, Tandberg \& Fryar, 2015, p. 5). There is little research on whether PBF achieved changes in outcomes such as graduation rates (Bell, 2005; Dougherty \& Hong, 2006; Phillips, 2002). Some studies do suggest that PBF has had an immediate impact on institutions as changes in 
internal funding and greater awareness of state priorities, and an intermediate impact as greater use of data in institutional planning.

Sanford and Hunter (2011) explored the effect of PBF in Tennessee and found that PBF policies had no impact on retention or graduation rates. They claimed that PBF might be insufficient to provoke change in institutional performance and outcomes, arguing that the question remains, is performance funding a useful policy tool. Other studies also could not find that PBF produced a positive change in graduation rate or degree production, which is the primary goal of PBF (Fryar, 2011; Sanford \& Hunter, 2011; Shin, 2010; Volkwein \& Tandberg, 2008). This research puts into question whether PBF does what it is meant to do, that is, increase degree productivity to keep pace with changes in the labor market. Dougherty and Reddy (2011) suggest that the absence of findings that performance funding does produce significant improvements in student outcomes should not lead one to dismiss it but to keep researching it.

The purpose of this study was to explore the role of PBF in the two public highereducation systems in Florida. In order to understand the role of PBF in Florida, this study analyzed student success outcome variables over time. Specifically, this study attended to changes in graduation and retention rates, student employment data, student to faculty ratios, and institutional expenditures trends over 12 years. These variables are determinants of degree productivity for both the FCS and the SUS. Exploring changes in these outcomes helped us understand the role of PBF in the public higher education system in Florida.

Two main questions guided this study: 1) what is the role of Performance-Based Funding (PBF) in student success, specifically, as it attends to changes over time on 
graduation rates, retention rates, and student employment data before and after the implementation of PBF in Florida's public higher education systems? 2) What is the role of Performance-Based Funding (PBF) as it attends to changes over time on student to faculty ratio and institutional expenditures in Florida's public higher education systems?

To answer both research questions, this researcher conducted a comprehensive descriptive analysis of educational outcomes before and after the creation of PBF using data from IPEDS. The analysis was conducted to explore trends in student and institutional outcomes throughout the implementation of PBF programs in Florida. The analysis included FCS and SUS institutions participating in a PBF program.

\section{Research Question 1: Role of Performance-Based Funding (PBF) in Student}

\section{Success}

The first question guiding this research project had to do with student success outcomes, specifically graduation rates, retention rates, and employment data. For the graduation rate, most of the institutions in the SUS increased after the implementation of PBF in 2013. Twenty fourteen showed a higher rate of change for more institutions in the SUS than any other year. For employment or continuing education one year after graduation, the years with the highest employment rates were 2015 and 2016. Institution positioning within the group showed one institution that separated itself from the rest, New College of Florida. The year with the highest rate of change was 2015.

Retention rates trends for each of the institutions in the SUS had similar patterns; the rate of change fluctuated between negative one percent and one percent for the 12 years. The retention rate trend for UF positioned this institution above the other 10 with a 
graduation rate ranging in the $90 \mathrm{~s}$. Institution positioning changed after the implementation of PBF; four institutions had joined the top third group after 2013.

The FCS graduation rates increased in 2013 from 35 to 38 percent. This increase was the highest in the twelve years. PBF implementation for this system was not until 2015. In 2013, Florida was preparing for implementation of PBF in SUS. The increase in the graduation rate for FCS was $2 \%$ for a total graduation rate of $38 \%$, the highest in the last 12 years. Future research can explore if the adoption of PBF for the SUS in 2013, was related to such increase.

FCS Job Placement or continuing education variable showed the 2015 cohort of graduate students a point of interest. All the institutions within the system decreased performance for this cohort. Researchers should explore FCS Job Placement or continuing education rates concerning PBF adoption. Further, retention rates for the FCS increased after the implementation of PBF in 2015. This increase seems to be true for all the institutions within the FCS except for Daytona State College, Florida Keys Community College, and Miami Dade College.

Looking at the graduation rates, employment rate, and retention rate, this researcher concludes that PBF seems to have a positive influence on student success outcomes. Graduation rates, retention rates, and employment all increased after the implementation of PBF. The increases were small and did not differ from the three variables trends before the implementation of PBF. At this point, the data in this study agrees with Bell (2005), Dougherty and Hong (2006), Dougherty and Reddy (2013), Phillips (2002), and Shin's (2010) findings. These authors agreed with the positive effect of PBF on graduation rates, while at the same time, all of them asked for caution when 
claiming the increase in degrees or graduation rates is due to the implementation of PBF. Hillman, Tandberg, and Fryar (2015) suggest that even when PBF may have little to no effect on degree completion, it is possible that it has a positive effect on intermediate outcomes such as student retention. The data show that the role of PBF on retention rates is minimal as the increases after the implementation of PBF were small. When more data becomes available, it will be possible to see if these initial findings hold through time.

\section{Research Question 2: Role of Performance-Based Funding (PBF) in}

\section{Administrative Outcomes}

As previously explained, the student to faculty ratio is a measure to evaluate how many students could be per instructor in the institutions. It implies that a small student to faculty ratio is a signal of smaller teaching groups and a higher quality of education.

There seems to be an effort to decrease this measure since 2013. The SUS, as well as the FCS, had similar trends for this variable. The pattern is visible in the change of percentage for the systems as well as individual institution trends. Both systems decreased their student to faculty ratio. The decrease in student to faculty ratio coincides with the adoption of PBF for the SUS in 2013 but not with the adoption of PBF for FCS in 2015. Authors such as Bound, Lovenheim, and Turner (2010) found that the shift in preparation of students and the increases in college student to faculty ratios "accounted for about one-quarter of the observed completion rate decline" (Bound, Lovenheim \& Turner, 2010, p.2). Perhaps the declining trend in the student to faculty ratio relates to a possible increase in completion rates. Future research could explore the relationship between this student to faculty ratio and degree completion in Florida. 
Last studied was the role of PBF on Florida's public higher education systems institutional expenditures. When looking at the institutional expenditure for both systems, instruction expense is the category with the highest investment per FTE for both systems. This finding indicates the importance of instruction in higher education. Two thousand and ten presents the highest increase in instruction expenses in the 12 years. Two thousand and ten is also the year that all other core expenses decreased drastically for the SUS (-53\%). All other core expenses include expenses not reported in the other six institutional expenditures categories; a sudden decrease in this area with a sudden increase in instruction expenses may indicate a shift in how the SUS expends funds. This shift is also visible for the FCS with an increase of $17 \%$ in instruction in 2010 while having a decrease of $52 \%$ in all other expenses. Further research should look into the reasons for these changes in expenses from other expenses to instructional expenses.

A second pattern visible for the SUS in the institutional expenditures is the increase in institutional support in 2014, a year after PBF implementation, whereas the FCS increased by $10 \%$ instruction expenses in 2016, a year after PBF implementation. In 2016, all the expenses increased for the FCS except for all core expense, which decreased.

In Summary, the data presented support what the literature about PBF has found. Changes in the graduation rates seem slow and small, while retention rates seem to be unaffected by the implementation of PBF. Dougherty and Hong (2006), Phillips (2002), Bell (2005) and Shin (2010) all agree with the positive effect of PBF on graduation rates, while asking for caution when claiming the effect on graduation rates are due to PBF. Tandberg and Hillman (2014) questioned if PBF has a delayed effect on graduation rates. 
In their study, they found that PBF started to affect graduation rates seven years after implementation. Future research in Florida may explore the impact of the policy and evaluate if Tandberg and Hillman's (2014) findings are replicated.

On retention rates and PBF, the work of Hillman, Tanberg, and Fryar (2015), Stanford and Hunter (2012) and Rutherford and Rabovsky (2014) supports our findings. These authors found no effect of PBF on retention rates. Although these studies were done with PBF 1.0, which involved less state funding than PBF 2.0, it is interesting to find that the initial role of the policy in both of these student outcomes appears to follow a similar pattern to the effect of PBF 1.0. Future studies may help understand if indeed this is a case of delayed effect or if PBF 2.0 in Florida does not have an effect on these student outcomes.

Employment data shows a constant increase for the SUS, while for the FCS it decreases for the 2015 cohort. As mentioned in chapter two, the research about employment data and PBF is minimal. Much of the published work focuses on unemployment rates as a control variable and its relation to graduation rates (Hillman et al., 2015; Hillman Tandberg \& Gross, 2014; Rutherford \& Rabovsky, 2014; Sanford \& hunter, 2011; Sin, 2010). The employment data in this dissertation show an increase in the SUS. Shin and Milton (2004) explain that low graduation rates are related to a high unemployment rate. Perhaps the slight increase in graduation rate is related to the increase in the employment rate in Florida. The increase found on the employment data also coincides with the Bureau of Labor and Statistics which shows employment rates increasing from 2010 to 2018 (https://data.bls.gov/pdq/SurveyOutputServlet). Future 
research may explore the connection between graduation rates and employment rates as well as the reasons for the decrease in employment rates in 2015 for the FCS.

Student to faculty ratio decrease patterns seem to be unaffected by the adoption of PBF. Bound, Lovenheim, and Turner (2010) explored college completion declines in 2010 and found an increase in student to faculty ratios in sectors experiencing declining completion rates. Our finding is aligned with Lovenheim, and Turner's (2010) study. Graduation rates slightly increase while student to faculty ratios keep decreasing for both systems (SUS, FCS).

Institutional expenses seem to shift to instruction (for FCS), and institutional support (for SUS), two of the expenses that relate to increasing graduation rates. Data for the FCS agrees with Robovsky's (2012) work, who found evidence that institutions with PBF dedicate a higher percentage of their institutional expenditures to instruction. Despite expenditures for the SUS' shift to institutional support, their instructional expenditure did not increase; instead, they shifted from other expenditures to institutional support. Future researchers should consider all these patterns when further exploring the effect of PBF in Florida. The next section presents some of the implications for these findings.

\section{Implications and Recommendations for Practice, Policy, and Research}

The goal of PBF was motivating institutions to graduate more students. Even when the results of this investigation cannot evaluate the impact of PBF in Florida's public higher education system, it did look at the role of PBF in Florida's public higher education systems. Considering the results, graduation rates, retention rates, and employment increased after the implementation of PBF. The increases are in some cases minimal, and subtle and it is not clear if they have anything to do with PBF; that been 
said, public higher education institutions are moving toward improving their student outcome metrics as discussed in this research. This tendency was present before the implementation of PBF.

When looking at the relationship between PBF and the system from the institution perspective, not all of the institutions increased their student success outcomes after the implementation of PBF. This finding is especially concerning because if the funding designated to each institution is based on their performance, such institutions with decreases in the student outcomes would be receiving less funding from the state. Hillman and Corral (2017) explain that fewer resources from the state may result in institutions increasing their student to faculty ratio, limiting student and academic support services, or increasing tuition. Any of these outcomes would make it more difficult for the institution to improve retention and degree completion. Consequently, it would result in additional funding cuts. These outcomes, if left uncorrected, may generate unintended consequences, worsening the condition of higher education.

Future research should explore the impact of PBF on such institutions with decreases in student outcome after the adoption of PBF. For example, FAMU was one of those institutions that decreased graduation rates after the implementation of PBF. Four of the ten metrics used in the PBF program for the SUS include graduation rates or a form of graduation rate. If the trends in this research are any indication of how FAMU is performing in graduation rates PBF related outcomes, then it is of great importance to explore the case of such institutions. The goal of PBF is to improve graduation. As higher education professionals, we should evaluate if policies such as PBF are detrimental to some institutions and therefore a cause of educational inequality. 
Another interesting finding was the shift in institutional expenditures. Even when this is not a direct measure of any of the PBF programs in Florida, clearly each system is spending more dollars in those areas they believe could help them improve graduation rates. The SUS invested more in institutional support after PBF. Institutional support refers to "expenses for the day-to-day operational support of the institution. It includes expenses for general administrative services, central executive-level activities concerned with management and long-range planning, legal and fiscal operations, space management, employee personnel and records, logistical services such as purchasing and printing, and public relations and development. Also, it includes information technology expenses related to institutional support activities" (NCES, 2018, p. 3). The SUS is then investing in administrative areas and planning. This increased investment in the administrative outcomes of the institution is what Dougherty et al. (2016) classified as an unintended consequence of PBF. Specifically, they called it compliance cost. In their research, they found institutions having to invest in expanding their capacity to track students, including the cost of software, personnel, and expansion of Institutional Research departments, among other administrative functions needed to gather and disseminate data. Future research should evaluate the increase in institutional support expenditures and the differences between both system's compliance costs.

The FCS invested more in instruction. Based on IPEDS (2018), Instruction refers to "a functional expense category that includes expenses of the colleges, schools, departments, and other instructional divisions of the institution and expenses for departmental research and public service that are not separately budgeted" (p.18). This type of expense excludes expenses for academic administration where the primary 
function is administration (e.g., academic deans). It is clear the FCS has chosen to focus on the teaching and the programs offered to students and not on academic administration. Future research should explore the reasons behind these differences and whether the institutional expenditures in those areas are a response to the implementation of PBF and its role in Florida's higher education systems as a strategy to increase graduation rates or degree completion.

\section{Limitations and Areas for Future Research}

As with any study using public data sets such IPEDS, there were some limitations in this study. First, IPEDS provided aggregated data for each institution in the system, but it did not provide individual student data. Thus, only how PBF affected public higher education institutions in Florida could be explored, not how individual students could be affected. Future research should explore how PBF affects the student. Another significant limitation of using IPEDS is that the database provides outcome data on a limited subset of students.

Most importantly, the graduation rates data only included cohorts of first-time, full-time students. Although this is a significant limitation to keep in mind, it is important to note that student success measures in PBF programs are mostly limited to that specific subset of students, that is, first-time, full-time students. Future research should explore how PBF affects different groups of students such as transfer students, part-time students, and perhaps non-traditional students.

Another limitation of this study was that both PBF programs in Florida have not been in place long enough to fully evaluate their impact, which would require more years of data. It was not the purpose of this study to address causality or the political 
implications of the policy in Florida. However, it explored only changes over time in the two public higher education systems to provide the groundwork for future impact studies of Florida. In the future, researchers could use this dissertation as their initial step in studying the impact of PBF in Florida and the political implications of it.

\section{Conclusion}

The purpose of this research was to explore the role of PBF in Florida's public higher education system. Although PBF did not affect some of the variables studied, some of the analyzed trends seem to correspond with the implementation of PBF. As the literature indicated, the influence of PBF on variables such as graduation rates and retention rates seems to take some time to present itself fully. While conducting the research, some slight increases were visible, but only time will tell if those will sustain or change over time. The other aspect evaluated was the student to faculty ratio. This variable seems to decrease with time, and this was a stable trend for both systems, the SUS, and the FCS. Since this is a metric used as an indicator of quality in higher education (i.e., US World and News report) before the implementation of PBF, it is expected that institutions will work on decreasing these rates. What was not expected was the trend on the institutional expenditures' variables.

Dougherty et al.'s (2016) research revealed that one of the unintended consequence of PBF was the compliance cost. Compliance cost refers to the "expenses of building IR capacity, extra work resulting from the need to more closely track student progress, and less attention to instruction" (p.188). Although it is not clear if the increase in institutional support after PBF in the SUS relates to "less attention to instruction," it is a concern that it has increased by more than $40 \%$ after the implementation of PBF, 
primarily, because this was not replicable for the FCS. Such finding, at first sight, speaks to an effort to better track data and information but does not speak to an effort to prepare students. It is unclear if this increase has to do with financing programs to help the students graduate or if it is an effort to improve the collection of student data.

The literature on PBF focuses on exploring the impact of PBF on graduation rates. There is no literature on the role of PBF on institutional expenditures, much less how this relationship differs by type of institution. However, there is some research on institutional expenditures in higher education. Astin (1993) argued that student service expenditures have a robust positive effect on student retention. Ryan (2004) found evidence that instruction and academic support expenditures positively affect graduation rates, which confirms Astin's findings. Gansmeyer-Topf and Schul (2006) found a direct relationship between institutional expenditures, retention and graduation rates, indicating that instructional expenditure may contribute to first-year retention and six-year graduation rates. Webber and Ehrenberg (2010) found student service expenditures to influence graduation and persistence rates positively. Exploring the changes over time in institutional expenditures could help understand the role of PBF in higher education institutions more deeply. It is time that researchers in higher education shift their focus from how PBF affects the graduation rate to how it affects institutional expenditures and other aspects in higher education.

Instead of waiting to see whether graduation rates will increase, researchers should explore how institutions are embracing PBF by looking at how they are expending their funding after its implementation, what they expect to improve by shifting their institutional expenditures, and how do they think these shifts in institutional expenditures 
contribute to higher graduation rates and better-prepared students. Researching institutional expenditures may give us useful information on how PBF is influencing higher education and if indeed this new PBF is shifting institutions to graduate better prepared students.

This research was the first study focusing on the role of PBF in Florida's higher education systems. This work expands the limited body of research about PBF and lays down the initial steps in understanding PBF. Researchers should be asking questions such as why some of the institutions regularly score towards the bottom, and how the institution reacts to PBF regarding program creation to improve higher education quality. Studying changes in trends and positioning of the institution, and conducting a comprehensive descriptive study was the initial step in a series of studies that should be conducted about PBF in Florida. Fully understanding how PBF affects the system, each institution within the system, and how it can be used to serve students should be a priority. 


\section{REFERENCES}

AASCU [American Association of State Colleges and Universities]. (2012, January). Top 10 higher education state policy issues for 2012. Policy Matters, pp. 1-6.

Abet, J.R., Deitz, R. \& Su, Y. (2014) Are recent college graduates finding good jobs? Current issues in economics and finance, 20(1), 1-8.

Akey, L. D. (2012). Institutional accountability and competition for resources in undergraduate education among U.S. public four-year institutions (Doctoral dissertation). Retrieved from ProQuest Dissertations and Theses databased. (UMI No. 3494636)

Atkinson, R.C. \& Geiser, S. (2009). Reflections on a century of college admissions tests. Research \& Occasional Paper Series: Center for Studies in Higher Education (CSHE.4.09).

Alexander, F. K. (2000). The changing face of accountability: Monitoring and assessing institutional performance in higher education. Journal of Higher Education, 71, 411-431. Retrieved from http://eds.a.ebscohost.com.ezproxy.fiu.edu/ehost/pdfviewer/pdfviewer?sid=08f09 caf-a6dd-4228-b8e95c7a2b4c1003\%40sessionmgr4002\&vid=2\&hid=4111

Alfonso, M. (2006). The impact of community college attendance on baccalaureate attainment. Research in Higher Education, 47, 873-903. doi: 10.1007/s11162006-9019-2

Astin, A. W. (1984). Student involvement: A developmental theory for higher education. Journal of College Student Personnel, 25, 297-308.

Astin, A. (1993). What matters in college: Four critical years revisited. San Francisco, CA: Jossey-Bass.

Bailey, T., \& Xu, D. (2012). Input adjusted graduation rates and college accountability: What is known from twenty years of research? New York: HCM Strategists and Community College Research Center, Teachers College, Columbia University. Retrieved from http://www.hcmstrategists.com/contextforsuccess/papers/LIT_REVIEW.pdf

Barnetson, B., \& Cutright, M. (2000). Performance indicators as conceptual technologies. HigherEducation, 40, 277-292. doi:10.1023/A:1004066415147

Becker, G. (1992, December 9). The Economic way of looking at life, Nobel lecture. Chicago, IL. 38-58. 
Belfield, C. R., and Thomas, H. R. (2000). The relationship between resources and performance in further education colleges. Oxford Review of Education 26: 239253.

Bogue, E. G. \& Jonson, B.D. (2010). Performance incentives and public college accountability in the United States a quarter century policy audit. Higher Education Management and Policy, 22(2), 9-30. doi:10.1787/hemp-22$5 \mathrm{kmbjh} 05 \mathrm{fxd} 3$

Borden, V. M. H. (2011). Suggestions for Improvements to the Student-to-Faculty Ratio in IPEDS. U.S. Department of Education. Washington, DC: National Postsecondary Education Cooperative. Retrieved [date] from http://nces.ed.gov/npec

Bound, J., Lovenheim, M. F., \& Turner, S. (2010). Why Have College Completion Rates Declined? An Analysis of Changing Student Preparation and Collegiate Resources. American economic journal. Applied economics, 2(3), 129-157.

Burke, J. C., \& Minassians, H. P., (2004). Implications of state performance indicators for community college assessment. New Directions for Community Colleges, 2004(126), 53-64. doi: 10.1002/cc.154

Burke, J., \& Modarresi, S. (2001). Performance funding programs: Assessing their stability. Research in Higher Education, 42(1), 51-70. doi:10.1023/A:1018764511093

Bowles, S., \& Gintis, H. (1976). Schooling in capitalist America: Educational reform and the contradictions of economic life. New York: Basic Books.

Cabrera, A., \& Nora, A. (1994). College students' perception of prejudice and discrimination and their feelings of alienation: A construct validation approach. The Review of EducationPedagogy, 16, 387-409. doi:10.1080/1071441940160310

Christopher, M. T. (2010). Performance indicators, accountability, and quality: An analysis of key indicators at two Georgia postsecondary institutions (Doctoral dissertation). Retrieved from ProQuest Dissertations and Theses databased. (UMI No. 3409256)

Contreras, F. \& Contreras, G. J. (2015). Raising the bar for Hispanic serving institutions: An analysis of college completion and success rates. Journal of Hispanic Higher Education, 14, 151-170. doi: 10.11.77/1538192715572892 
De Witt, H. (2002). Internationalization of higher education in the United States of America and Europe: A historical, comparative, and conceptual analysis. Westport, Connecticut: Greenwood Press.

Dougherty, K., Natow, R., Bork, R., Jones, S., \&Vega, B. (2013). Accounting for higher education accountability: Political origins of state performance funding for higher education. Teachers College Record 115, 1-50. Retrieved from http://www.tcrecord.org/library

Dougherty, K., \& Reddy, V. (2011). The impacts of state performance funding systems on higher education institutions: Research literature and policy recommendations. New York, NY: Columbia University.

Dougherty, K., \& Reddy, V. (Eds.). (2013). Performance Funding for Higher Education: What Are the Mechanisms? What Are the Impacts?. San Francisco, California: Jossey-Bass.

Dougherty, K., Jones, S., Lahr, H., Natow, R., Pheatt, L., \& Reddy, V (2014). Performance funding for higher education: Forms, origins, impacts, and futures. The annals of the American Academy of Political and Social Science 655, 163184. doi: $10.1177 / 0002716214541042$

Ellis, R. (2015). Performance-Based Funding: Equity Analysis of Funding Distribution among State Universities. Journal of Educational Issues, 1(2), 1-19. doi:10.5296/jei.v1i2.7412

Florida Department of Education. (2015). Florida college system performance funding overview - draft for consideration by the state board of education. Tallahassee, FL: Author. Retrieved: https://www.floridacollegesystem.com/sites/www/Uploads/files/Performance\%20 Funding/DFC_PerformanceFundingOverview_FINAL.pdf)

Frolich, N. (2011). Multi-layered accountability: Performance-based funding of universities. Public administration, 89(3), 840-859. doi: 10.1111/j.14679299.2010.01867.x

Fryar, A. (2011). The Disparate Impacts of Accountability - Searching for Causal Mechanisms, Public Management Research Conference, Syracuse, NY, 2011. Retrieved: https://www.maxwell.syr.edu/uploadedFiles/conferences/pmrc/Files/HicklinFryar _TheDisparateImpactsofAccountabilitySearchingforCausalMechanisms.pdf

Gansemer-Topf, A. M., \& Schuh, J. H. (2006). Institutional selectivity and Institutional expenditures: Examining Organizational Factors that Contribute to Retention and Graduation. Research in Higher Education, 47(6), 613-642. https://doiorg.ezproxy.fiu.edu/10.1007/s11162-006-9009-4 
Garcia, G.A. (2012). Does percentage of Latinas/os affect graduation rates at four-year Hispanic Serving Institutions (HSIs), emerging HIS, and non-HSIs? Journal of Hispanic Higher Education, 12, 256-268. doi: 10.11.77/1538192712467203

Giddens, A. (1990). The consequences of modernity. Stanford, California: Stanford University Press.

Gill, S. (1994). Knowledge, politics, and neo-liberal political economy. In R. Stubbs, \& R. D. Geoffrey (Eds.), Political economy and the changing global order (pp.7588). New York, Manhattan: Martin’s Press.

Goenner, C. F., \& Snaith, S. M. (2003). Predicting Graduation Rates: An Analysis of Student and Institutional Factors at Doctoral Universities. Journal of College Student Retention: Research, Theory \& Practice, 5(4), 409-420. https://doiorg.ezproxy.fiu.edu/10.2190/LKJX-CL3H-1AJ5-WVPE

Hillman, N. \& Corral, D. (2017). The equity implications of paying for performance in higher education. American behavioral scientist, 61(14), 1757-1772. doi: $10.1177 / 0002764217744834$

Hillman, Fryar \& Crespín-Trujillo (2017). Evaluating the impact of performance funding in Ohio and Tennessee. American education research journal, XX(X), 1-27. doi:10.3102/0002831217732951

Hillman, Tandberg \& Fryar (2015). Evaluating the impact of "New" performance funding in higher education. Educational Evaluation and Policy Analysis, 37(4), 501-519. doi: 10.3102/0162373714560224

Hinkle, D. E., Wiersma, W. \& Jurs, S. G. (2003). Applied Statistics for the behavioral sciences. Boston, Mass: Houghton Mifflin.

Jaquette O., Parra E.E. (2014) Using IPEDS for Panel Analyses: Core Concepts, Data Challenges, and Empirical Applications. In: Paulsen M. (Eds.) Higher Education: Handbook of Theory and Research. Higher Education: Handbook of Theory and Research, 29. Springer, Dordrecht Switzerland, doi: https://doi.org/10.1007/97894-017-8005-6_11

Jenkins, P. D., Wachen, J., Moore, C., \& Shulock, N.(2012). Washington state student achievement initiative policy study: Final report. New York, NY:Community College Research Center, ColumbiaUniversity. Retrieved from http://ccrc.tc.columbia.edu/media/k2/attachments/student-achievementinitiativefinal-report.pdf 
Jongbloed, B., \& Vossensteyn, H. (2001). Keeping up performances: An intentional survey of performance-based funding in higher education. Journal of Higher Education Policy and Management, 23(2), 127-145. doi: 10.1080/136008001200886205

Levidow, L. (2005). Neoliberal agendas for higher education. In A. Saad-Filho \& D. Johnson (Eds.), Neoliberalism: A critical reader (pp. 156-162). London, England: Pluto Press.

Lechner, M (2010). The Estimation of Causal Effects by Difference-in-Difference Methods. Foundations and Trends in Econometrics. 4 (3), 165-224. doi: $10.1561 / 0800000014$

Long, B. T. \& Kurlaender, M. (2009). Do community College provide a viable pathway to a Baccalaureate degree? Educational Evaluation and Policy Analysis, 31, 3053. doi: 10.3102/0162373768327756

Martinez, M.S. (2012). The influence of institutional practices and resources on Latino baccalaureate completion rates (Doctoral dissertation). Retrieved from http://etdr.utoledo.edu/thesis-dissertations

McKeown-Moak, M.P. (2013, Spring). The "new" performance funding in higher education. Educational Considerations, 40(2), 3-12. Retrieved from http://df9uh2wc8b.scholar.serialssolutions.com/0146-9282

Montgomery, R. \& Montgomery, B. L. (2012). Graduation rates at historically black college and Universities: An underperformance measure for determine institutional funding policies. The Journal of Continuing Higher Education, 60, 93-109. doi: 101080/07377363.2012690623

Nankervis, B. (2011). Gender inequities in university admission due to the differential validity of the SAT. Journal of College Admission, (213), 24-30. Retrieved from http://ezproxy.fiu.edu/login?url=http://search.proquest.com/docview/1009072322 ?accountid=10901

NCES (2018) 2018-19 Survey Materials: Glossary. Retrieve from https://surveys.nces.ed.gov/ipeds/VisGlossaryAll.aspx

Nora, A. \& Crisp, G. (2012). Future research on Hispanic students: What have we yet to learn? and what new and diverse perspectives are needed to examine Latino success in higher education? Retrieved from HACU website: http://www.hacu.net/images/hacu/OPAI/H3ERC/2012_papers/Nora\%20crisp $\% 20$ -\%20future $\% 20$ research $\% 20$ on $\% 20$ hispanics $\% 20-\% 202012$.pdf 
Orozco, V. (2012, August) Florida's great cost shift: How higher Education cuts undermine its future middle class. Retrieved from Demos: ideas \& action: https://www.demos.org/publication/florida $\%$ E2\%80\%99s-great-cost-shift-howhigher-education-cuts-undermine-its-future-middle-class.

Ortiz, C.J., Valerio, M. A. \& López, K. (2012). Trends in Hispanic academic achievement: Where do we go from here? Journal of Hispanic Higher Education, 11, 136-148. doi: 10.11.77/1538192712437935

Pritchard, D. (Ed.). (2004) The American heritage dictionary. New York, NY: Houghton Mifflin Company.

Power, M. (2000). The audit society-second thoughts. International Journal of Auditing 4, 111-119. doi: 10.1111/1099-1123.00306

Rabovsky, T. (2012). Accountability in higher education: Exploring impact on state budgets and institutional spending patterns. Journal of Public Administration Research and Theory, 22(4), 675-700.

Ryan, J. F. (2004, March). The relationship between institutional expenditures and degree attainment at baccalaureate colleges. Research in Higher Education, 45, 97-114.

Ryan, C. L., \& Bauman, K. (2016), Educational attainment in the United States: 2015 (Report No. P20-578). Retrieved from United States census bureau website: https:/www.census.gov/library/publications/2016/demo/p20-578.html

Rutherford, A. \& Rabovsky, T. (2014) Evaluating impact of performance funding policies on student outcomes in higher education. The Annals of the American Academy of Political and Social Science, 655, 185-208. doi: 10.1177/0002716214541048

Sandy, J., Gonzales, A. \& Hilmer, M.J. (2006). Alternative path to college completion: Effect of attending a two-year school on the probability of completing a four-year degree. Economics of Education Review, 25, 463-471. doi:

10.1016/j.econedurev.2005.05.003

Sanford, T., \& Hunter, J.M. (2011). Impact of performance-funding on retention and graduation rates. Education Policy Analysis Archive, 19(33), 1-30. doi: http://dx.doi.org/10.14507/epaa.v19n33.2011

Shin, J. C, (2010). Impacts of performance-based accountability on institutional performance in the U.S. Higher Education, 60, 47-68. doi:10.1007/s10734-0099285-y 
Shin, J., \& Milton, S. (2004). The Effects of Performance Budgeting and Funding Programs on Graduation Rate in Public Four-Year Colleges and Universities. Education Policy Analysis Archives, 12(22). Retrieved from http:/http://search.ebscohost.com/login.aspx?direct=true\&db=eric\&AN=EJ85230 $5 \&$ site $=$ eds-live

Tandberg, D., \& Hillman, N. (2014). State higher education performance funding: Data, outcomes and policy implications. Journal of Education Finance,39, 222-243.

Thelin, J.R. (2011). A history of American higher education (2nd ed). Baltimore: Johns Hopkins University Press.

Torres V. (2006). A mixed method study testing data-model fit of a retention model for Latino/a students at urban universities. Journal of College Student Development, 47, 299-318.

U.S. Department of Education. (2006). A test of leadership: Charting the future of U.S. higher education. Retrieved from U.S. Department of Education website: https://www2.ed.gov/about/bdscomm/list/hiedfuture/reports/pre-pub-report.pdf

Zarkesh, M., \& Beas, A.M. (2004). UCLA community college review: performance indicators and performance-based funding in community college. Community College Review, 31(4), 62-76. Retrieved from http://ezproxy.fiu.edu/http://go.galegroup.com/ps/i.do?id $=\mathrm{GALE} \% 7 \mathrm{CA} 118689081 \& \mathrm{v}=2.1 \& \mathrm{u}=\mathrm{miam} 11506 \& \mathrm{it}=\mathrm{r} \& \mathrm{p}=\mathrm{AIM} \& \mathrm{sw}=\mathrm{w} \& \mathrm{asid}=\mathrm{f}$ 0d450688a726e358375b35ab041aade

Wagner, J.M. (2015). Hispanic minority college students at selective colleges: What matters with degree completion? Journal of Hispanic Higher Education, 14, 303326. doi: $10.11 .77 / 1538192714568607$

Zumaeta, W.M. (2011). What does it mean to be accountable? Dimensions and implications of higher education's public accountability. The review of higher education, 35, 131-148. doi: 10.135/rhe.2011.0037 


\section{APENDIX B}

\section{Definition of Terms}

Board of Governors $(\mathrm{BOG})=$ Florida's "Board of Governors is comprised of seventeen members, fourteen of whom are appointed by the Florida Governor and confirmed by the Florida Senate for a term of seven years. The remaining members include the Chair of the Advisory Council of Faculty Senates, the Commissioner of Education, and the Chair of the Florida Student Association. The Board oversees the operation and management of the Florida public university system's twelve institutions" (https://www.flbog.edu/ board/members/index.php, parr. 1). The Board also collects data from the Florida public University systems and assigns the PBF scores based for each institution.

Florida College System (FCS) $=$ The FCS is a system composed of 28 public community and state colleges in Florida.

Florida College System (FCS) Employment Rates $=$ The FCS employment rate of student employed or continuing education 1 year after graduation is calculated by the SBOE. This rate is based on the information from five sources: Community College and Technical Center Management Information System (CCTCMIS), Department of Education (DOE), Florida Department of Revenue (DOR), National Student Clearinghouse (NSC), U.S. Office of Personnel Management (OPM), and Wage Record Interchange System 2 (WRIS2).

Florida Department of Education (FLDOE) $=$ The Department of Education serves as the single repository of education data from school districts, state and community colleges, universities, and independent postsecondary institutions - allowing us to track student performance over time and across varying education sectors" (http://www.fldoe.org/about-us, Parr. 1).

IPEDS 6-year Graduation Rates = Full-time, first time, degree or certificate-seeking students who started and finished at the same institution. Students included in the graduation rate do not represent all students at an institution (https://nces.ed.gov/pubs201 7/2017046.pdf).

IPEDS Retention Rates $=$ The percentage of first-time, full-time undergraduate students who returned to the same institution the following fall after admissions.

IPEDS Expenditures $=$ Institutional expenditures collected in the IPEDS Financial Survey. It includes Instruction expenses, research expenses, public service expenses, academic support, institutional support, other core expenses, and student services expenses. The expenses are calculates based on FTE (Full-time Equivalent). 
State Board of Education (SBOE) = Is the committee within the Department of Education that administers k-12, and the State colleges. They also administer the PerformanceBased Funding Program for the Florida College System.

State University System (SUS) = The SUS consists of 12 public higher education institutions in Florida including Florida A\&M University, Florida Atlantic University, Florida Gulf Coast University, Florida International University, Florida Polytechnic University, Florida State University, New College of Florida, University of Central Florida, University of Florida, University of North Florida, University of South Florida, University of West Florida.

State University System (SUS) Employment rate = The SUS rate of student employed or continuing education 1 year after graduation is calculated bt the BOG. The rate is based on the information from three sources: the SUS internal data set for military and postenrollment data, the national student clearinghouse for post-enrollment data, and the Florida education and training placement information program for employment data. 
VITA

MADELYN E. CINTRON

1997-2003

2004-2007

2007-2008

2008-2011

2011-2013

2011-2015

2015- Present

2013-2019

B.A., Secondary Education Biology University of Puerto Rico

Rio Piedras, Puerto Rico

M.ED., Research and Evaluation in Education

University of Puerto Rico

Rio Piedras, Puerto Rico

Dean of Students

CCI School of Counseling

Miami, Florida

Recruitment, Retention \& Research Specialist,

Title V Grant-Project ACE

Miami Dade College

Miami, Florida

Research Consultant

Title V Grant-Project ACE

Miami Dade College

Miami, Florida

Evaluation Coordinator

Title V HSI Program

Florida International University

Miami Florida

Statistical Coordinator

Office of Analysis and Information

Management

Florida International University

Miami Florida

Doctoral Candidate

Florida International University

Miami, Florida 


\section{PUBLICATIONS AND PRESENTATIONS}

Artze-Vega, I. Cintron, M., Juarez, E., \& Wells, L. (2013). Title V Opening the Gateway: The High-Tech High-Touch Initiative. Presentation, Hispanic Association of Colleges and Universities (HACU). Chicago, IL.

Bonilla, V. E., Fernandez, L. M., Cintron, M. E., \& Roman, R. L. (2006) Predictive validity of the Advanced Placement test scores. Cuadernos de Investigación, 12. College Board-Puerto Rico and Latin American Office: San Juan, PR

Bonilla, V., López, A., Ramírez, S., Cintrón, M., \& Román, R. (2005). Feminization of the enrollment in higher institutions in Puerto Rico. Cuaderno de Investigaciones Educativas, 20, 114-143.

Cintron, M. (2005). Steps to Follow when Constructing an Instrument. INEVA en acción, 2(3), 5-7. Retrieved from: http://ineva.uprrp.edu/boletin/v0002n0003.pdf

Cintron, M. (2005). Attitude towards testing: Aspects requiring investigation.. INEVA en acción, 3(2), 4-6. Retrieved from: http://ineva.uprrp.edu/boletin/v0003n0002.pdf

Cintrón, M. (2005). Characteristics of Qualitative Methodology. INEVA en acción, 2(4). Retrieved from: http://ineva.uprrp.edu/boletin/v0002n0004.pdf

Cintron, M. (2007). Student's Attitude toward Essay and Multiple Choice Test (thesis). San Juan, PR: University of Puerto Rico, Rio Piedras Campus. 